

Digitized by the Internet Archive in 2011 with funding from

LYRASIS members and Sloan Foundation 



\title{
Diseases and Decays of Connecticut Tobacco
}

\author{
IP. J. ANDERSON
}

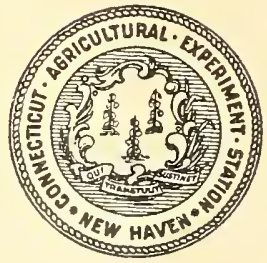

(Tmmectiout

Agrioultural Fxpreriment Station

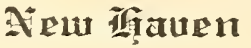



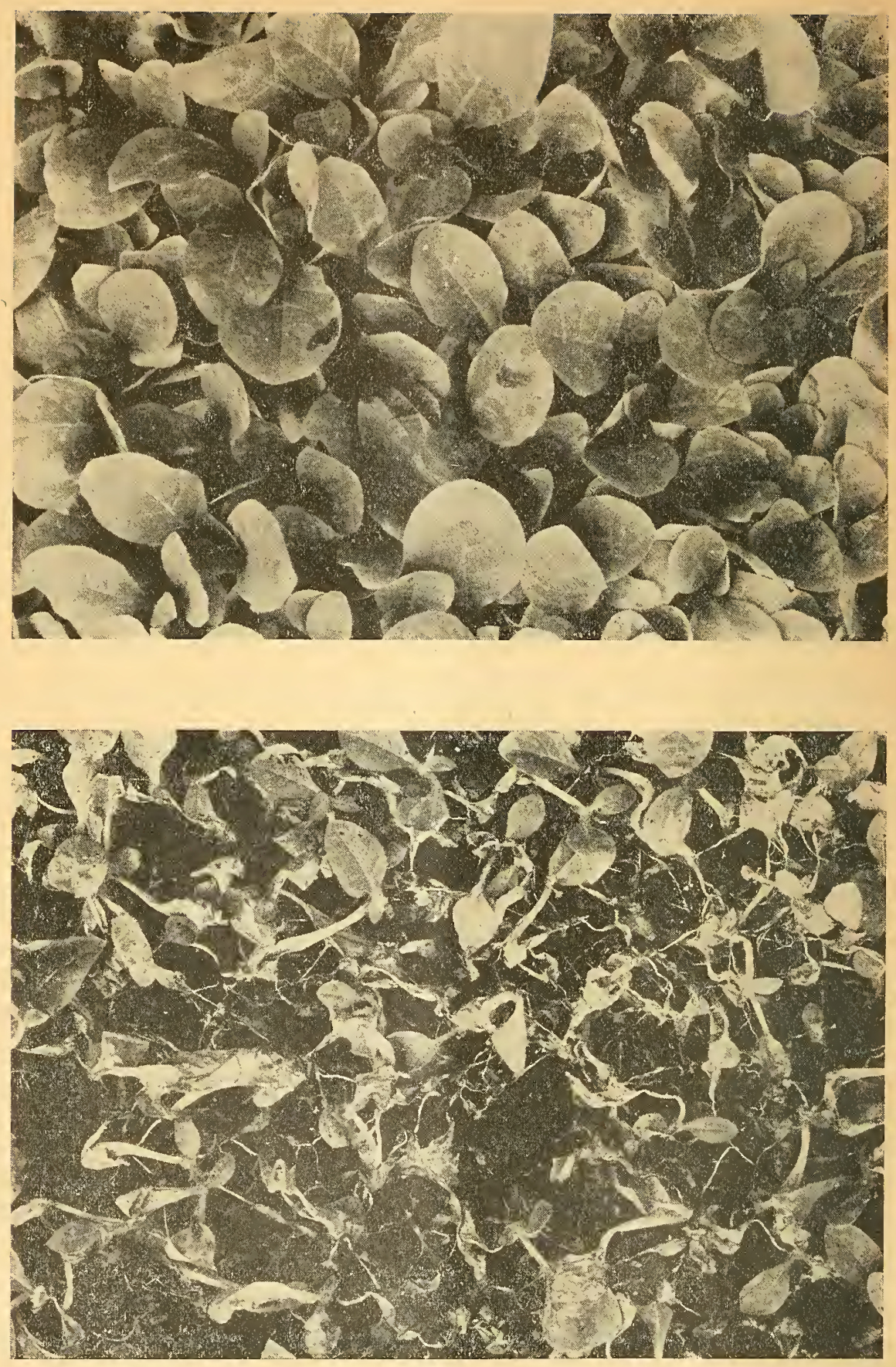

Figure 1. Downy mildew. Looking down on a diseased (below) and a bealthy part (above) of the same bed. (See page 112). 


\section{CONTENTS}

INTRODUCTION

Definition of Disease................................ 93

The Causes or Agents of Disease ........................ 93

\section{Seedbed Diseases}

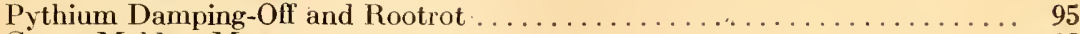

Green Mold or Moss. . . . . . . . . . . . . . . . . . . . . . . . . . . 98

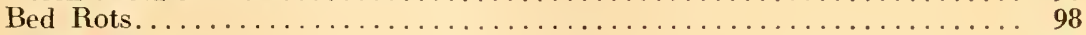

Ammonia Injury ................................. 102

Potash Deficiency .................................. 102

Diseases that are Destructive both in Seedbed and Field

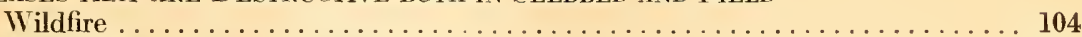

Blackfire or Angular Leafspot. . . . . . . . . . . . . . . . . . . . 108

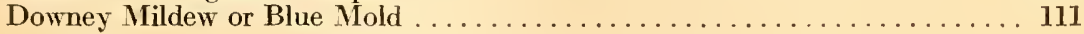

\section{Root Diseases}

Black Rootrot..................................... 118

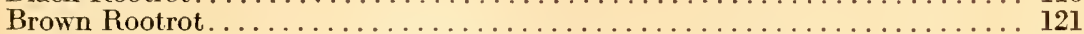

Stalk Diseases in the Field

Pythium Stalk-rot of Transplants . . . . . . . . . . . . . . . . . . . 122

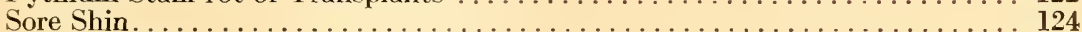

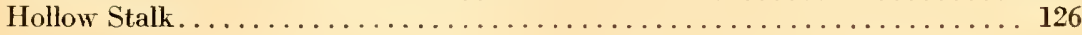

Leaf Diseases in the Field

Mosaic or Calico . . . . . . . . . . . . . 128

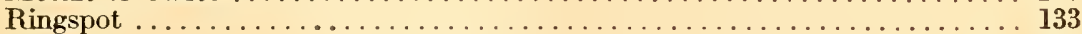

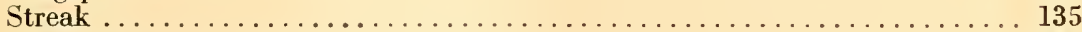

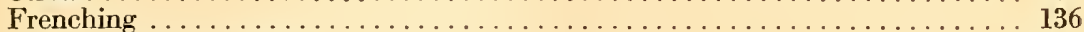

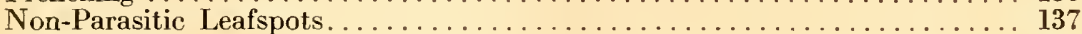

Brown Spot....................................... 139

Dead-Blossom Leafspot . . . . . . . . . . . . . . . . . . . . . . . . . . 140

Leaf Blotch or Scab................................. 141

Malnutrition Disorders . . . . . . . . . . . . . . . . . . . . . 143

Magnesia hunger or sand-drown. . . . . . . . . . . . . . . . 143

Calcium deficiency . . . . . . . . . . . . . . . . . . . . . . 144

Nitrogen starvation. . . . . . . . . . . . . . . . . . . . . 144

Phosphorus deficiency . . . . . . . . . . . . . . . . . . . . . . . 145

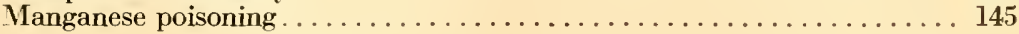

Decays and Disorders During Curing

Pole Rot ............................ 146

Freckle rot...........

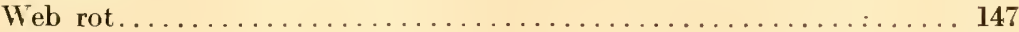

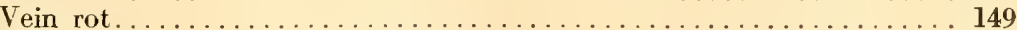

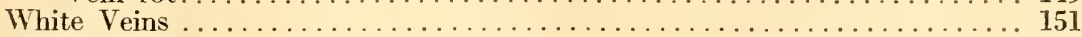

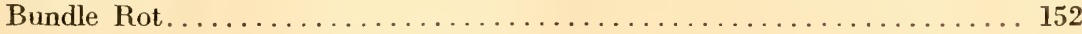

Decay and Mold of Fermenting of Stored Tobacco . . . . . . . . . . . 152

Black-rot in the case . . . . . . . . . . . . . . . . . . . . . . . . . . 153

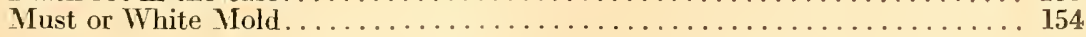

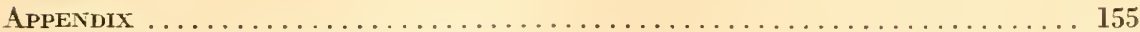

Sterilizing the Soil in the Seedbed . . . . . . . . . . . . . . . . . . . . . 155

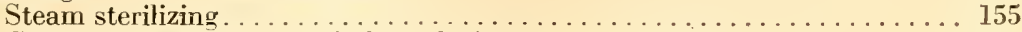

Chemical sterilization with formaldehyde or acetic acid . . . . . . . . . 157

Preparation of Bordeaux Mixture for Spraying Seedbeds .............. 157

Curing with the Aid of Charcoal Fires...................... 158 


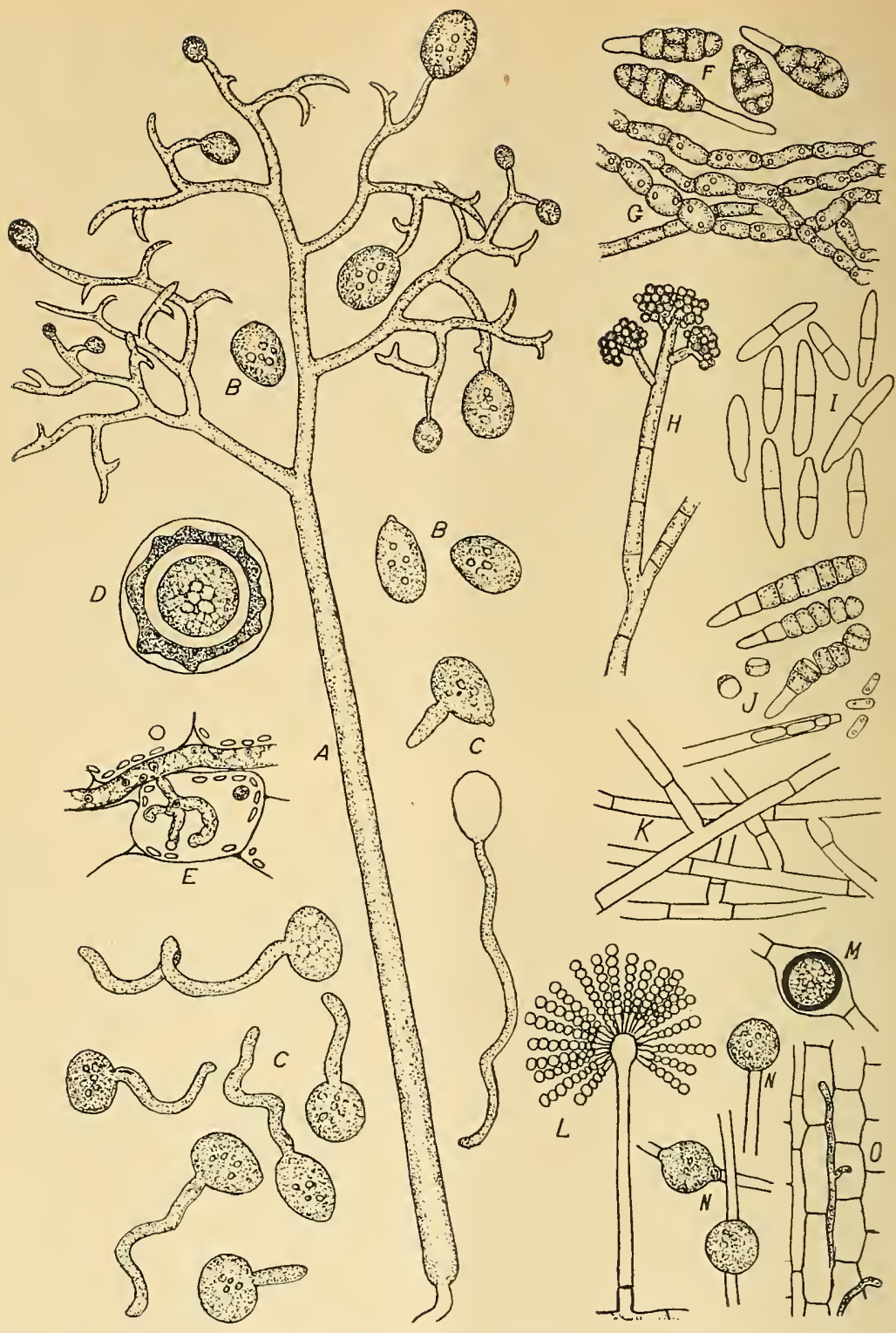

Figure 2. Some fungi that cause tobacco diseases, all greatly magnified. A-E, the mildew fungus Peronospora tabacina. A, Sporophore with developing summer spores at tips. B, Mature summer spores. C, Germination of the summer spores. D, Crosssection of a winter spore. E, Haustorium inside a leaf cell and a segment of mycelium between the leaf cells. F, Spores of the fungus Allernaria tenuis, causing brown-spot and freckle rot. G, Mycelium of the same fungus. $H$, Sporophore and heads of the spores of one of the pole rot fungi, Botrytis cinerea. I, Spores of the blotch fungus, Fusarium affine. J, Spores of the black rootrot fungus, Thielaviopsis basico!a, thick-walled black Chlamydospores above and thin-walled endoconidia below. K, Mycelium of Rhizoctonia, a bed-rot fungus. L, Sporophore and summer spores of Sterigmatocystis nigra the fungus causing black rot in the case. M, N, O. The damping-off fungus, Pythium debaryanum. M, A thick-walled winter spore. N, Thin-walled summer spores. O, A strand of mycelium running between the cells of a young plant. 


\title{
Diseases and Decays of Connecticut Tobacco
}

\author{
P. J. ANDERSON
}

THE object of this bulletin is to make arailable to the grower of tobacco adequate information to enable him to escape, or at least reduce, the losses from the various crop diseases and disorders with which he is confronted. In order to apply the remedies successfully, he must first recognize and distinguish between the diseases, know something of their causes, their course of development and the influence of weather and some other environmental conditions. For this reason, under the discussion of each disease, the symptoms, cause and environmental influences are described before presenting directions for application of remedial or preventive measures.

Since this bulletin is intended solely for the use of practical growersnot for plant pathologists or other agricultural scientists-all scientific discussions, descriptions of parasitic organisms, and like material are avoided. If any reader wishes to study a disease in more detail, he may find such information in our annual reports and bulletins and in various other publications. ${ }^{1}$

\section{WHA'T IS A DISEASE?}

A comonon definition is: A disease is any deviation from the normal. Having lived with his crop in all stages of development and seasons of the year, the grower subconsciously has established in his mind a standard of the appearance of a healthy tobacco plant. Such is the norm. He quickly recognizes any change or unusual behavior in its development or appearance. Deviation from his established concept is, in a broad sense, disease.

Defined in this general way, perhaps the definition is somewhat too comprehensive for our present discussion. It would include insect injuries which we omit because they were fully covered in Bulletin 379 of this Station. It would also include occasional mutations (sports) and accidental injuries from various causes which are not of sufficient importance to warrant discussion here.

\section{THE CAUSES OR AGENTS OF DISEASE}

Fron the standpoint of the agents which produce tobacco diseases, we recognize the following groups: Diseases caused (1) by fungi, (2) by bacteria, (3) by viruses, (4) by malnutrition, (5) by unfavorable weather conditions and (6) by unknown or little understood causes.

Fungi are tiny, very simple plants which grow parasitically on the living tobacco or saprophytically on the dead plants. Just as a tree sends

\footnotetext{
1 For the benefit of those who are interested in a more complete discussion of the various diseases, at the end of the section on each is a list of references to publications of the Connecticut Agricultural Experiment Station where more information may be found. The following abhreviations are used in these references: R-Annual Report of the Station; B-Regular Station Bulletin; TB-Bulletin of the Tobacco Substation: C-Circular.
} 
its branching roots into the soil to get water and food, so the fungus sinks a branching system of feeding tubes, called the mycelium, into the interior tissues of the plant, draining it of food as a leech sucks blood from a victim. At the same time it emits a toxin that poisons the plant cells. As a result of these two actions, dead or abnormal spots, (lesions) appear, or the entire plant may die. This is disease. The individual threads of the mycelium inside the tissues of leaf, stalk or root, are too small to be seen with the naked eye but sometimes they are visible on the surface. For example, in some types of bedrot they may be seen running from plant to plant or on the surface of the ground.

The patches of white mold often observed on the moist soil surface of the beds when the tobacco seeds are sprouting are masses of fungous mycelium. Some fungi develop special sucking organs, called haustoria, which penetrate to the interior of the individual cells. A haustorium of the downy mildew fungus is illustrated in Figure $2 \mathrm{E}$.

Just as weeds are disseminated and live over from one season to the next by seeds, so fungi are spread by microscopically small spores that are blown about by wind or carried from plant to plant or farm to farm by different agents. The various shapes of these spores are illustrated in Figure 2. Functionally they are of two kinds: the short-lived summer spores and the long-lived winter spores. Some of the summer spores live only a few hours but are produced in enormous numbers and serve for rapid spread of the fungus during the growing season (Figure 2, B, I, J, L). They are usually borne on simple or variously branched stalks called conidiophores as shown in Figure 2. The winter spores are resistant to cold, extreme drying, or other adverse conditions and serve to keep the parasite alive over winter and start the disease the next season (Figure 2, D, M).

Weed seeds sprout when conditions are right for their growth; in the same way spores germinate under favorable conditions of moisture and temperature. They send out a slender tube (germ tube) which bores into the interior of the plant, immediately develops into a new mycelium and proceeds to repeat the life cycle (Figure 2, C). Some of the tobacco diseases caused by fungi are mildew, damping-off, bedrot, black rootrot, brown spot, pole rot, canker and must.

Bacteria are also tiny plants, much smaller than fungi, never visible to the naked eye and never developing mycelium like the fungi. None of those causing tobacco diseases forms spores but all reproduce themselves with great rapidity and kill the tobacco cells by mass action and the toxins they secrete. The common bacterial diseases of tobacco are wildfire, blackfire, blackleg and hollowstalk. All are highly infectious.

Viruses are not living organisms but produce diseases some of which are highly infectious. The substance which carries the disease-producing capacity, the virus, cannot be seen even with the microscope, and its particles are so small that they pass through the pores of the densest filter. Since their physical characteristics, identity and nature are still a matter of controversy among scientists, no good purpose would be served in trying to define or describe them in more detail here. The most common virus disease of tobacco is mosaic, (calico). Virus diseases of less importance are ring-spot and streak. 
Malnutrition diseases are caused by unbalanced conditions in the supply of the various plant food elements. Definite symptoms of sickness are produced either by too much or too little of some of the essential elements, or by too great absorption of some non-food elements from the soil. "Sand drown" or magnesia hunger is one of the best known of this group.

Unfavorable weather conditions often cause injuries or abnormal growth which would come under our definition of disease but are not so classified by farmers in general. Losses from frosts, hail, rain bruise and lightning are known to most growers.

Causes unknown or little understood. In addition to the diseases classified above, there are a number for which we have not been able to find the causal agent, or for which the cause is in dispute among agricultural scientists. When these are sufficiently investigated, it will probably be found that each can be relegated to one of the foregoing groups. The best known of this class is the brown rootrot. "Frenching" is a less wellknown example. The physiological leaf spots may for the present be put in this group although ultimately investigations will probably reveal that they are malnutrition or virus troubles.

In the following pages the diseases are not divided into groups as indicated above. They are arranged roughly in the order in which they occur in the growing season. First, those that are predominantly seedbed troubles; then those that occur in the field are divided into root diseases, stalk diseases and leaf diseases. Those occurring during the curing process in the shed are next considered, and finally those which occur in packed tobacco. Naturally this is not a strict classification since there are various diseases which may occur both in the seedbed and in the field and there are other examples of overlapping.

\section{SEEDBED DISEASES}

\section{PYTHIUM DAMPING-OFF AND ROOTROT}

THIs disease, involving loss of the very young seedlings before they have sprouted, or after they have sprouted and before they are a half inch high, is the first disease of the season and is confined strictly to the seedbed. Because of its very early occurrence, as well as its distinct causal agent, we distinguish it from bedrot which kills the plants in the seedbed after they are well grown. It is widespread and of long standing in the Connecticut Valley and is probably responsible for a considerable proportion of the poor stands of plants in the seedbeds. On account of its inconspicuous symptoms, and the rapid disappearance of the affected seedlings; the disease has received scant attention and its ravages have been attributed largely to other agencies. For the same reason the extent of damage in the State can only be estimated, but it is safe to say that it is one of the very common seedbed troubles.

Symptoms. The symptom which the grower first notices is that the very young seedlings are disappearing shortly after germination. Every 
day the stand appears thinner. This may continue until there are not enough plants left to pay for further care and the bed is abandoned. More often, however, it results only in a reduced stand so that the grower has not sufficient plants to set his intended acreage and must purchase them elsewhere.

The stages of this mysterious disappearance of plants may be found by close observation of the beds in the germinating period. Some of the small, two-leaved plants will be found lying on the ground with a part or all of the



Figure 3. Damping-off of young seedlings. Note shrivelled stems of prostrate plants.

little stems dead and shrivelled to a mere thread (Figure 3). The shrivelled part is most often just at the surface of the soil. Other plants are prostrate, or entirely upside down, and are not attached to the ground at all. The stems are healthy but the roots are completely rotted away. Thus the disease may affect either the roots or the stem. After the plants topple over, they disappear very quickly. They may be covered by the splashing of soil during watering. Under dry conditions they disappear by shrivelling; under moist conditions they rot and disintegrate quickly. 
At about the time that the second pair of leaves appears, the stem becomes resistant to further attack but the roots remain susceptible for several weeks. This later rootrot causes the plants to become stunted and yellow in spots in the bed. Some of them die, but most of them linger for a long time with very little further growth. Such spots give the bed an uneven appearance. On careful examination the larger part of the roots are found to be soft, or completely disintegrated, except for a central, thread-like strand which remains intact but may easily be pulled out of the rotted cortex. These roots do not turn black but remain white or yellow until they disappear.

Causes. The disease is caused by a parasitic fungus, Pythium debaryanum Hesse, which inhabits most fertile soils naturally. (See Figure 2, M, N, O). Here it may live indefinitely on dead organic matter and spread under and over the soil with extreme rapidity. When its branches come into contact with the young stem or root, they bore through the epidermis and live parasitically on the interior cells of the tobacco plant causing them to collapse and die. Spores are produced in great abundance and may be carried about by water, wind, tools and other agencies, thus spreading the disease to new centers. Many other seedlings, such as beets, tomatoes, cucumbers and pines, are also attacked by the same fungus.

Effect of Environmental Conditions. The growth of the fungus is favored by a high temperature, high humidity of air, or moisture of the soil. There is also a belief that a high percentage of vegetable matter in the soil fosters growth but this has not been demonstrated satisfactorily.

Control. Steaming the soil, the common practice in this State, has not controlled the disease. The writer has found many of the worst cases in steamed beds. In tests at the Experiment Station, in which numerous materials for sterilizing the soil or the seed were tried, the best control was obtained by treating the soil at the time of seeding with formaldehyde dust at the rate of one and one-half ounces to each square foot of soil. The dust was w orked into the top two inches, the soil heavily watered, and the seed sowed immediately. The dust is a mixture of 15 parts by weight of commercial formaldehyde and 85 parts of an absorbent dust. Finely ground charcoal, or a peat soil composed mostly of decayed organic matter, gave good results when used as the absorbent dust. Because the formaldehyde fumes are irritating to the nose and eyes, it is best to put the ingredients in a closed container such as a barrel or drum which may be rolled about until the mixture is complete. The material should be prepared shortly before using and kept in a tight container until needed.

A simpler method of applying the formaldehyde was developed later. Since most seedbeds contain large amounts of absorptive organic material, peat, humus, rotten manure, etc., the charcoal is not essential to absorb the formaldehyde fumes. The formaldehyde was sprayed directly on the seedbed soil with a fine nozzle at the rate of one gallon of commercial formaldehyde to 500 square feet of bed, the soil being thoroughly mixed with a rake during the application. Immediately afterward the soil was pressed down and watered and the seed sown. This method gives just as good results as the charcoal dust and involves less work. Unless a very fine nozzle is available, it is best first to dilute the commercial formaldehyde with five or six times its volume of water in order to give better distribution. 
Complete control of damping-off has also been accomplished by "gassing" with benzol or with paradichlorobenzene every second night. The method of application is described under Downy Mildew.

Treatment of the seed with cuprous oxide or with Semesan has given some degree of control but was not found nearly so effective as treatment with formaldehyde dust.

Spraying the plants with Bordeaux mixture did not control the disease. References: R 1906:326. B 311:269。 B 359:336-353.

\section{"GREEN MOLD" OR "MOSS" IN THE SEEDBEDS}

IN the early seedbed period, while the soil must be kept constantly moist to insure good germination, growers often are troubled by the appearance of a bright green scum over the surface of the ground. This has received the popular names of "moss" or "green mold". Both are unfortunate because the growth is neither a moss nor a mold but one or more species of green algae. Although none of these algae is parasitic on tobacco seedlings, their dense growth may smother the sprouting seeds. There is considerable difference of opinion as to the extent of the damage but at least such a condition is not desirable.

Control. It is a common practice to sprinkle a thin coat of sharp, dry sand over the ground to check the green algae. The benefit derived from this treatment, however, is probably more imagined than real. Applications of Bordeaux mixture at intervals of two or three days give much better control, but there may be some detriment to the germinating seeds if this treatment is started before the cotyledons appear.

Green mold is usually eliminated by treating the soil at the time of seeding with formaldehyde dust, as previously described for control of Pythium damping-off.

These algae thrive only under high moisture conditions of soil and air. 'They can be checked by removing the sash during bright days and thus drying out the surface of the ground. However, this should not be attempted when the seeds are beginning to germinate.

Reference: B 359:354.

\section{BED RO'TS}

THE general term "bedrot" is used to describe a condition in the beds in which patches of the partly grown plants collapse and slough off in a rapid, soft wet rot. Characteristically it comes when the plants are of considerable size, about ready for setting in the field, and are crowding each other, or in damp, poorly ventilated beds, in heavy soil, or during wet weather. This has also been called "damping-off". The writer, however, has restricted the use of the term "damping-off" to a disease of the younger seedlings which kills them just after the seed has germinated. Obviously this distinction is artificial, since it is quite possible for plants to die at any stage of growth, but it is convenient for purposes of discussion. 
Bedrot may be caused by any one of several different parasitic organisms, some of which produce symptoms differing on close inspection from those produced by others. There are thus several bed rots of tobacco that may be distinguished both by causal agents and symptoms.

Three types of bedrot which the writer has had occasion to study and has described in the annual reports may be designated as: (1) Rhizoctonia bedrot, (2) Pythium bedrot and (3) Blackleg. Although these have the same general symptoms, each also has some specific characteristics which are described below.

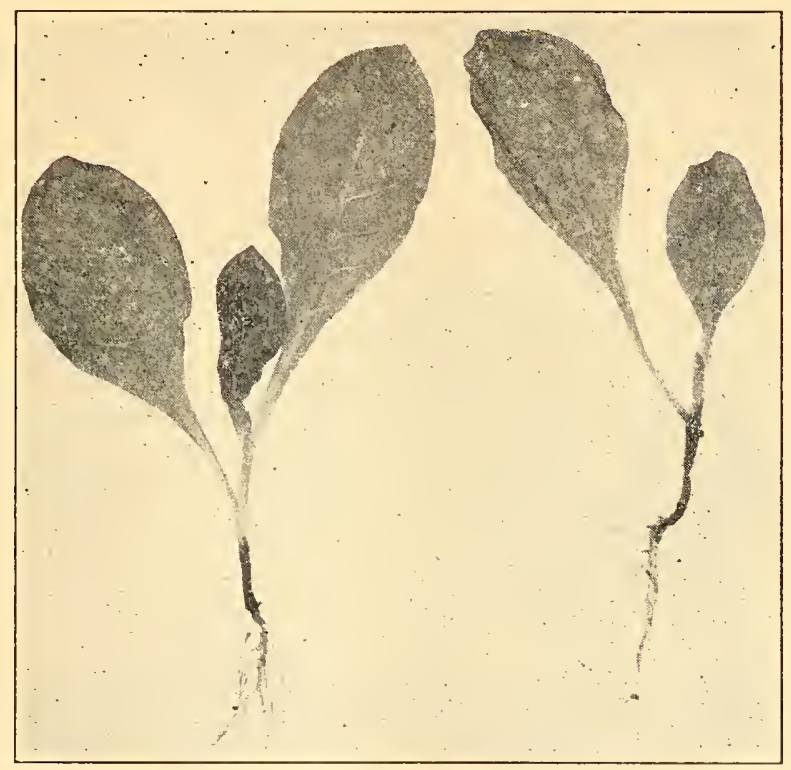

Figure 4. Bedrot caused by Rhizoctonia. Note the black and rotted bases of stalks.

Symptoms. Rhizoctonia rot. By far the most prevalent type in this section is the one produced by the fungus Rhizoctonia. Until recently, the writer has not found any other organism connected with the many cases examined. This bedrot usually occurs in circular patches from a few inches to a foot or more in diameter. The stems are affected first with a brown wet rot (Figure 4) followed quickly by rotting and collapse of the leaves. In severe cases, every plant in the center of the patch is killed. If less moist conditions are then introduced, the leaves fall flat and form a parchmentlike dry covering over the soil. For a considerable distance about the margins of these dead patches one finds most of the plants with brown lesions on the stems. Under moist conditions these enlarge and kill the plants, but with less humidity they dry out, seem to remain stationary and the affected plants do not die.

Pythium Bedrot. The patches of dead plants are definitely localized and from two to six inches in diameter in the crowded parts of the beds. 
This is a rapid wet rot, causing all the plants in the patch to fall to the ground in a water-soaked, dark green, slimy decay, leaving the spot quite bare. On drying out, the ground is covered with a brown crust of the bleached leaves (Figure 5). Unlike the Rhizoctonia disease, this is not characterized by definite dark brown lesions on the stalk of the plant. The stalk becomes soft and watery and the bud rots out. The writer has been unable to determine whether infection starts in the stalk or in the bud. A very characteristic symptom is the manner in which the light brown rot runs up the petiole into the lower part of the leaf, discoloring it in a fanshaped area corresponding to the base of the leaf (Figure 16).

Blackleg. In all cases observed here, blackleg first becomes evident when the plants are several inches tall and about ready for transplanting to the field. We have never seen it on younger plants. The first evidence of trouble which the grower notices is that patches of plants in his bed look wilted and dark in color with the least drying on a warm day or when the

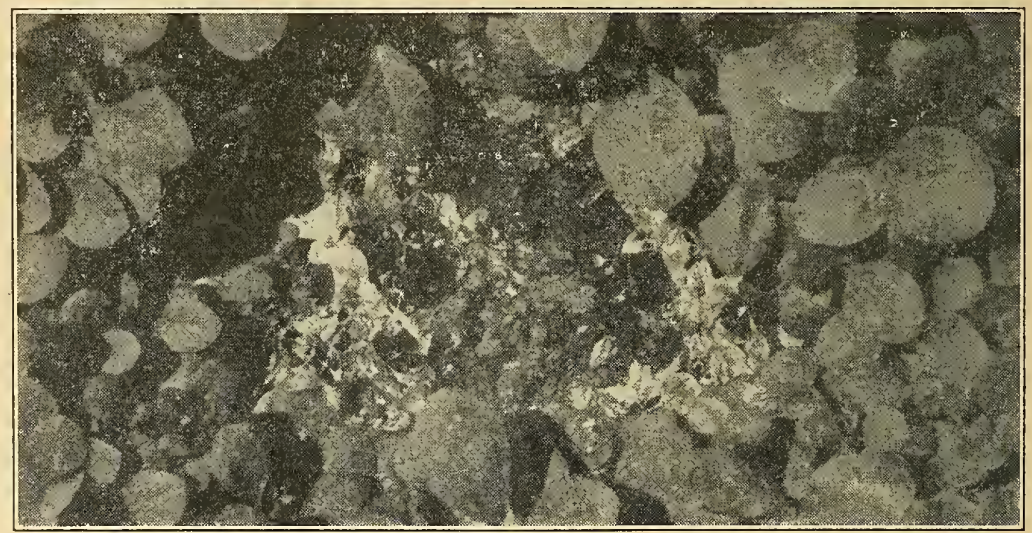

Figure 5. A bedrot spot caused by the fungus Pythium aphanidermalum.

sash are removed. Soon afterwards the plants collapse in a wet rot and the decaying leaves and stalks sink to a flat black crust over the surface of the ground. Under moist conditions the affected patches spread rapidly in a centrifugal direction until they may be several feet in diameter and, in the worst cases, entire beds are destroyed.

A closer examination of the individual plants shows that the bases of the stalks are first attacked by a soft, slimy, dark, wet rot which advances up to the bases of the leaves. These droop and become dark green and watersoaked as they collapse. As they come into contact with other leaves, the rot spreads from leaf to leaf, runs down the leaf petiole to the stalk and thus spreads from plant to plant. Sprinkling the plants with water also spreads the germs over the soil so that leaves in contact with the ground serve as agents for conducting the disease to the stalk or to the next plant. The original infection may thus occur either through the leaf or through the stalk. 
Cause. Parasitic organisms cause all three types of bedrot. The parasite of the Rhizoctonia bedrot, Rhizoctonia solan $i=($ Corticium vagum), is a common fungus which lives in most fertile soils here. Under moist conditions the spider web-like threads (mycelium) of the fungus (Figure 2, $\mathrm{K}$ ) may be seen spreading over the surface of the ground and even through the air from one plant to another. Spores are rarely produced, but the fungus is disseminated by the vegetative hyphae and also by hard, black resting bodies (sclerotia) about the size of a pinhead or sometimes larger, which may frequently be found, by close examination, on the surface of the soil in the infested patches. The fungus, Pythium aphanidermatum, which causes the second type described above, is similar to that which causes damping-off but of a different species. Sometimes the mycelium of this fungus may be seen spreading from leaf to leaf but it is never so prominent as that of Rhizoctonia. Both types of spores are produced in great numbers and serve to spread the disease and carry it over the winter.

Blackleg is caused by parasitic bacteria of the soft-rot group, organisms which cause a slimy decay of many kinds of vegetables: carrots, turnips, cabbage, etc. This same organism is capable of producing a wet stalk decay of mature plants in the field, a disease commonly known as "Hollow Stalk" which is described later in this bulletin. Since the soft-rot bacteria are known to live and overwinter in soil and are probably present in all of our soils, it is likely that the organisms pass from this source to the leaves or other parts of the seedlings in contact with the ground. Whether or not a wound is necessary for entrance of the germ has not been determined, but the rapidity with which the disease involves all the plants about a focus of infection would indicate that it is not.

Effect of Environmental Conditions. The disease develops only when humidity is high and the soil damp. Such conditions are ideal when the stand is thick and aeration about the stem base is poor. A relatively low temperature is more favorable for Rhizoctonia than a high temperature but the temperature relations of the other types are not so well known. Forced, succulent, rapidly growing plants are more susceptible than others.

Control. The first measure of control should be sterilization of the soil by steaming, acetic acid or formaldehyde. (See Appendix for directions.) Soil sterilization, however, cannot always be depended on to give control, as can be seen from numerous severe cases found in sterilized beds. These exceptions are probably due to re-contamination. Regulation of environmental conditions is the best method to prevent the trouble. Most cases are found in beds where the stand is too dense, in beds that are not sufficiently aired, or where the plants are kept too constantly moist or are forced too much. If such faults are avoided, there is little danger of bedrot. Watering should be thorough but not too frequent. Plants should not be forced by too generous applications of nitrogenous top dressings. There should be constant aeration by raising the sash except in most severe weather.

If there are only a few patches in the bed, they should be destroyed with formaldehyde in the same manner recommended for eliminating wildfire patches.

Keeping the beds constantly sprayed with Bordeaux mixture, as recommended against wildfire, is also effective against bedrot. 
Gassing with benzol or paradichlorobenzene, described under Downy Mildew, has given promising results in preliminary tests against the first two types of bedrot, but both materials need further trial on a larger scale before a recommendation can be made.

References: R 1905:276. R 1906:324, 326-329. B 410:408. B 422:33-40.

\section{AMMONIA INJURY IN SEEDBEDS}

SOMEtimes excess ammonia in the soil kills or stunts young plants in the early seedbed stages and may ruin entire beds. This malnutrition disorder is difficult to diagnose, requiring soil analysis and microscopic root examination before absolute confirmation. Sometimes the seed does not germinate at all but usually the seedlings come up and struggle along for a while before disappearing. As most commonly found, the disease occurs in patches of a few inches to a foot or more in diameter where the plants die off before they are a quarter of an inch high. First they turn yellow ${ }^{1}$ and then fall over and disappear, leaving ragged bare spots scattered over the beds. Even those which do not die are likely to be stunted and of slow growth. Microscopic examination of the affected plants shows that the stems are sound and normal but the roots are brown and dead without any fungous mycelium or signs of disintegration. These symptoms distinguish this trouble from the various forms of rootrot and damping-off with which it can easily be confused.

Cause. Ammonia injury occurs only on bed soils which have been steamed in the spring. A soil test shows huge quantities of ammonia liberated from such organic materials as fish meal, cottonseed meal, manure, and others, during the process of steaming. This ammonia is very toxic to the young roots.

Prevention. The control lies primarily in avoiding the application of nitrogenous materials, such as those listed above, just previous to steaming. Also it is well to delay seeding as long as possible after steaming in order to permit the ammonia to be converted to nitrate. Steaming the beds in late autumn instead of in the spring will also eliminate the trouble. In less severe cases it has been found that the injury may be overcome by applications of nitrate of lime and of land plaster which neutralize the effect of the ammonia.

Reference: B 422:30.

\section{POTASH DEFICIENCY}

This is not a very common trouble but a few cases are brought to our attention almost every year. Shortage of potash in the soil produces characteristic symptoms on the leaves of the plants. The most severe cases that the writer has seen in this State were in seedbeds, but mild cases have been found in the field also. Under the Connecticut Valley practice of heavy potash fertilization, however, they are not common in the field.

1 A trouble in Australia which appears to be the same is called "yellow patch". 
Symptoms. In the earliest stages, the potassium-starved leaves are mottled with yellow near the margins and tips, resembling somewhat the early stages of ripening. Soon the surface of the leaf beconres rough and puckered, "hobbly". Meanwhile the centers of the mottled areas have died and the margins and tips of the leaves are speckled with numerous small white spots. As conditions grow worse, margins of the leaves turn downward, giving them a rim-bound appearance (Figure 6). In severe cases the dead portions may coalesce and fall out or break and make the leaf appear ragged. On large leaves in the field, when potassium deficiency is not great, we have found the only symptoms to be a yellowing and sharp downward recurving of the leaf tips.

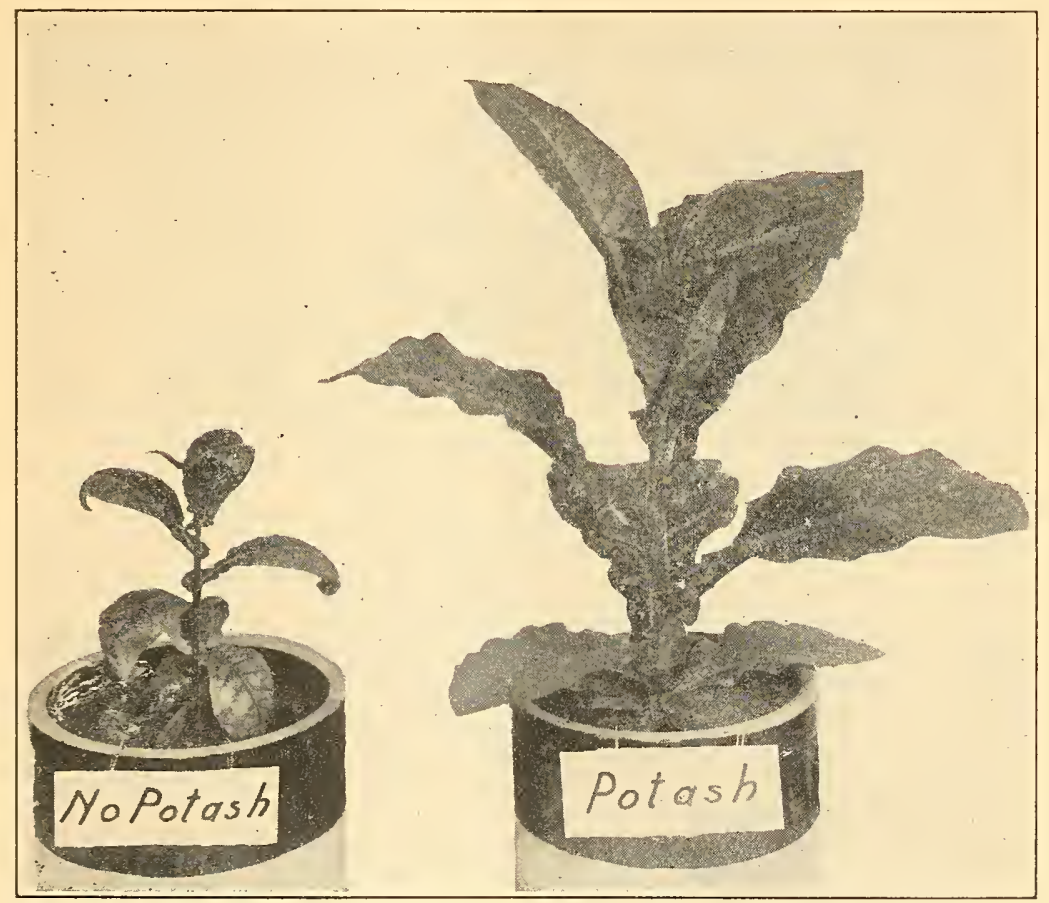

Figure 6. Potash deficiency. The large plant at the right had all nutrients supplied. The small plant had all nutrients except potash. Note the small size and rim-bound leaves with recurved tips. The plants are the same age.

Unlike magnesia hunger, the symptoms of potash hunger do not always appear first on the lower leaves. These may be quite normal and the worst symptoms occur on the middle leaves. In severe cases plants are dwarfed, but we have not seen such a case in the fields of the Connecticut Valley.

Plants with low potash supply are the first to wilt during dry weather or on hot days. The cured leaves do not come into "case" in the shed so quickly as those which have more potash. They are dry, harsh, non-elastic and have poor fire-holding capacity. 
Control. When this disorder occurs in the beds, the plants should be thoroughly sprinkled with a solution of nitrate of potash made by adding two pounds of this material to a barrel of water. After the solution has been applied, it should be washed from the leaves with clear water. Even when the plants are severely affected in the beds, they may be set in the field safely since they recover rapidly there. The remedy in the field consists in supplying any of the potash materials commonly used in the fertilizer mixture. The trouble in the field, however, is rarely observed until it is too late to undertake remedial measures for the current year.

Reference: B 334:140.

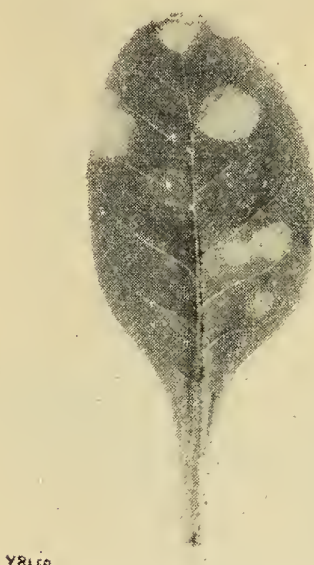

Y8159

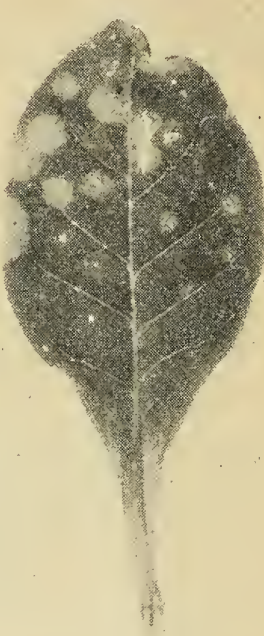

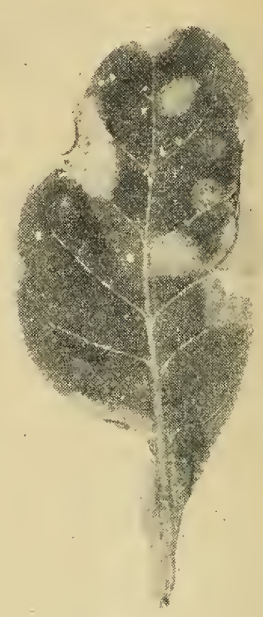

Figure 7. Wildfire on young leaves from the seedbed, showing halo spots.

\section{DISEASES DESTRUCTIVE IN SEEDBED AND FIELD}

\section{WILDFIRE}

W ILDFire appeared first in Connecticut in 1919 having been brought from the southern states. It increased rapidly, became serious locally in 1920, and was widespread and very destructive throughout the Connecticut tobacco districts in 1921 and 1922. For a few years it was the most serious tobacco disease in the State. The damage varies from season to season but in general, during recent years, it has become less and less evident so that it is now regarded as one of the minor ailments. Whether this indicates a decline in virulence of the wildfire organism, or is due to a succession of years unfavorable to its spread, or to a more thorough adoption of remedial measures by the growers, cannot be definitely stated. There is no demonstrated reason why, under favorable conditions, it should 
not become as prevalent as it was in the early Twenties, and certainly precautionary measures against it should not be relaxed.

Symptoms. This is essentially a disease of the leaves but the lesions may appear on any green part of the plant. It occurs both in the seedbed and in the field but does not spread on tobacco in the shed. The main damage is caused by the spots on the leaves, thus destroying or reducing their value as wrappers or binders. In early stages of development, spots caused by wildfire can be distinguished from all others by the presence of a broad, chlorotic, marginal band called the "halo" (Figure 7). In the center of the spot there is a small, dry dead point, at first no larger than a pinhead, surrounded by the yellow halo of living tissue, from an eighth to a quarter of an inch broad. The spots are circular--or semi-circular if on the leaf marginwith regular, smooth outlines. They may run together, however, and produce large lesions of irregular shape. When the leaf is attacked before it is completely unfolded, it becomes distorted. Severe infection in the bud causes all leaves which unfold from it later to be yellow, dwarfed and misshapen.

As the disease progresses in the field, the central dead part enlarges and in dry weather the entire chlorotic area may become dry, brittle and white leaving no marginal yellow band. In this stage the spot is not easy to distinguish from various other kinds of leaf spots. Under moist conditions, however, the halo continues to develop in advance of the dry center. After the spots are dry and dead, they often crack or fall out, leaving the leaf ragged. Badly diseased tobacco, when cured, can be sold only for stemming. Figure 8 shows a diseased leaf from the field.

In the seedbed, where the plants are thick and conditions more humid, the disease often takes the form of a wet rot in which all the leaves in areas which may be a foot or more in diameter are reduced to a watersoaked, slimy pulp. This may occur at any time after the leaves are as large as the finger nail. It may be distinguished from bedrot, which it resembles, in two ways: First, there is the presence of the regular halo spots on some of the leaves; and second, in this disease, the leaves are principally affected, while in the case of bedrot, the stalks are attacked first.

Cause. Wildfire is caused by the presence within the leaf tissues of enormous numbers of parasitic bacteria, Bacterium tabacum. A single bacterium is microscopically small and short-lived but it multiplies with extreme rapidity and a lesion is produced by the combined effect of a mass of millions of individuals. These live on the decomposition products of the leaf cells which they destroy. At the same time they secrete a toxin that spreads into adjacent cells and breaks down the green chlorophyll, thus creating the yellow halo. The bacteria then ooze out to the leaf surface and are carried by splashing rain or by wind-borne water to other leaves. They may also be carried by tools, horses, workmen and other agents. The surface of a healthy leaf must be wet for several hours at least after contact to permit infection. While infections take place most easily through wounds in the leaf, for example hail holes or wind rips, it is probable that a considerable proportion in the field enters through the natural openings of the leaf surface, stomata and hydathodes.

Bacteria may exist for a few weeks in the soil and be splashed or otherwise carried up to leaves, but it is doubtful whether they live over the winter 
to any extent under these conditions. They are more likely to winter under dry conditions, in diseased leaves in the sheds, or on sash, boards or tools

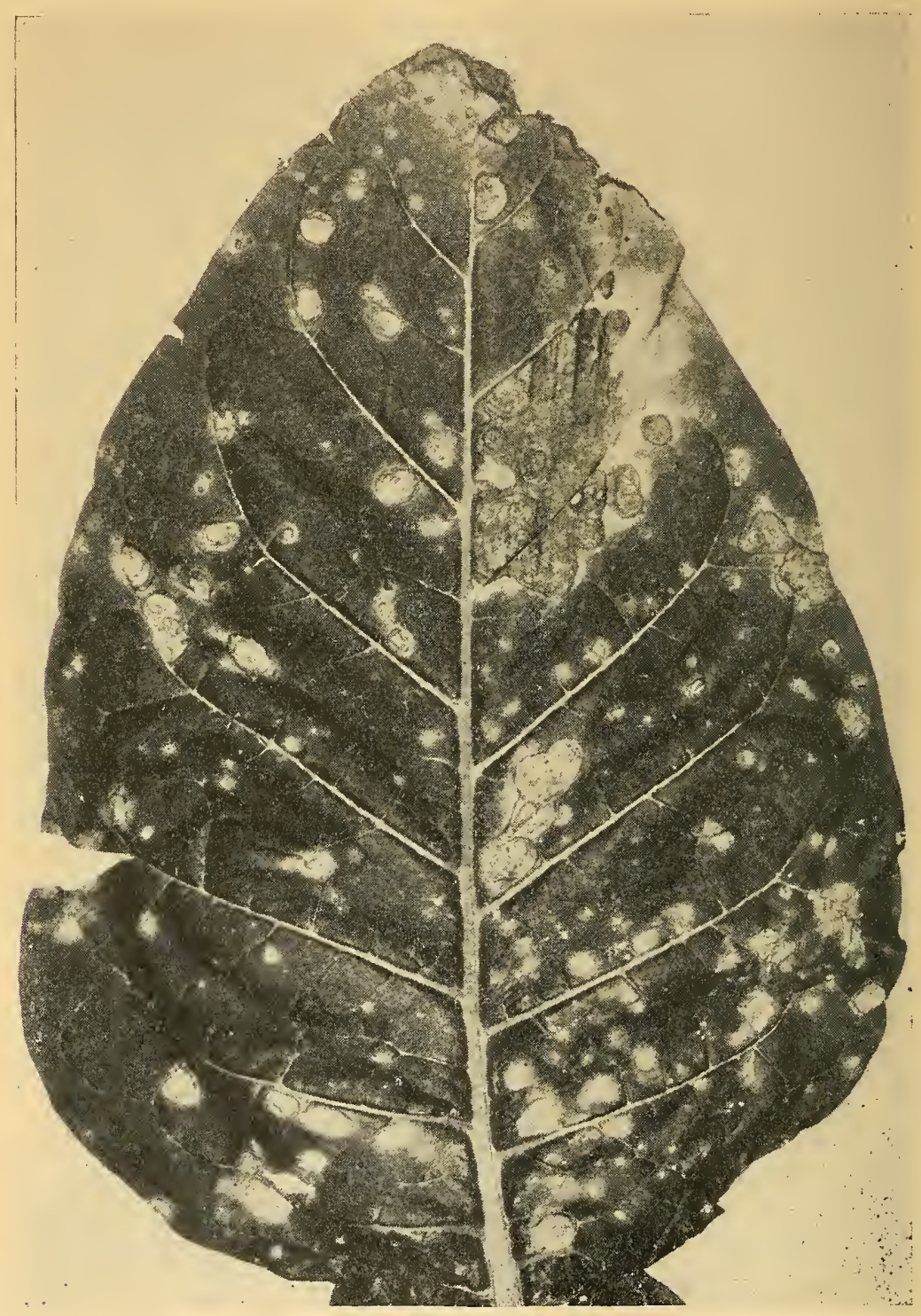

Figure 8. Wildfire is shown in the advanced stage on a mature leaf from the field.

stored in the sheds. Their transfer from these to the seedbeds probably accounts for most spring infections and the start of the new season's epidemic. 
Effect of Environmental Conditions. For reasons stated above, a wet year, characterized particularly by long continued rainy periods when the water stands a long time on the leaves, is particularly favorable to wildfire. Hailstorms and rains accompanied by high winds furnish excellent conditions for spreading the disease. Rapidly growing plants are more susceptible than slow growing ones. Variations in temperature are not known to have any influence.

Control. Practically all wildfire in the field starts from plants which come from diseased seedbeds. Control measures are therefore directed mostly toward keeping the beds free from disease. The most effective method is to keep the seedlings constantly covered with Bordeaux mixture or a copper lime dust. The ordinary 4-4-50 Bordeaux, which is commonly used for spraying potatoes, is the cheapest and safest material, and sticks to the leaves better than any other fungicide. Directions for making a convenient quantity for tobacco beds are printed in the Appendix.

\section{Application of Spray}

Use one and one-half to two gallons of this mixture per square rod of bed, depending on the size of the plants and fineness of the spray. Use a fine spray and high pressure.

Keep the leaves covered with Bordeaux all the time after the second pair appears. This means spraying every four or five days when the plants are growing rapidly.

Spray when the leaves are dry and then do not put the glass on again until the Bordeaux has dried. Don't spray at night, but earlier in the day when the material will have time to dry.

If the mixture has been made and applied properly, the plants will appear blue when dry, and the spray will not wash off when the bed is watered.

Any kind of a spray pump that gives a fine spray and fairly high pressure is satisfactory for the work. The barrel pump or wheelbarrow type are convenient. The hose used in watering the beds is suitable for spraying.

Commercial Bordeaux Mixtures. Ready-made commercial products may be purchased at hardware or farmers' supply stores. On the outside of each package there are directions for diluting the contents with water to make it equal to 4-4-50 Bordeaux. Follow the directions. A number of these products have been found satisfactory, and if a small bed is to be treated, they may be economical. None of them is as cheap or any better than the Bordeaux made at home.

Copper Lime Dust. Copper lime dusts are effective and in common use, being preferred by many good growers. They should be applied somewhat more frequently than Bordeaux, and they stick best if applied when the leaves are moist. The dusts are more expensive than Bordeaux but have the advantage of covering the underside of the leaves better than spray. It is not necessary that they should contain arsenicals if they are used only to control wildfire.

If wildfire was prevalent on the farm during the preceding year, precautions should be taken against transferring any infected material from 
the sheds to the beds. If wildfire was in the beds, it is well to drench the sash and boards with formaldehyde diluted at the rate of one part in 25 parts of water.

Frequently wildfire appears only in isolated spots or areas in the beds. Whenever such an infection is found, all the plants in the area, as well as those bordering on it for a foot or more, should be destroyed by drenching it with formaldehyde diluted at the rate of about one part in 25 parts of water. Glass should be removed from the bed during this operation, and for at least the next 24 hours, to prevent the fumes from spreading and injuring other plants.

If the infected spots are numerous, or the disease is distributed generally throughout the bed, it is best to destroy the bed entirely by drenching with a one to 50 solution of formaldehyde on a hot day and leaving the glass on tight.

Wildfire is contagious. Tools used in infected beds should be dipped in formaldehyde before being brought into contact with healthy plants. If it is at all practicable, no plants should be pulled from beds in which wildfire is present.

Control measures taken after the disease is in the field are not dependable for the most part. If only a few diseased plants are found when they are quite young, they may be removed and carried from the field. If the infection is more general, this method is questionable because healthy plants, set where the diseased ones have been pulled, commonly become infected from bacteria left in the soil. Removal of diseased leaves generally has not been successful in stopping wildfire when weather conditions favor its spread. Thorough spraying of the young plants in the field may reduce spread somewhat but this is not practicable or effective when the plants are large. Plowing under a diseased stand and setting the field with healthy plants will eliminate wildfire only when following weather conditions are unfavorable for spreading it.

When there is any wildfire in the field, cultural operations should be carefully avoided while the leaves are wet.

References: B 239:365-423. TB 1:1-4. TB 2:1-38. TB 4:1-3. TB 6:68. B 367: 118. B 391:108. B 422:27.

\section{BLACKFIRE (ANGULAR LEAF-SPOT)}

B Lackfire causes considerable damage both in the seedbeds and in the fields of the more southern tobacco states but has never been very serious in New England. Almost every year the writer has observed occasional fields where, late in the season, blackfire spots could be found on some of the leaves, but the damage has been negligible.

Seedbed infections here are rather unusual except for occasional years. There is some difference of opimion among pathologists as to whether the disease in the seedbed, angular leaf spot, is the same as that called blackfire in the field, but as a matter of convenience we shall consider them together without reference to the question of their identity.

Symptoms. Since the symptoms in the seedbed differ somewhat from those in the field we shall describe each separately. In seedbeds in Connecti- 
cut the disease occurs in small spots or patches of a foot or more in diameter and is not scattered generally over the beds as it is said to be in the South. It starts from a focus and spreads centrifugally, involving all the plants in its path. Sometimes only one affected patch is found on a farm, sometimes a dozen.

The characteristic symptom of this disease is the occurrence on the leaves of numerous little dark dead spots, the number on each leaf ranging from a half-dozen to 50 . In early stages, the color of these spots is black, or a very dark green, and the affected tissue is watersoaked. As they dry out, the color blanches through various shades of brown and gray to almost white. The young black spots vary from pinhead size to a quarter of an inch across but frequently they coalesce to form larger, irregular patches. The spots are always much smaller than those found on mature leaves in

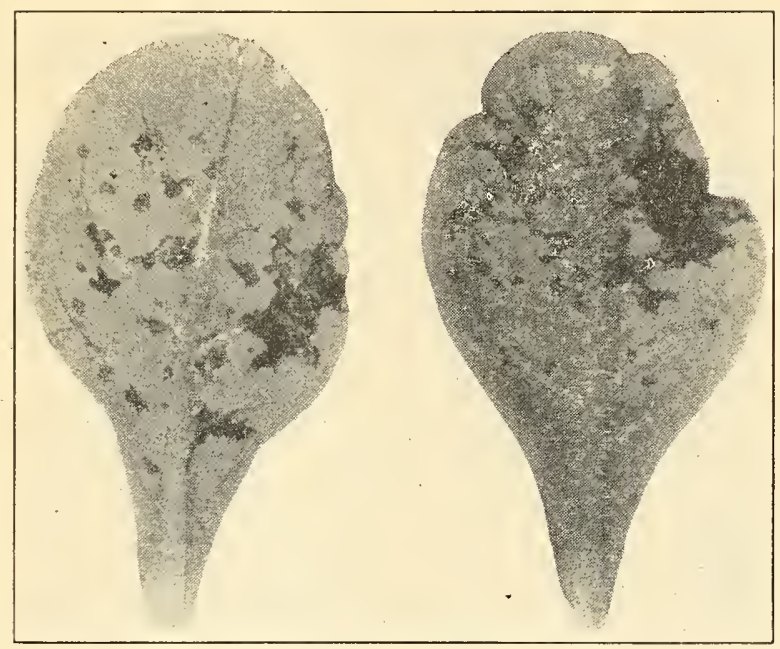

Figure 9. Blackfire or angular leafspot in the seedbed. Spots at first are dark and watery.

the field. They are irregular in outline (Figure 9), only rarely perfectly round, with no definite margin or halo. These characters make it easy to distinguish them from wildfire spots. At first they give one the impression of flea beetle injuries, but closer examination shows that the leaf tissue is not eaten but is collapsed and sunken, with the epidermis intact. As the spots get older and dry after a few days, the tissue becomes brittle and easily cracks and falls out, leaving irregular, ragged holes. As the disease progresses, the leaves become somewhat distorted and the margins and tips turn downward. In severe cases the plants are badly stunted but not killed.

When examined under the microscope, the leaf tissue is found to be collapsed and disintegrated in a soft rot and teeming with motile bacteria.

In the field, usually only a small percentage of the plants is attacked. The writer has never found more than 10 percent infection, and the disease 
is confined to the lower leaves. The dead spots vary in size from an eighth to a half-inch or more in diameter, but sometimes these run together to kill larger areas. They are commonly larger on Broadleaf than on Havana Seed.

The spot differs in appearance from the wildfire spot because it is usually angular instead of round in outline, and lacks the broad, definitely margined

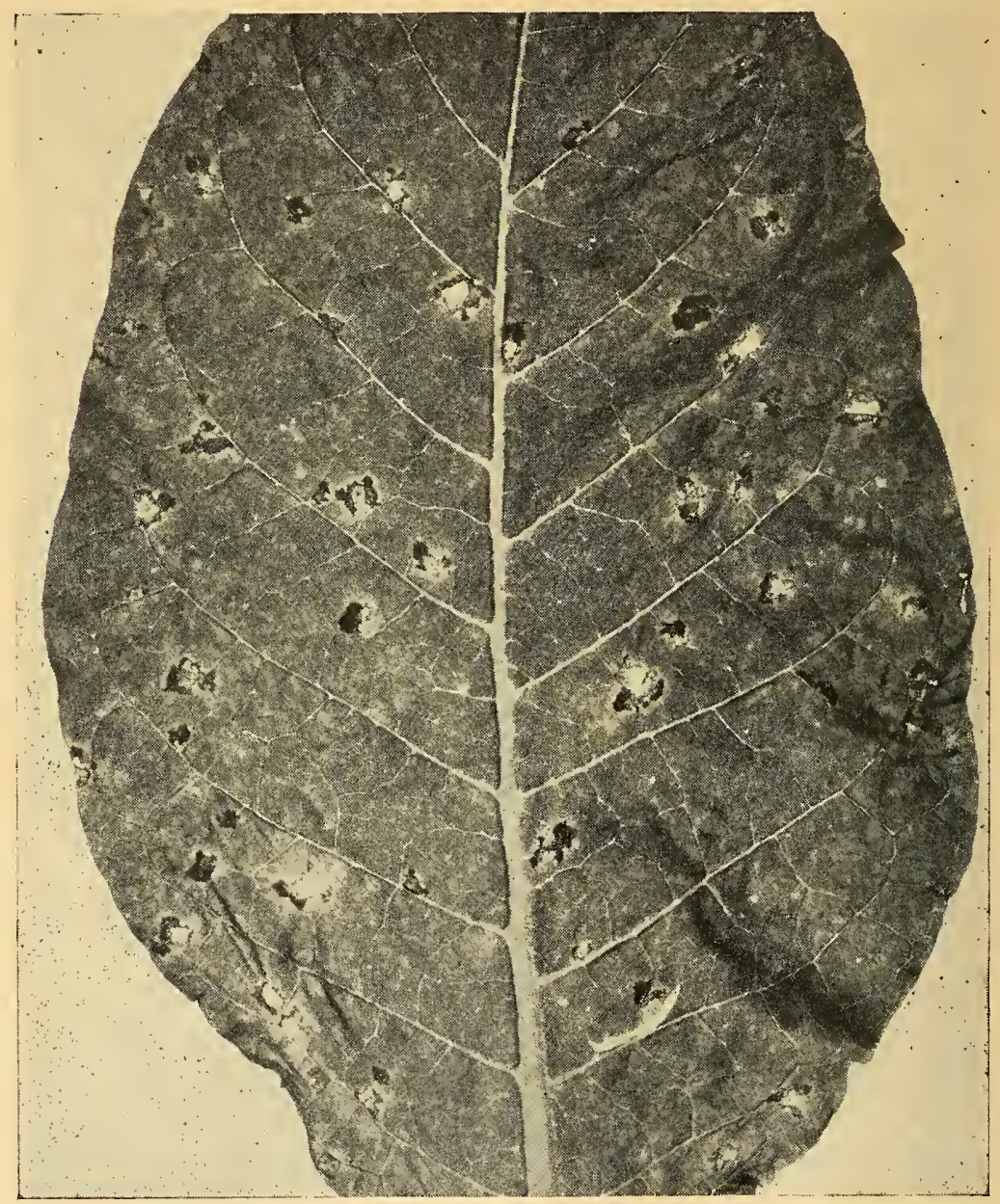

Figure 10. Angular leafspot on mature Broadleaf. Note the irregular angular outline of spots and difference in colors.

halo. When there is any yellow around the spots, it runs off irregularly into the green and has no smoothly defined, outer margin. Another characteristic of blackfire is that the spots usually show several shades of brown, from tan to black, in the same spot. The accompanying photograph (Figure 10) shows a leaf of Broadleaf. On heavier leaves une spots may be more circular 
and less irregular in outline and the surface marked by somewhat concentric ridges. After curing, the spots remain white, conspicuous and rigid and do not soften easily during "casing". A severely affected leaf is worthless.

Cause. Blackfire, or angular leaf spot, is produced by parasitic bacteria, Bacterium angulatum, invading the leaf tissue. There are various ways in which they may be introduced into the beds. In Virginia, it has been shown that they may live over from one season to the next on the seed, dry tobacco leaves, refuse, or plant-bed covers. In Kentucky, it has been shown that chewing tobacco used by workmen about the beds is a prolific source of infection. There is also some evidence that the bacteria may winter over in the soil.

In the field, the most important factor in spreading blackfire from plant to plant is prolonged periods of rain. In the beds also, frequent watering, the prevalence of high moisture conditions and the operations of weeding and pulling the plants, when wet, undoubtedly spread it quite effectively.

Control. Blackfire has never been of sufficient importance here to warrant special control measures. If it should become more prevalent it will be necessary to take precautions to keep it out of the seedbeds since it has been shown in other sections that the principal source of field infection is the setting of diseased plants from infected beds. Such control measures would be essentially the same as those used commonly here for control of wildfire and would not involve much additional work.

References: TB 6:70. B 367:120. B 386:593. B 422:31.

\section{DOWNY MILDEW (BLUE MOLD)}

A Mong tobacco diseases, downy mildew is the most recent immigrant

to Connecticut, having made its first appearance here in May, 1937. It had been known as a destructive disease in Australia for 50 years, was first found in this country in Florida in 1921, disappeared for 10 years, and then began to spread in the South. Since that time it has invaded new states every year and has now reached all tobacco growing sections except Wisconsin.

Damage is mostly to the plants in the seedbed but it has also caused some losses on the lower leaves in the field. The extent of this field loss has been negligible on Broadleaf and Havana Seed tobacco but more serious on Shade tobacco on which the loss in 1939, the worst year, was estimated at $\$ 100,000$.

Symptoms. Since the field symptoms are not just the same as those in the seedbed, it will be necessary to describe the two separately.

In the seedbed. A badly diseased bed in late stages of development looks as if it had been thoroughly burned by pouring scalding water or a toxic chemical, like formaldehyde, over it. All the leaves are dead, dry, and shrivelled to mere strings, flattened out on the surface of the ground (Figure 1). Usually the plants are not affected equally in all parts of the bed. At one end they may be completely withered while they are progressively less affected as one approaches the other end.

Another symptom that is unmistakable after a little experience is the 
rank odor-especially if the beds have been closed-suggesting rapidly drying, decaying or steaming vegetable matter. It is not unlike the odor of potato mildew.

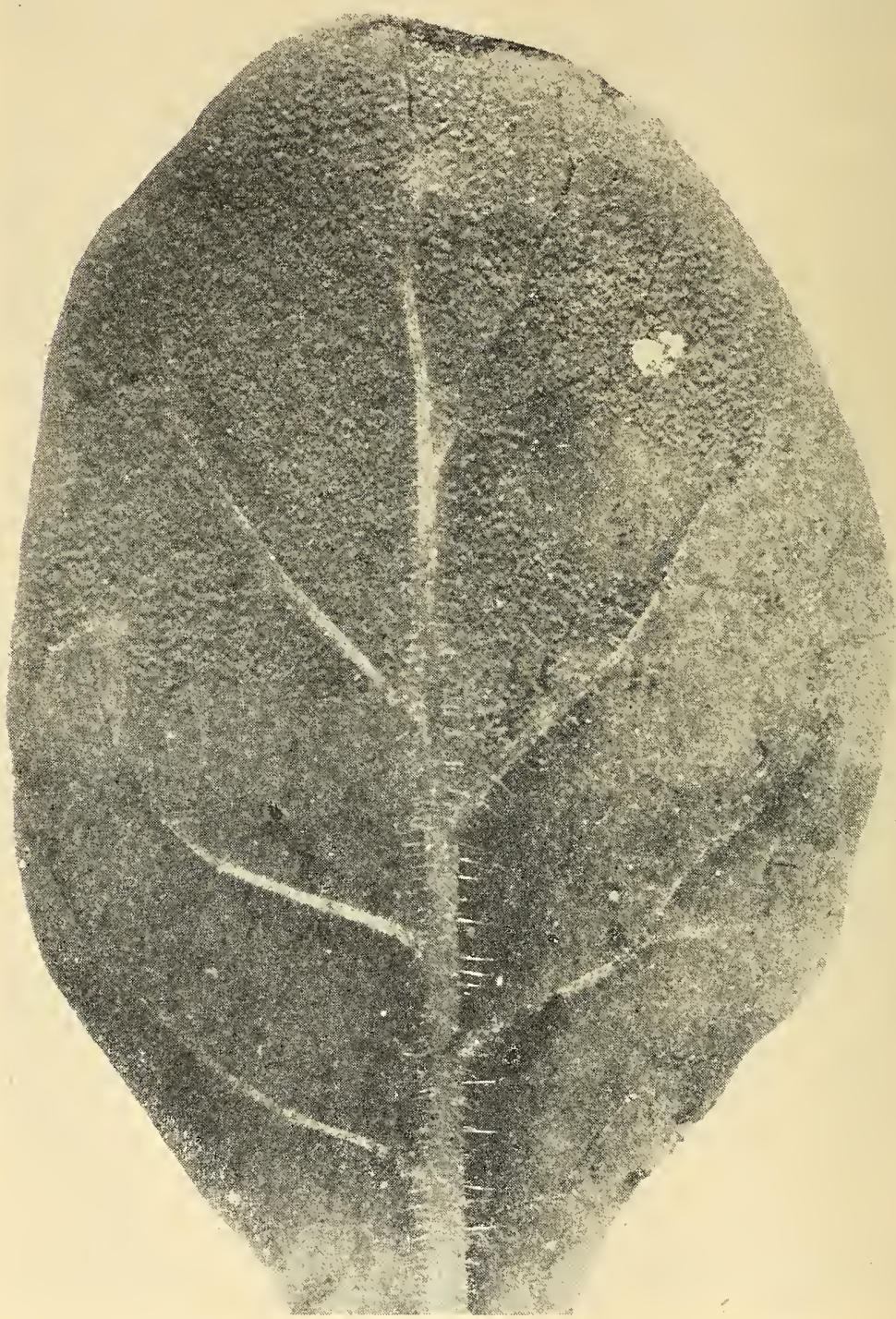

Figure 11. Downy mildew. This leaf from the seedbed shows the fungus covering part of the lower surface. (Somewhat enlarged.)

The smaller plants in these badly diseased areas are dead but the stronger ones still have green bud leaves although all the larger, outer leaves are withered. 
But if one wishes to see the beginnings of infection and observe the stages by which such destruction has cone about, he must examine the opposite end of the bed or look for beds where the infection is still new. In such places he will find the first indication of disease in small areas where the tips of the leaves, or indefinite spots on the leaves, are faded or rusty yellow. Such leaves are not flat, as they should normally be, but are irregularly puckered, humpy, contoured or cupped, and commonly twisted until the lower surface faces upward.

If it is early in the morning or the weather is cloudy, the lower surface of some of these leaves will be covered with a downy felt of fungus (Figure 11), the symptom which gives the disease its name. The color of the down varies. It may be white or gray, or, if older, rusty brown. Young, fresh infections, especially if viewed obliquely, have a distinct violet tint. The presence of this felt-like growth is the only infallible symptom visible to the naked eye. Later in the day and during dry weather, as well as during the later stages of the disease, this disappears and diagnosis becomes more difficult. The subsequent changes in appearance of the affected spots vary with the weather. When it is wet, the diseased tips take on a dark green to black, dead, water-soaked appearance as they wilt and wither progressively downward. In dry weather the affected spots become brown, dry and brittle. The colors which the dead tissue takes on are so varied that they furnish no criterion for diagnosis. Neither is the shape of the spots regular or characteristic and it furnishes no proof for identity of the disease.

A remarkable characteristic of downy mildew is the capacity of badly diseased beds to recover. It is only the small plants, up to an inch high, that are killed. In the larger plants the bud and "chit" leaves do not die. After the initial attack, the plant appears to acquire a certain degree of immunity and develops normally. Beds which seem to be completely ruined when first observed often appear perfectly normal, with no mildew on them, when examined after 10 days. Plants from such beds show no injurious effect when transplanted.

In the field. Entire leaves usually do not die in the field but the disease appears as spots of a half-inch to more than an inch in diameter, one to a dozen on a leaf (Figure 12). In the first stages one sees only a faint, indefinite yellow blotch on the upper side of the leaf. This blotch rapidly becomes more definite and more yellow, and as the leaf tissue dies, it turns to a light brown. The majority of the spots show no fungus on the lower surface at this time, but if the weather is damp one may find it, especially on leaves close to the ground. On examining the young spots closely, one notices numerous little brownish or blanched or sunken specks visible on both surfaces. Some persons have mistaken these for flea beetle injuries but examination under the glass shows that there has been no chewing of the tissue.

In wet weather the spots on the leaves enlarge to a certain extent but when dry they quickly cease to show any further development. When the tobacco is cured, the spots appear as blanched, dry areas which greatly reduce the value of the leaves as wrappers or binders.

Cause. Downy mildew is caused by invasion of the leaf by a destructive, rapidly-growing parasitic fungus, Peronospora tabacina. After this 
fungus has vegetated for four to seven days inside the leaf (Figure 2, E), robbing and killing the host cells, it breaks out on the surface in the form of the downy felt which has been mentioned above as the distinctive, visible symptom of this disease. This felt holds enormous numbers of shortlived summer spores (Figure 2, A, B) which are so light that they are wafted away by the slightest air movement, like fine particles of dust, and may be carried for miles to infect other plants. Thus the life cycle is repeated about once a week (Figure 2, C).

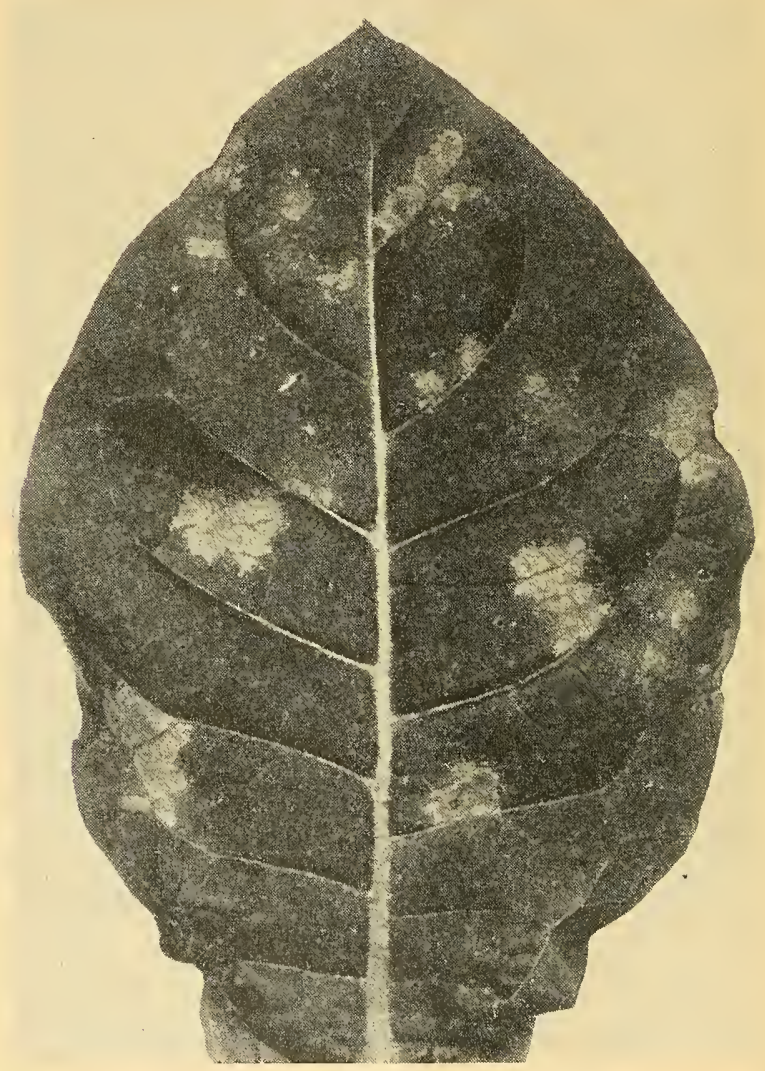

Figure 12. Mildew spots on Shade leaf in the field. (One-third natural size.)

In the decaying leaves which fall to the ground, spores of another type, thick-shelled winter spores (Figure 2, D), are developed which are resistant to adverse weather conditions, remain in the soil all winter and germinate to start the disease again the next spring.

Effect of the Weather. Mildew comes on suddenly and disappears as suddenly. Some years it is very destructive; other seasons it causes little or no damage. Sometimes it spreads with almost unbelievable rapidity, and again it remains stationary. Its erratic and puzzling behavior makes 
it impossible to predict what it will do at any one time. For the most part, these peculiarities of the disease can be explained by the effects of the weather on the development and distribution of the causal fungus.

Continued cool, moist weather is most favorable to the disease. The spores in the beds are developed during the early hours of the morning at temperatures of 42 to 63 degrees $\mathbf{F}$. with the most abundant production at about 56 degrees. Little, if any, production of spores occurs above 68 degrees $\mathrm{F}$., or below 36 degrees F. Naturally the disease spreads little when no spores are produced. In the beginning of our seedbed period, the nights are too cold for spore production; at the end of the season they may, at times, become too warm; but for most of the period, the night temperature range in seedbeds is quite favorable to sporulation.

High temperatures during the day inactivate or kill the mycelium. The critical temperature above which the mycelium does not develop is around 84 degrees $\mathrm{F}$.

Like most fungi, the mildew pathogen is favored by moisture. Since our beds are constantly watered and the sash prevent too much evaporation, the humidity is close to saturation most of the time. Even though the uppermost leaves may be dry, when the plants are crowded, there can be very little ventilation around the basal leaves and a high humidity near the ground is inevitable. Such conditions are ideal for the luxuriant development of the sporophores and spores that form the felt-like covering on the lower surface of the leaf.

Water plays a more important role, however, in the germination of the spores and infection of leaves. In water, the spores germinate within two hours or less and in another hour the germ tube could have entered the stomate of the leaf. Thus any condition under which drops of water remain on the leaf as long as three or four hours will permit infection. Naturally, the longer the leaves remain wet, the greater the chances for infection and the more sever the disease. In the field also, long periods of rain may easily result in spreading the disease.

Direct sunlight is lethal to the summer spores, killing them within a few hours. It also dries the leaf off more quickly and thus delays infection.

Control. Cultural practices. In the management of the seedbeds some practices may be adopted to reduce the risk of infection and retard the spread of mildew but none of these alone can be relied on to keep the beds free from disease.

1. Steaning the soil, as commonly practiced, kills the spores in the soil and should be beneficial in preventing primary infection.

2. Shaded, swampy, or poorly drained bed sites should be avoided on account of the environmental factors mentioned above.

3. Thorough ventilation of beds is important because it permits the leaf surfaces to dry off quickly. This may be done by raising the sash or by removing them altogether in favorable weather.

4. Just as soon as the setting is completed, all remaining plants should be removed or killed with formaldehyde to destroy the winter spores and 
also to prevent further production of summer spores which will blow into the fields. To kill the plants, drench them with a 1-50 solution of formaldehyde in water, leaving the sash on the beds during a warm day.

Spraying the beds. A great variety of fungicidal preparations in solution or suspension in water have been tested both here and in other states but none has proved entirely satisfactory in Connecticut. A mixture of one-half pound red copper oxide, two quarts cottonseed oil and one quart lethane spreader in 50 gallons of water is used as a spray with considerable success in some of the southern states. This has not been the experience under our conditions in trials both at the Experiment Station and in the beds of a number of growers. In many cases the spray caused considerable burning of the plants. It did not prevent mildew but only delayed its appearance. The mixture is bothersome to prepare and is liable to do serious injury unless properly made. Finally, in view of the much better control achieved by the gassing method, it does not seem wise to depend on the spray.

Gassing the plants. Mildew may be completely eliminated by evaporating either benzol or paradichlorobenzene in the closed seedbeds at night. Although paradichlorobenzene is most convenient and safer to handle, it has the one fault of vaporizing too slowly at low temperatures. At temperatures in the seedbeds below 4.5 degrees $\mathrm{F}$., the vaporization is so slow that the gas in the air does not build up to a concentration lethal to the parasite. Perhaps a means of overcoming this handicap will be found but, for the present, benzol seems to be preferable at least in the early part of the season when cold nights may be anticipated.

Success in either of the gassing methods depends first of all on making the sidewalls and sash, or cloth covers, as nearly air-tight as possible to prevent too much leakage of the gas. Both benzol and paradichlorobenzene vaporize when exposed to the air, and if this air is sufficiently confined, the percentage of vapor will soon reach a point of concentration high enough to kill the mildew on the plants. But if the gas leaks out through holes in the glass, cloth, or sideboards too rapidly, it never becomes sufficiently concentrated to be lethal to the mildew fungus. Obviously it is not possible, nor is it necessary, to make the beds absolutely air-tight, but, within practical limits, the tighter they are, the more certain will be the control, and the smaller will be the quantity of chemical needed. If a cloth cover is used, it should have over 50 threads to the inch. When such cloth is sprinkled with a hose at sun-down, the water fills the pores and makes a covering almost impervious to the passage of gas.

Both of the gassing methods described here are curative, and not preventive, measures. Therefore it is not necessary to apply them before the disease appears. As soon as it is found in one bed in a neighborhood, it is time to start control measures, because this is usually an indication that it will soon appear in the neighboring beds.

When the treatment is first started, it is advisable to continue for two or three nights in succession if mildew has been seen in the beds. If not, every second or third night is sufficient.

Benzol. Shallow pans of benzol are distributed throughout the closed beds during the night and removed the first thing in the morning. Pie tins, 
or the wash basin type of firing pans-used for charcoal curing-are used most commonly, but any kind of shallow pan which will hold benzol is suitable. These pans should be supported above the plants up close under the glass for two reasons: First, so that drops of water falling from the sash will not splash the benzol on the leaves, injuring them; secondly, because benzol vapor is heavier than air and will distribute itself better if the pans are elevated. Some prefer to place a metal shield above the pans to prevent splashing. This is not necessary if the pans are close to the glass.

The number of pans required for a bed naturally depends on the area of the pan bottom. In tight glass beds with little gas leakage, or beds properly covered with wetted cloth as described in a previous section, a ratio of one square foot of evaporating surface of benzol to 100 square feet of bed area to be protected is adequate. In beds only fairly tight, a ratio of $1: 72$ is necessary. For example, with an average pan of .5 square foot area, one pan to every third sash in a very tight bed, or one pan to every second sash in one only fairly tight, is required.
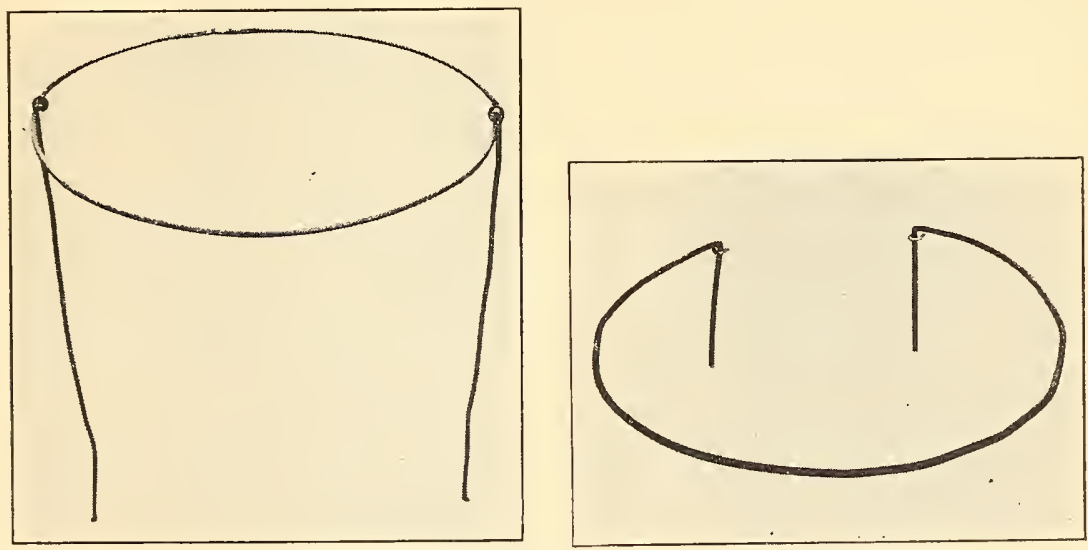

Figure 13. Wire supports for the benzol evaporating pans. A loop supported by legs which are pushed into soil (left) and type in which the ends of the hoop are bent down and supported by staples in the side boards (right).

There should be enough benzol in each pan to last throughout the night. The rate of evaporation will vary some with the temperature and wind, but, in general, if the bottom of the pan is covered a quarter of an inch deep with benzol, it will be sufficient and almost all will be evaporated the next morning. If any is left, it may be poured back into the container to be used again. If water has dripped into the pans, it may be separated by carefully pouring the lighter benzol off the top.

Benzol of the commercial grade known as 90 percent is suitable. Commercial benzine, motor benzol, or types containing impurities should not be used.

Tarious methods of supporting the pans over the plants have been derised. The type most popular with the growers in the past season was a simple standard constructed of heavy wire, consisting of a hoop of proper 
size to fit the pan, supported either by two or three long wire legs which are pushed into the soil (Figure $13 \mathrm{~A}$ ), or by staples in the sideboards (Figure $13 \mathrm{~B}$ ). From the standpoint of the distribution of the vapor, the best position for the pans seems to be in a line along the center of the bed. Since this arrangement is quite inconvenient to manipulate, and actual tests have not demonstrated the necessity of a central position, they are usually placed close to the higher and lower sides of the bed in alternating sequence.

Wick evaporators. An effective, safe and time-saving apparatus for evaporating the benzol has recently been placed on the market. This consists of a series of compact closed cans spaced at regular intervals along the inner side of the headboard and connected by copper tubing. A long wick with one end immersed in the benzol in the can and the other end hanging free in the air permits the benzol to evaporate at a uniform rate. The entire line of cans is filled from a reservoir outside the end of the bed. In this way the whole bed can be gassed without disturbing the sash and much time and labor saved.

Precautions. Benzol is inflammable and should be kept from contact with lighted matches.

It should not be left in closed beds during bright days. At such times the vapor becomes concentrated and the plants, with their breathing pores open, absorb the gas too rapidly and are injured.

When benzol splashes or drips on the leaves, it kills the tissues and produces dead spots.

Paradichlorobenzene. The principles of this method are the same as those with benzol. Paradichlorobenzene is a white crystalline material, a derivative of benzol, which vaporizes when exposed to the air in the beds. It is not inflammable.

The crystals may be placed in pans, as described above for benzol, or on narrow, continuous shelves, 3 inches wide, nailed inside the upper and lower boards of the bed.

Another form of container for the crystals, which may prove more convenient, economical of material, and as effective in control, is a wire basket hung on two finish nails driven into the sideboard.

The rate of application of the paradichlorobenzene should be about onefourth ounce to the square yard of bed, using crystals of not over oneeighth inch diameter. An amount greatly in excess of this, however, does not seem to be harmful. If pans or baskets are used, they should not be spaced more than 6 feet apart.

The paradichlorobenzene should never be kept in closed beds during warm, bright days.

References: B 405:65-82. B 410:406. B 422:26. C 128:1-5.

\section{ROO'T DISEASES}

\section{BLACK ROOTROT}

During the first 25 years of this century, black rootrot was the most serious of all tobacco diseases. It was probably here and causing serious damage long before the Experiment Station began investigations on it 
in 1906. Methods of control have been found and their more general adoption during recent years has so reduced the losses that now black rootrot is among the less important diseases. It occurs somretimes in the seedbed but is more serious as a field disease.

Symptoms. The first symptom of the disease that the grower notices in the field is that the tobacco doesn't grow. The plants are stunted, with narrow, thick, tough leaves that are either a starved yellow color or, where the nitrogen supply is high, a very dark green, commonly called "black" by the tobacco man. On hot days the leaves wilt or "flag" more quickly than on healthy tobacco. The dwarfed plants "top out" prematurely. Only rarely is a field equally affected in all parts. Usually there are patches, from a square rod to several acres in extent, where the tobacco is short, while in other parts of the field growth is normal. In the diseased patches the plants are frequently very uneven in development.

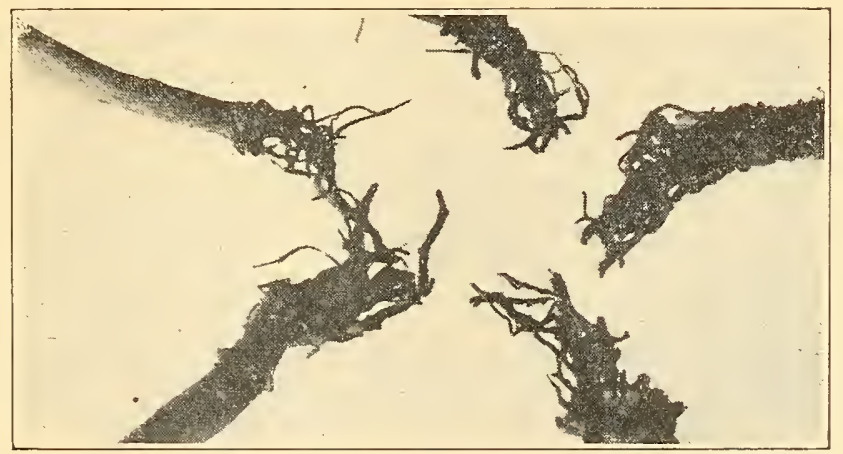

FIGURE 14. Black rootrot causing complete destruction of the roots of young plants.

From the above-ground symptoms, however, it is not possible, even for an expert, to be sure that this is black rootrot. Other troubles, such as brown rootrot, lack of fertilizer, or water-logged soil may produce the same appearance. One must dig the plants and wash the soil from the roots to see the lesions which are ummistakable signs of black rootrot. Normal young roots are white, but on a diseased plant many are black, brown at first, either throughout their length or only in segments, with other segments appearing normal (Figure 14). Most of the ends of the small roots are black, indicating that, in digging the plants, the roots broke at this point and the decayed ends were left in the soil. The tissue of the smaller roots is rotted through, but on the large roots there occur enlarged, rough, scurfy lesions which may or may not kill the interior tissues. Frequently the tap root is entirely rotted off at the bottom and there is an increased number of laterals. This results in a brush-work of intermingled brown, black and white small roots just above the blackened end of the main root. The character which distinguishes this disease from all other tobacco ailments is the coal black color of parts of the roots. The reduced root system is unable to se- 
cure sufficient water and soil nutrients for normal growth of the aboveground parts of the plant. Hence the dwarfed growth and flagging on hot days.

Black rootrot may also occur in the seedbeds where it exhibits the same symptoms: slow growth, yellow or black color of leaves, flagging, and black rotted roots. Many of the plants also die. The beds look very uneven.

Causes. The disease is caused by a parasitic fungus, Thielaviopsis basicola, which is present in most, if not all, tobacco fields, living in the soil indefinitely on dead vegetable matter. It becomes parasitic on the tobacco roots when the environmental conditions mentioned below are favorable. Two kinds of spores are produced in the diseased roots (Figure $2 \mathbf{J}$ ). The black color of the affected roots is due to the great abundance of one type of spores, chlamydospores.

Effect of Environmental Conditions. Although the disease cannot occur in absence of the causal parasite, the extent of injury is much more dependent on the environmental conditions under which the tobacco grows than on the fungous population of the soil.

The reaction, degree of acidity, of the soil is important. It is never serious in the more acid soils. Those testing above $6.0 \mathrm{pH}$, on the other hand, are favorable to the disease. A low temperature increases the disease and explains the variation in severity of black rootrot from year to year. For the same reason it is usually most injurious in the spring and early summer. Crops badly stunted in the cool, early part of the growing season often make rapid recovery and almost normal growth with the advent of hot weather later. Poorly aerated, compact soils are more conducive to rootrot than soils which are loose and do not pack so easily. Wet seasons increase rootrot probably by keeping the soil at a lower temperature and more compact. Heavy applications of manure also increase rootrot.

Control. In the seedbeds the disease is satisfactorily controlled by sterilizing the soil with steam, acetic acid or formaldehyde. (See Appendix for soil sterilization method.)

The most successful control in the field has been through regulation of the soil reaction. Connecticut Valley tobacco soils are for the most part rather acid, $5.2 \mathrm{pH}$ or lower. It was only after this natural acidity had been neutralized by large applications of lime, wood ashes, or alkaline fertilizers that rootrot became serious. When such treatments are omitted for several years, the soil gradually returns toward its original reaction. Avoidance of too much alkaline material on the land thus offers the most logical means of control. It has been found that black rootrot is rarely if ever serious on soils testing below $5.6 \mathrm{pH}$. Only those testing below $5.0 \mathrm{pH}$ should be limed, and then sparingly, not over 500 pounds to the acre at any one time except in extreme cases. Stable manure, wood ashes, or alkaline fertilizers should be avoided on soils testing near or above the danger point, 5.6.

The most effective method of controlling black rootrot is by planting strains of tobacco which are resistant to the disease. The $4 \mathrm{R}$ strain of Shade tobacco developed by the Experiment Station 10 years ago produces a good crop on land where other types are a failure. It is not distinguishable from the regular shade strains in any other respect. In the Havana Seed type we 
now have a number of strains which are resistant and also produce larger crops than the non-resistant kinds without losing anything in quality. No satisfactory rootrot-resistant strains of Broadleaf have been developed but this type is naturally more resistant than the other two and there does not seem to be so much need for more highly resistant strains.

Regular rotation of tobacco with other crops is a method of control which has been successful in certain sections of the country. This is not practicable in Connecticut where continuous cropping of tobacco year after year on the same land is considered better practice than rotation.

References: R 1906:342-368. R 1907:363-368. B 269:539-554. TB 8:47-4.9. B $311: 256-263$.

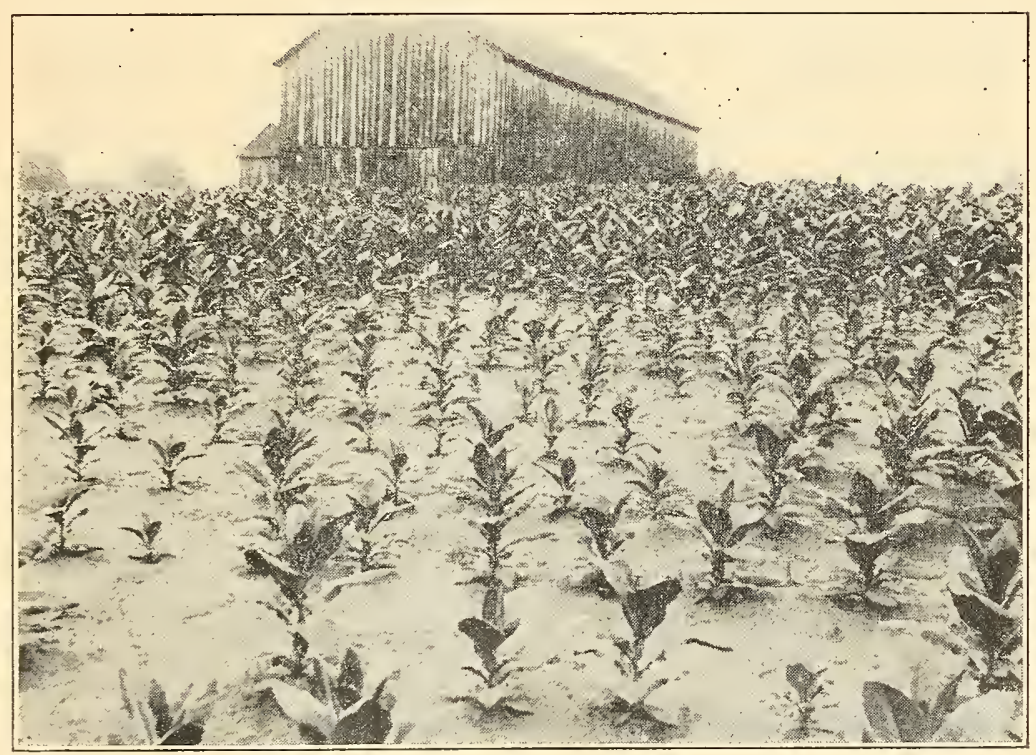

Figure 15. Brown rootrot patch in a field of Havana Seed.

\section{BROWN ROOTROT}

B

Rown rootrot is a trouble of long standing in Connecticut. However, on account of its obscure nature and cause, it has received recognition as a distinct disease only within the last 15 years. Under favorable conditions it may become serious and cause heavy losses, but over the Valley as? whole it is neither so general, nor so injurious, as black rootrot.

Symptoms. The above-ground symptoms are the same as those of black rootrot and need no separate description (Figure 15). It is only by examination of the roots that the two diseases can be distinguished. Here there are no black lesions or scurfy enlargements. The roots are brown, and many of them are rotten, so that the outer cortex slips easily away from the central strand when they are pulled. Death of the lateral roots induces 
new growth of successive crops of laterals from the main root, or bottom of the stalk, with the result that a veritable brown broom of roots appears when the disease is severe. When there are only a few brown roots, diagnosis is attended with considerable uncertainty.

Cause. The only diagnostic symptom of this disease is the presence of dead brown roots in smaller or larger number. Since a root naturally turns brown when it dies, regardless of the killing agent, and since no one species of fungus or bacterium has been found constantly associated with the mialady, it is not at all certain that brown rootrot is a single disease always produced by the same agent. Some investigators believe that the cause is a parasitic organism which has not yet been isolated. Others are sure that it is a malnutrition trouble produced by such factors as lack of nitrates, lack of calcium, or excess of ammonia. Regardless of the direct cause, it has been demonstrated that the common type of brown rootrot found in the Connecticut Valley is an after-effect of a preceding crop. Thus it often occurs when there was a crop of timothy, corn, clover, alfalfa or rye on the land the preceding year. The disease is rarely serious after a potato crop, and least of all when tobacco is grown continuously.

Control. For this type of brown rootrot, which is clearly linked with the previous cropping system, the obvious remedy lies in avoiding a rotation which will bring tobacco immediately after a hay or cereal crop. As a general rule, there seems to be no advantage in rotating tobacco with other crops in Connecticut. The best kind is produced by growing tobacco continuously on the same land. Under this condition, brown rootrot rarely is found.

For various reasons, however, a grower sometimes wishes to raise tobacco on a new field which has been in timothy or one of the other injurious crops mentioned above. If he goes directly from this to tobacco, he may have trouble from brown rootrot, or he may not. There is an inexplainable difference in fields in this regard. Some growers raise potatoes the first year after timothy, and plant tobacco the second spring, thus avoiding the danger of severe after-effects. When tobacco follows hay or forage, the after-effect may occasionally continue through two or three years but becomes less pronounced each season.

References: TB 6:66. B 311:247-256.

\section{STALK DISEASES IN THE FIELD}

\section{PYTHIUM STALK-ROT OF TRANSPLANTS}

A Lthough not a common disease, in some years stalk-rot causes serious loss to the plants shortly after they are set in the field. It is a well known trouble in Sumatra where it has been most thoroughly investigated. Although treated as a field disease, it may possibly be only a field development of some of the types of bedrot.

Symptoms. This is a soft, watery, black (or at least very dark), mushy rot that completely disintegrates all the tissues of the stalk. It starts just at, or below, the ground level, but under favorable conditions 
quickly works upward, even into the bases of the leaves (Figure 16), and causes the plant to fall over and completely collapse. The stalk is so rotted that it no longer holds together when the plant is pulled up. If the plants are kept over night in a moist chamber, they become covered with a thick white felt of mold.

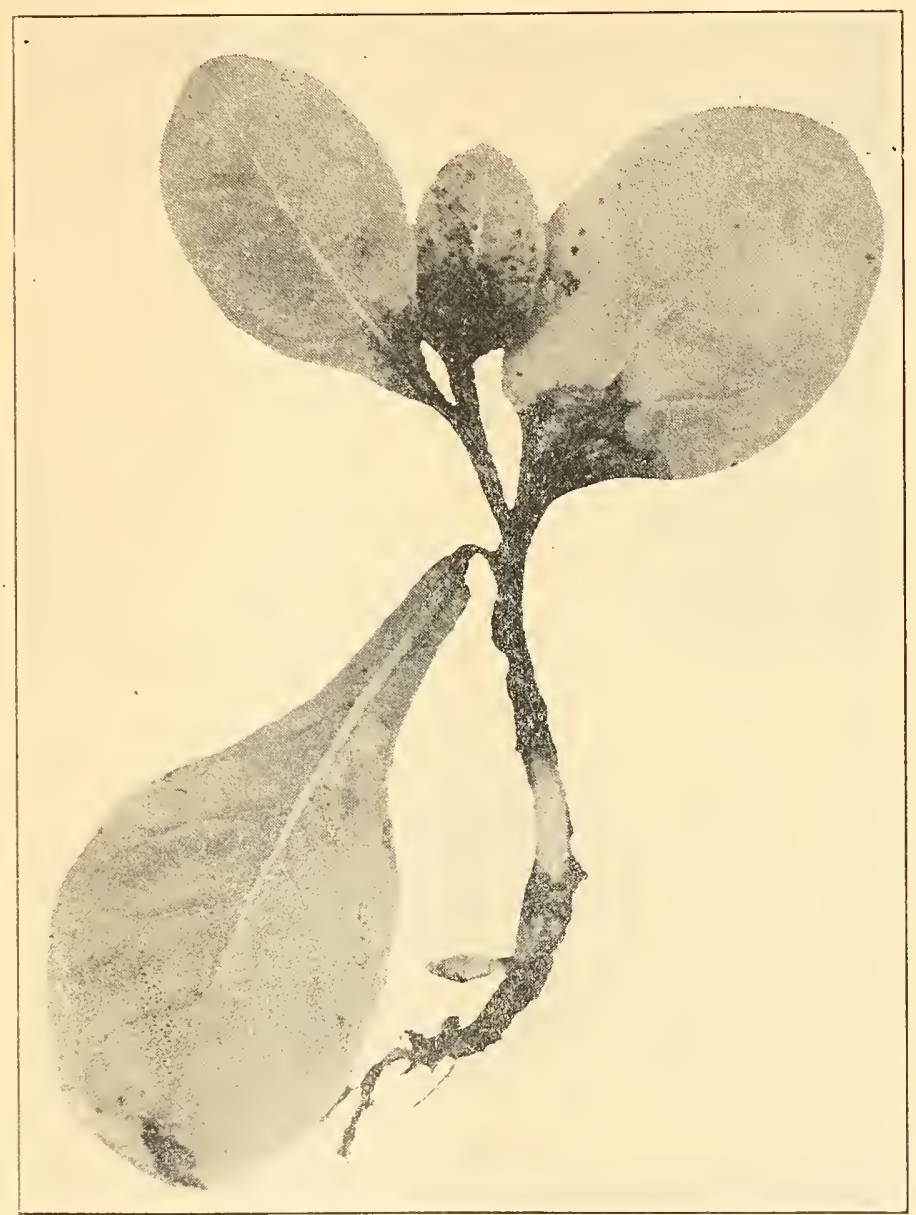

Figure 16. Pythium stalk-rot. Note the dead black stem and bases of leaves.

Effect of Environmental Conditions. This trouble has been preralent only during seasons of frequent rainfall under conditions when the soil remains wet and soggy for several days at a time.

Cause. Tжо species of fungi belonging to the genus Pythium, $P$. debaryanum and $P$. aphanidermatum, have been found associated with this rot in Connecticut (Figure 2, II, N, O). Two others of the same genus 
have been isolated from stem-rotted transplants in Sumatra. Since the two species mentioned above are the fungi which cause damping-off in the beds and also one of the types of bedrot, it is possible that the disease is carried to the field in seedlings already affected. The fungi are also inhabitants of field soil and the infection may originate there. Both methods of infection may operate.

Control. Since prevalence of the disease is undoubtedly influenced by environmental conditions, being worse where moisture is greatest, we may expect to find more or less of it any year when there are frequent rains during the setting season. Since the fungus is not new, there is no reason to fear that the disease will increase and become more prevalent than it was in the past. Since there is a possibility that at least some of the infection starts in the beds, one obvious control measure would be to keep the bed as free as possible from disease by sterilizing the soil, by aeration and keeping the stand thin, and by avoiding too moist conditions.

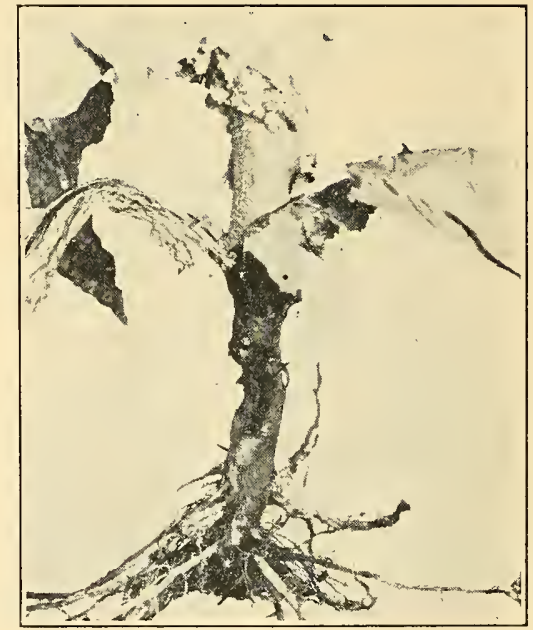

Figure 17. Sore shin, causing a black shrunken canker at base of the stalk.

Succulent, tender, fast growing plants appear to be more subject to attack than those which are hardened. In Sumatra it was found that the plants of the first pulling from the beds are more susceptible to attack than the later pullings. The use of well hardened and disease-free plants should do much to keep this stalk-rot under control. It might prove profitable to discard the first pulling and use only plants from the later pullings.

Reference: B 386:598-600.

\section{SORE SHIN}

Sore sHIN, which is also called stem canker, stem rot, collar rot, or black leg, is of common occurrence in Connecticut tobacco fields. It is rarely of major importance because the number of affected plants is usually 
small, and the total loss is not heavy. Sometimes, however, under favorable conditions, it may take a serious toll and even necessitate replanting of entire fields. Growers have been familiar with it for many years but it has not been carefully investigated here and very little has been written about it.

Symptoms. The characteristic symptom most commonly observed is a brown or black, sunken, rotted canker at the base of the stalk when the plants in the field are half grown or larger (Figure 17). The canker may be only on one side or may entirely girdle the stalk at, or just below, the surface of the soil. Or it may extend several inches up the side of the stalk, sometimes involving the lower leaves, which drop off after the bases of the midribs become rotten. The canker reduces transfer of water and nutrients through the stalk so that the whole plant becomes sickly, yellow, and smaller than neighboring healthy plants. During strong winds many of these plants are broken off at the canker and fall over. In older plants the rotted portion extends inward to the woody part of the stalk. In younger plants it may go clear through, thus causing them to wilt and die. Although the grower sees the disease more often on tobacco that is nearly full grown, the most serious loss is among the younger plants. These die during the first weeks after setting which necessitates repeated restocking and sometimes replanting of the whole field.

Cause. Various fungi and bacteria, believed to be the causal agents, have been found in the diseased tissues by different investigators. The one most commonly found in this State by the writer is Corticium vagum, Rhizoctonia, which has been mentioned previously as causing bedrot (Figure $2 \mathrm{~K}$ ).

It has been observed frequently that the most severe cases of sore shin were in fields set from beds known to be affected with bedrot. Sore shin, therefore, may be regarded for the most part as a later development of this disease. It is not at all improbable, however, that some infection of previously healthy plants may occur directly in fields. Injuries to the stalk by tools or insects probably facilitate field infection.

Influence of Environmental Conditions. Heavy, wet soils and periods of continuous rainfall favor development of sore shin. Under dry conditions the canker stops spreading, and dry, inactive scars which are apparently harmless may be observed on the stalk. With the return of moist conditions, however, activity of the parasite is renewed and the canker continues to spread.

Control. Since the seedbed is the focus of infection, all measures previously recommended for controlling bedrot should be practiced. This ofiers the best means of preventing sore shin. If it is practicable, plants from beds which have bedrot should not be used. If this is not possible, the plants should be carefully inspected when pulled and all which show the smallest brown stem lesions should be discarded. Even with such precautions, all diseased plants will probably not be eliminated. Frequent restocking shortly after setting is advisable but late restocking is hardly worth while. Heavy, wet soils and fields known to produce sore shin should be avoided. 


\section{HOLLOW STALK}

Hollow stalk is a disease of long standing in Connecticut. It belongs strictly to wet years and may not appear anywhere in dry seasons. During the very wet summer of 1938 the disease ruined as many as 10 percent of the plants in some fields. It is almost never found on Shade tobacco. A diseased plant is usually a total loss (Figure 18).

Symptoms. In general, hollow stalk appears first at about the time of topping. The characteristic symptom is the decay of the pith which in

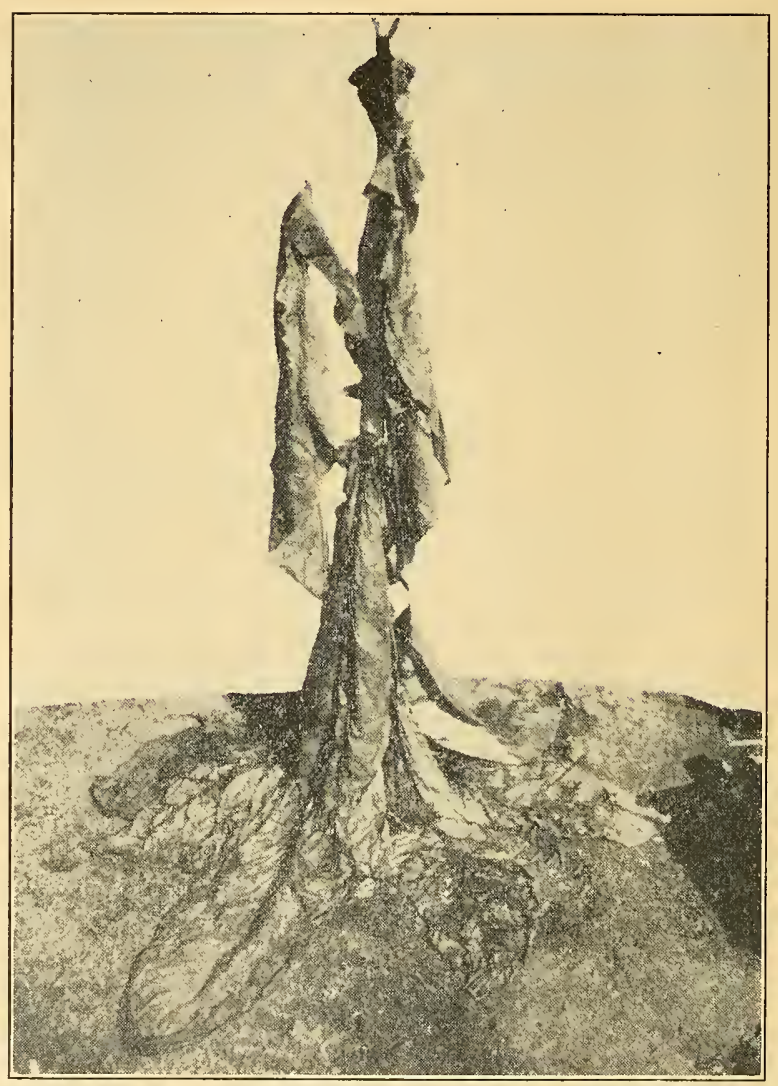

Figure 18. Hollow stalk. Bacterial decay runs from the pith into the bases of the leaves, causing them to collapse.

wet weather is reduced quickly to a dark colored, watery jelly (Figure 19). With the recurrence of dry weather, the rotten pith dries and shrivels, leaving the stalk hollow-hence the popular name of the disease. But the progress of the rot does not stop at the pith. From here it passes by natural channels into the bases of the leaves, causing them to droop and hang down (Figure 18), or to fall off, leaving the stalk bare. Even if the stalks are harvested in the early stages, the leaves do not cure well in the shed. 
The rot usually starts in the pith where the top has been broken out. During very wet years or in exceptionally damp locations it may start in the leaves and rot out the midribs or produce large holes in fleshy leaves.

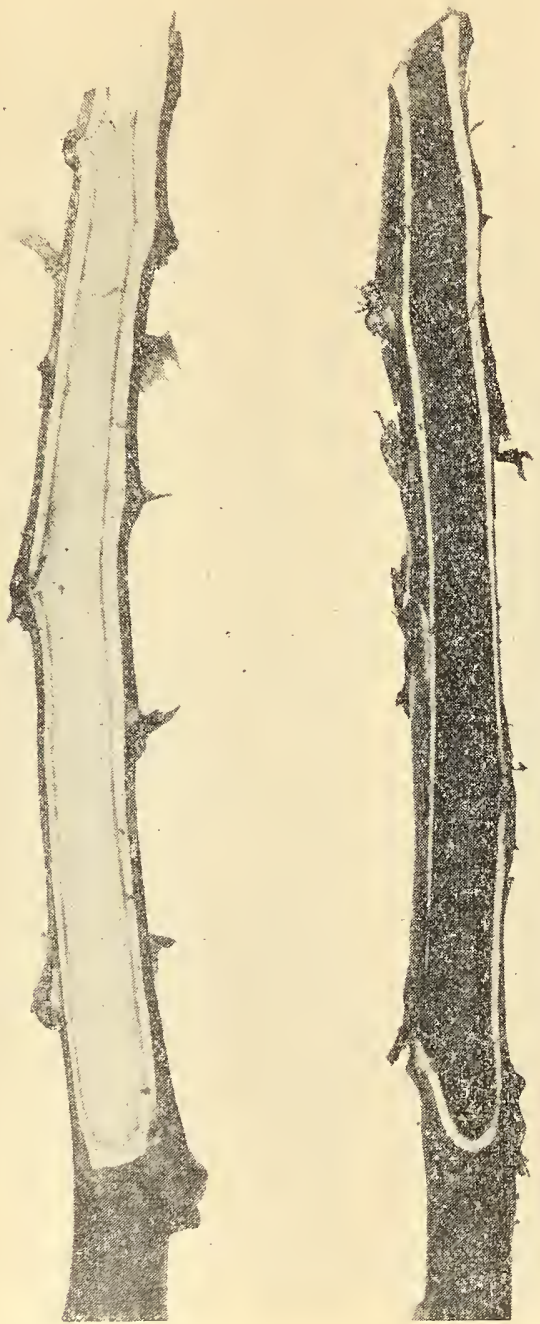

Figure 19. Hollow stalk. Blackened pith (right) compared with healthy white pith (left).

Cause. The rot is caused by invasion of the pith by parasitic bacteria, Bacillus aroideae. Finding the succulent pith a favorable food, they multiply and spread with incredible rapidity causing complete collapse of the 
interior of the stalks and the bases of the leaves within a few days. They are spread from plant to plant on the hands of workmen and gain access to the pith through the fresh wounds caused by breaking out the top or suckers. Broken midribs or other injuries give them access to the leaves.

This same species of bacteria formerly called Bacillus carotovorus, causes a soft rot of carrots and other vegetables. It is also the causal agent of blackleg.

Effect of Environmental Conditions. Moisture is the important element in incidence of hollow stalk. It is most prevalent when there is continuous rainy weather during the topping season. In a field where it can hardly be found previous to this time, it becomes widespread and quite evident in the tops of the broken off stalks within a few days after topping. Wet, soggy soils are also said to foster it. Hot, humid weather is favorable to it in that this makes the pith more succulent and wounds do not dry out so quickly.

Control. There is no known remedy for hollow stalk. The spread in the field may be reduced, however, by restricting the operations in an affected field to periods when the leaves are dry. Also the workmen should avoid touching or working with affected plants while topping or suckering.

References: B 222:477. TB 6:70. B 410:409. B 422:29.

\section{LEAF DISEASES IN THE FIELD}

In addition to injuries to the leaves in the field caused by wildfire, blackfire and mildew, the diseases described below cause more or less damage.

\section{MOSAIC OR CALICO}

"Calico", "mongrel", "brindle", "mottle", and "grey top" are the most common names applied by growers to this malady which the pathologist calls "mosaic". It can be found on almost any tobacco farm in the State but is usually not much feared because the percentage of plants affected is small. In some seasons, however, it becomes unusually severe in certain sections or in certain fields. During such epidemics the writer has seen areas in which 98 percent of the plants were affected. Under these conditions the loss is heavy and mosaic becomes a disease of major importance.

How long mosaic has existed here is not known. The first published account of it by the Experiment Station was in 1898 at which time it was apparently conmon.

Symptoms. Although mosaic sometimes originates in the seedbed the symptoms are rarely seen there. In the field, the disease can be recognized easily even at a considerable distance. Affected leaves have a mottled appearance due to irregularly shaped and alternating areas of light yellowish green and normal dark green, giving the appearance of a mosaic. All parts are commonly affected without any relation to position 
except that sometimes the darker areas follow the veins. On young, rapidly growing leaves, the darker spots are often puckered or puffed out (Figure 20). Frequently they are otherwise distorted or narrower than normal leaves. In the field, mosaic is more prevalent on the top leaves and suckers than on lower leaves. The suckers that grow from the stumps after harvest frequently are severely diseased. Plants which become infected at an early age remain smaller than normal. During hot, dry days, the sun kills irregular spots, particularly on the top leaves. Large areas thus killed turn a reddish brown color and account for the term "red
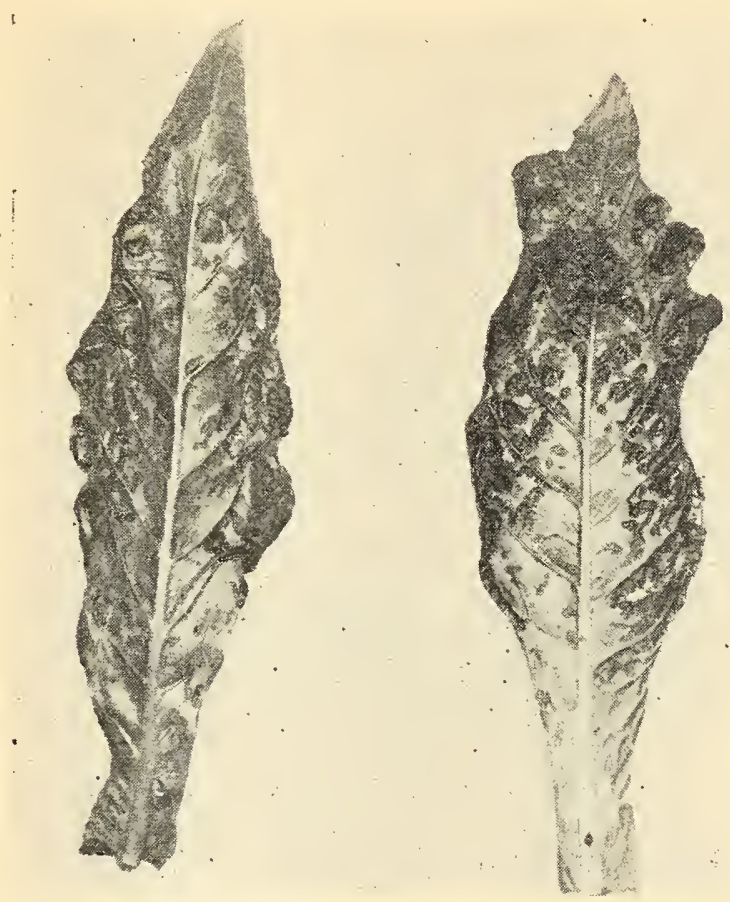

Figure 20. Mosaic on Broadleaf. Dark green puffedout blisters between the veins of narrow distorted leaves.

dust" which growers apply to this stage of calico. When cured, such leaves are worthless for wrappers or binders. Another symptom which frequently occurs when the leaves in the field are nearly mature is the appearance of numerous dead spots called "rust" by the growers. The term is rather loosely used, some persons applying it to all leaf spots, others to only one type. Some distinguish between a "red dust" and a "white rust".

Rust or other kinds of leaf spots, however, are by no means always present on plants with mosaic. Many that are severely affected never show any dead spots. Yet it is not unusual for the mottled leaves, especially just be_ 
fore harvest, to develop dead areas of various sizes, shapes and colors. In the most usual form, areas of irregular shape and size (Figure 21), especially on the top leaves, die and turn rusty brown. Sometimes the dead spots are

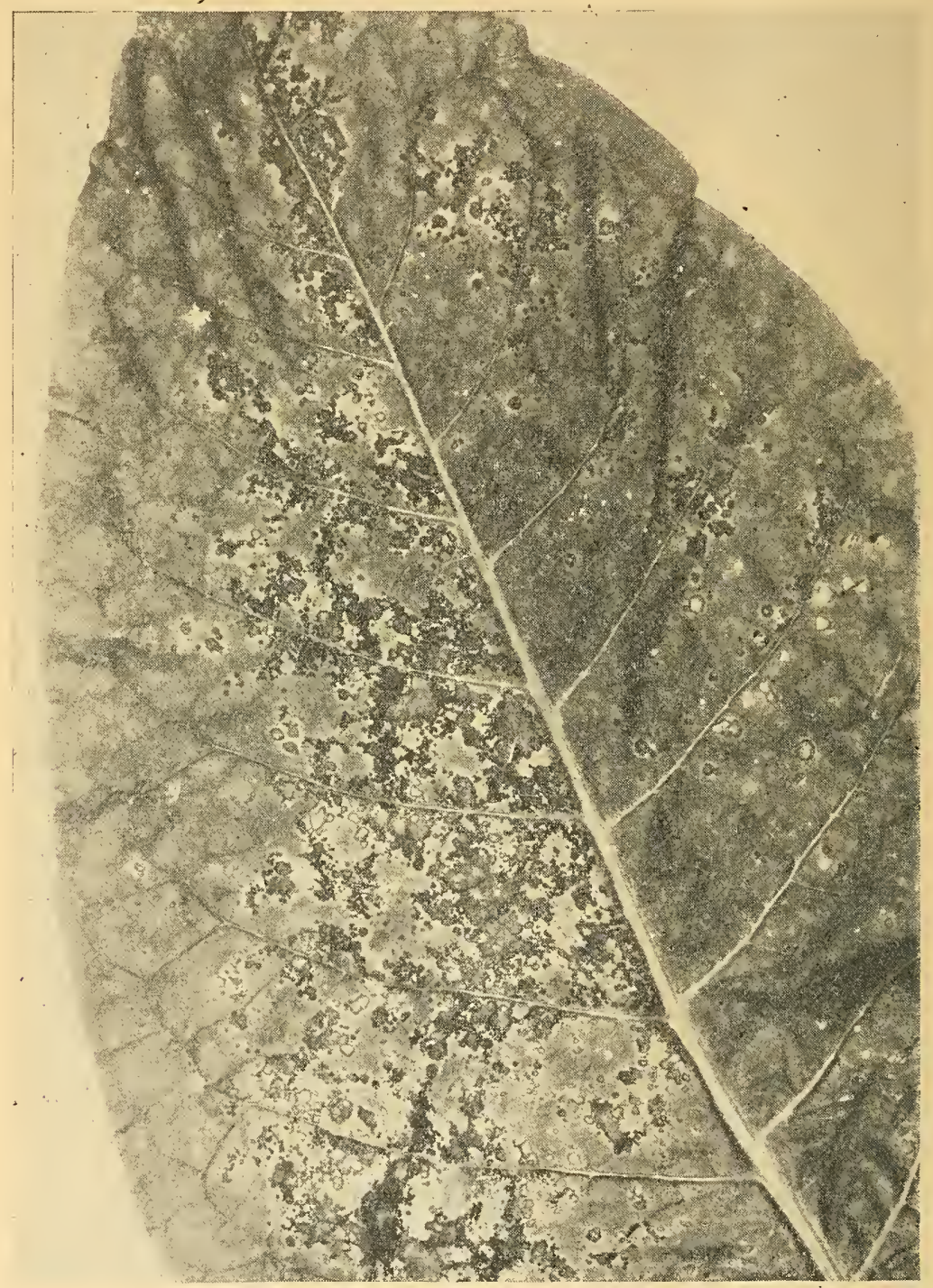

Figure 21. Red "rust" following mosaic. Irregular, dead, brown spots run together, killing large patches of the leaf.

several inches broad and may kill most of the leaf surface by running together. Often, however, they are small and scattered. In the "fleck" type (Figure 22), they are quite small-one-eighth to one-fourth inch across- 
very numerous on the leaf and are white instead of brown. There may be all gradations between these types. None of them, however, is predominantly round; neither do they have a definite yellow halo.

Cause. Calico is one of the so-called virus diseases. A virus is not a living organism but a substance whose nature, chemical make-up and

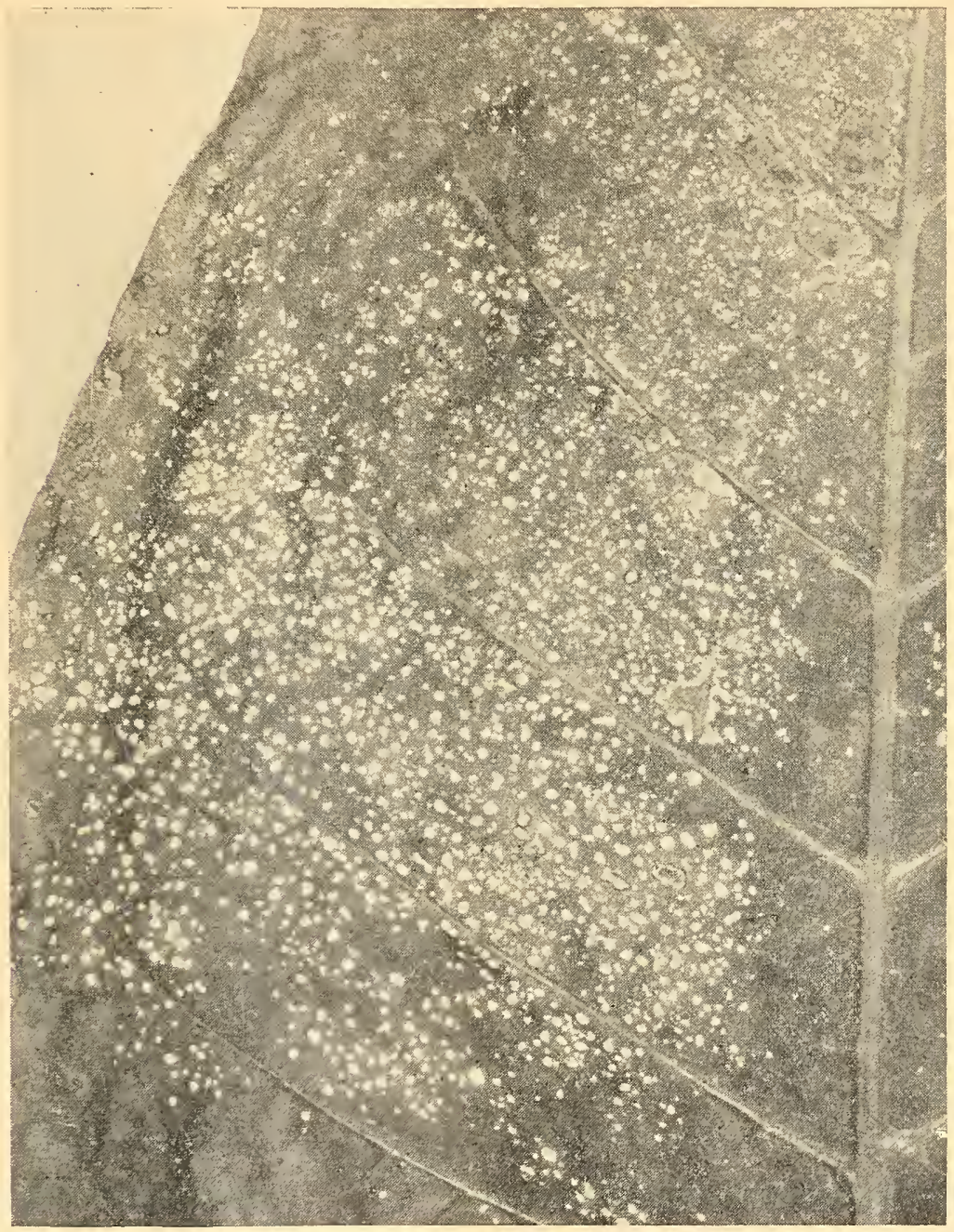

FigURE 22. White fleck following mosaic.

method of operation are not well understood. There are also several kinds of mosaic viruses, each producing different disease symptoms on tobacco.

Those described above are produced by the most common type of virus found here. The disease is highly infectious and is easily carried by various 
agents from diseased to healthy plants through the virus which exists in the plant juice. This substance permeates all parts of the plant although the symptoms appear only on those leaves which unfold after infection has occurred. Fortunately seeds do not contain the virus and healthy plants can be grown from the seed of those badly diseased. Other plants, particularly those of the same family, such as tomato, pepper and ground cherry, may contract the disease also, and it is possible that some of the wintering may be accounted for by perennial weed hosts. However, most of the wintering over probably depends on the fact that the virus lives for several years in dry, cured tobacco. Fragments of diseased leaves or other parts may carry the virus from sheds or shops to the beds where conditions for its spread are favorable and from which it is carried to the field. There it is spread on hands or tools of workmen during cultural operations and probably also by some insects, particularly plant lice. When a plant is once infected, regardless of its age, it never outgrows the disease.

Effect of Environmental Conditions. Variations in temperature, moisture or weather conditions are not known to have any influence on the occurrence or spread of mosaic. The nature of the soil in which the plant grows, and the kind of fertilizer or manure applied, are also without influence. Cultural operations have no effect except when they furnish opportunity for workmen to transfer the virus from one plant to another by contact.

Control. Since there is no known cure for the disease, all control measures must be precautionary rather than remedial. The most important measures come under the head of seedbed sanitation. The larger part of the field infection starts with plants which were diseased when they were taken from the seedbed. Steam sterilization for the purpose of controlling other troubles (appendix) is also helpful here because it destroys any virus which may be in old leaves or other parts of the tobacco plant, or in weed plants. Every precaution should be taken against bringing into the bed any dry fragments of leaves or stems from the preceding crop. Trash raked up from the floor of the curing sheds should never be put on or near the beds. Tobacco stems should not be used as fertilizers for the beds.

In Kentucky it has been proved that seedbed infection may come from workmen spitting tobacco juice, or from touching the plants after handling infected chewing or smoking tobacco. There is a chance that cigar stubs and cigarette butts thrown into the bed may start infection. Although symptoms of mosaic are seldom seen in the beds, they should be carefully watched for. If they are found, it is not safe to pull plants from that bed because there are undoubtedly many more diseased plants than can be seen. When a workman gets the juice from an affected plant on his hands, he may spread the virus easily to hundreds of others. During the first few weeks after the plants are set in the field, regular inspection should be made and any diseased plants found should be put in a basket and carried from the field. In doing this, the workmen should not be allowed to touch any healthy plant. Also in later operations, up to the time of topping, diseased plants should not be touched by workmen. In topping and suckering, this precaution is not necessary because leaves which are to be marketed are developed before that time.

References: R 1898:242-254. R 1914:365-424. TB 10:75-82. B 386:594. B 391: 109. 


\section{RINGSPO'T}

Ringspot is a minor disease of tobacco leaves that occurs sparingly in Connecticut every year. It has not received much attention here because the damage, in the aggregate, is small, and the symptoms are usually so inconspicuous that they may easily be overlooked.

This disease has been found on tobacco in all of the important tobacco growing regions of the United States and has been reported from a number of foreign countries. It appears to be much more prevalent in states to the South.

Ringspot is not a new disease in Connecticut, but there are no definite published records to show how long it has been here. The writer has observed it in small amount every year since he came to this Station in 1925.

Symptoms. The characteristic symptom of ringspot is the occurrence on the upper side of the leaves of irregular white, or light brown, lines about the width of a pencil mark. These are more or less continuous but broken lines are not uncommon. They make a variable pattern. Between the veins they generally form definite closed circles, or rings, which give the disease its name (Figure 23). The tissue enclosed by the circular lines retains, at first at least, its normal green color. In later stages, it may fade to yellow and finally die. Circles within circles are also common. The lines usually run parallel to the lateral veins, quite close on either side and tend to run out to points where secondary branches of these veins start. Sometimes the lines are broken into short segments scattered without any definite pattern over the leaf surface. Usually the leaf remains flat, but sometimes, especially in the case of the broken line type, the leaf is rough and puckered and becomes broken and ragged as it grows older.

Some plants show the symptoms on all leaves from top to bottom. More generally, some of the foliage is affected while the rest appears entirely normal. At times only a part of a leaf is affected. The lines may be so distinct that they can be seen for a considerable distance, or so indistinct that they would be overlooked unless one made a close examination.

The symptoms are usually observed first when the plants are nearly or quite mature. Severely affected leaves are rendered quite useless. Loss from mild attacks is probably slight or negligible. Stunting of the plants, as found in other tobacco sections, has not been observed here.

Cause. Ringspot is not caused by any parasitic organism or by insects. Neither is there any convincing evidence that it has any relation to the nutrition of the plant, although malnutrition has been suggested by some investigators as a causal agency. Like the mosaic disease, it appears to be caused by a virus, but the two diseases have no other relation to each other. The virus is in the sap of the plant and the disease can be transmitted by transferring the juice of an infected plant to a healthy one. Thus it is an infectious disease. Infected juice on the hands of workmen or on tools may spread it from plant to plant in the field. Possibly insects or other agents may also carry it but there is no experimental evidence on this point. It does not spread so readily as mosaic, however. If the infective capacity were not so low, the number of infected plants would be much larger. The 
virus of ringspot, unlike that of mosaic, is quickly destroyed when the leaves are dried in curing. Hence there is no danger of carrying it to the new crop from the cured leaves of the previous season.

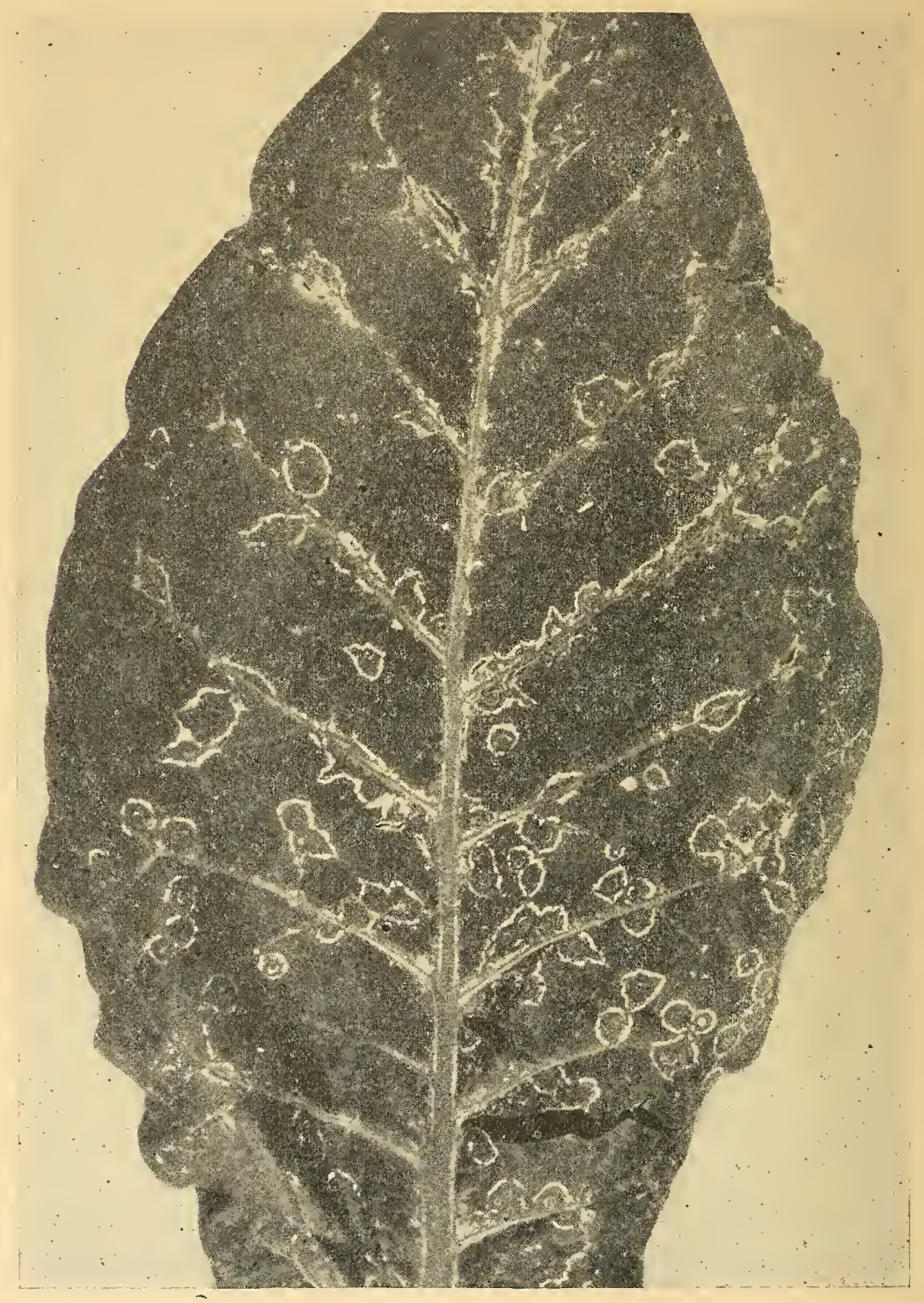

Figure 23. Ringspot. Continuous lines follow the veins or form rings between them.

Since no tobacco plants remain alive over winter in this climate, and all the virus must die out every winter, it is difficult to explain how the disease gets into the fields each year. 
In Virginia it was found that ringspot could be transmilted to a large number of species of other plants of 38 different genera in 15 families. It has also been found occurring naturally on some of these plants in the field. Many of them are common weeds and garden plants. Since some live over the winter, there is the possibility that they may serve as agents for keeping the virus alive until the next season. It is quite possible that there are weed plants around our tobacco fields and beds here which may serve as winter hosts and thus account for primary infection in the spring.

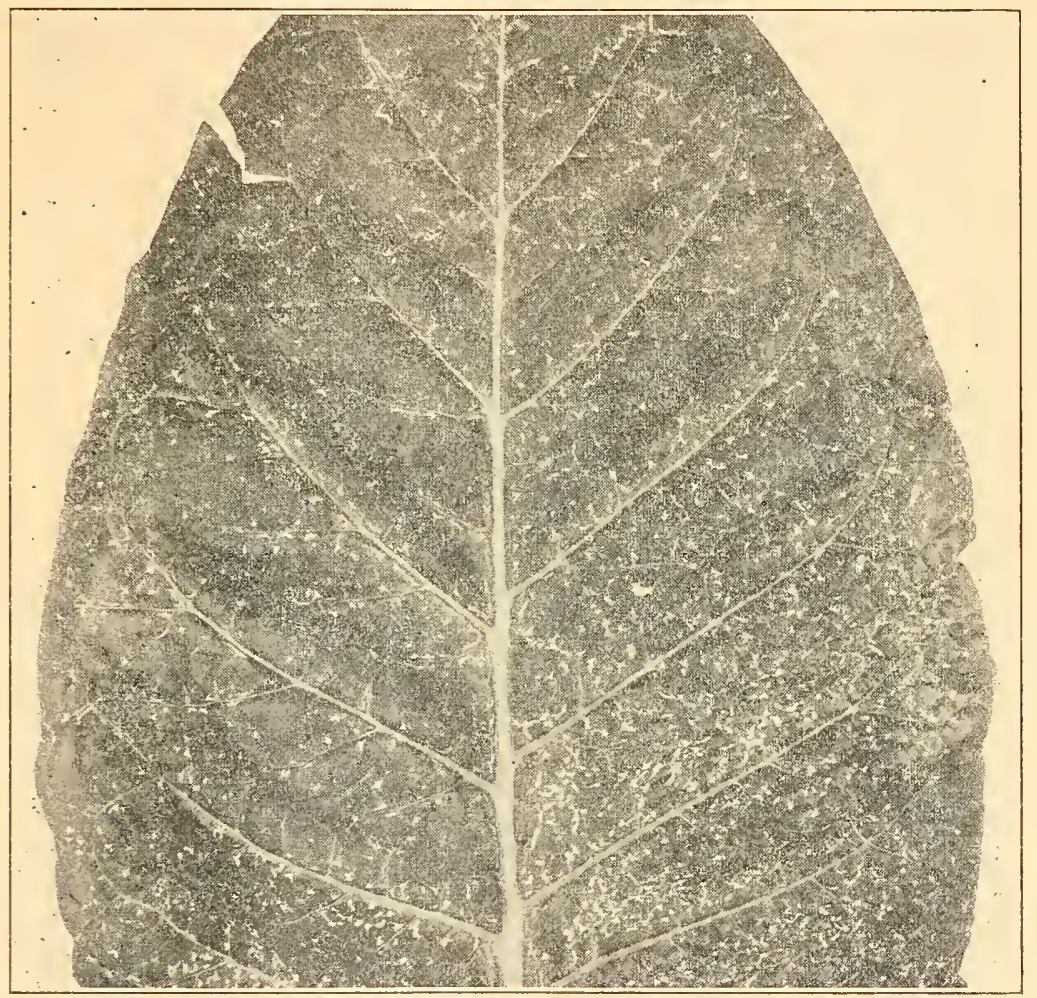

Figure 24. Streak causes dead white broken lines and zigzags.

Control. Ringspot is not of sufficient importance here to warrant special control methods. If it should become serious at any time, rogueing out the diseased plants would seem to be the logical control.

Reference: B $367: 120-125$.

\section{STREAK}

STREAK is a rare disease of minor importance but is found on a few specimens almost every year. It shows many similarities to ringspot with which it has probably been confused. 
Symptoms. The characteristic symptom of streak is the occurrence on some of the leaves of dead, white or brownish lines, streaks or zigzags of various lengths, usually about the width of pencil marks. In most cases they are not continuous and rarely form complete circles as in the case of ringspot. The accompanying photograph (Figure 24) shows the characteristic appearance of the lines better than it is possible to describe it. The middle leaves of a plant are most frequently affected. Those developing above them are likely to be perfectly normal, indicating that the plant has recovered. Sometimes only a part of the leaf is affected.

I Badly streaked foliage is dwarfed and the surface becomes rough and puckered. The leaf is thicker and more brittle than normally and becomes ragged and torn with age. No plants or leaves are killed by the disease but they are'naturally of very inferior quality when cured.

Cause. This is another virus disease. It is infectious and may be transmitted from one plant to another when the juice of a diseased plant is carried to a healthy one on the hands of workmen. Obviously it is not so infectious as mosaic since it spreads very little in the field. The same virus infects a number of other species of plants of the same family, such as Jimson weed and ground cherry, and probably is transmitted from these weed hosts to tobacco.

Control. No attempts to control streak have been made because the disease is of so little importance.

\section{FRENCHING}

Frenching is a rare disease in Connecticut. Not a dozen cases have been observed by the writer during the past 10 years. Although a severely affected plant is a total loss, the disease does not usually mean a serious loss to a grower. Only a small percentage of plants in the field is likely to be affected and these are confined to certain definite areas. If frenching occurs during succeeding years, the location in the field is likely to be the same. Often it disappears entirely after one season. Frenching is a disease of long standing liere, but the date of its first appearance is not recorded.

Symptoms. The earliest symptom is chlorosis, or fading of the bud to pale yellow. The most characteristic symptom comes somewhat later. The leaves become thick, brittle, narrow and strap- or sword-shaped, with wavy, scalloped or crinkled margins (Figure 25). They may or may not be mottled in a manner resembling mosaic. The leaf margins have a tendency to curl downward. In severe cases all the leaves on a plant are affected; in less severe cases, the lower leaves are normal, or nearly so, showing that the attack occurred after the plants were partly grown. The stem does not elongate naturally and the number of leaves is multiplied so that the whole plant appears as a bush of dagger-like leaves in unusually large number set very close together. This appearance may be intensified by abnormal branching of the stalk.

Cause. The cause of frenching is not definitely known. It is not associated with any fungus, bacterium, insect or other foreign organism. It cannot be transmitted from a diseased to a healthy plant (non-infectious). 
It is probably a trouble caused by malnutrition. Opinions expressed by several investigators, that it is caused by shortage of nitrogen, of potash or of phosphorus, or by excessive fertilization, however, are not supported by adequate experimental evidence. There is considerable observational and some experimental evidence to indicate that it is associated with poor aeration or excessive moisture in the soil. Such conditions may be due to poor drainage or heavy soils that pack easily. It occurs only on land of a high reaction ( $\mathrm{pH} 6.0$ or above). There is some evidence that a toxic substance in such soils is the direct agent.

Control. No method of control is known. The elimination of unfavorable soil conditions before setting, mentioned above, should be helpful. Growing of tobacco on fields where the disease is wont to occur should be avoided. The soil reaction should be kept below $6.0 \mathrm{pH}$.

References: R 1914:27-29. B 335:256-260.

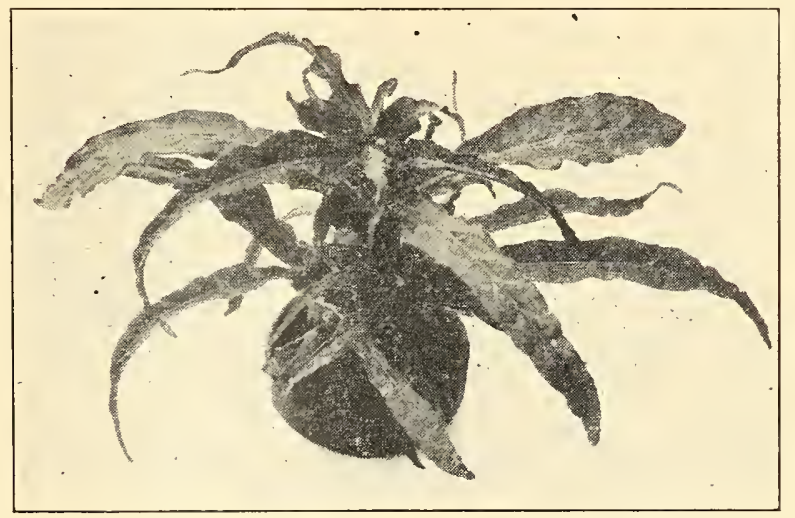

Figure 25. Frenching causes narrow, strap-shaped leaves with scalloped edges. Note compact bunchy growth of plant.

\section{NON-PARASITIC LEAF SPOTS}

DEAD spots on the growing leaves, ranging in color from white to dark brown, and of various shapes and sizes, have always attracted attention because the leaf is the all important part of the tobacco plant and should be free from blemishes. We know that some of these spots are caused by parasitic organisms, for example, the wildfire spots; some by virus diseases, such as the "rust" following mosaic; and others are malnutrition spots as described in other sections. Mechanical injuries, such as those produced by hail, or Paris Green poisoning, may also leave spots. Besides these, there are several types of spots that do not appear to be due to any of the above mentioned causes. We have grouped these last arbitrarily under the name of non-parasitic spots. Growers commonly call leaf spots "rust". To prevent confusion, however, it seems best to restrict that name to the type of spot caused by mosaic.

For the most part, the real cause of these spots is unknown. The tobacco leaf seems to be readily subject to local physiological breakdown of 
the tissues. Some of the types of spots seem to follow a hereditary predisposition. For example, there are two types of spots characteristic only of Broadleaf tobacco. The more restricted of these is the John Williams spot, so called because it occurs only on this kind of Broadleaf (Figure 26). Just when the leaves are ripening, suddenly they become thickly peppered with small, round white spots, an eighth to a quarter of an inch in diameter.

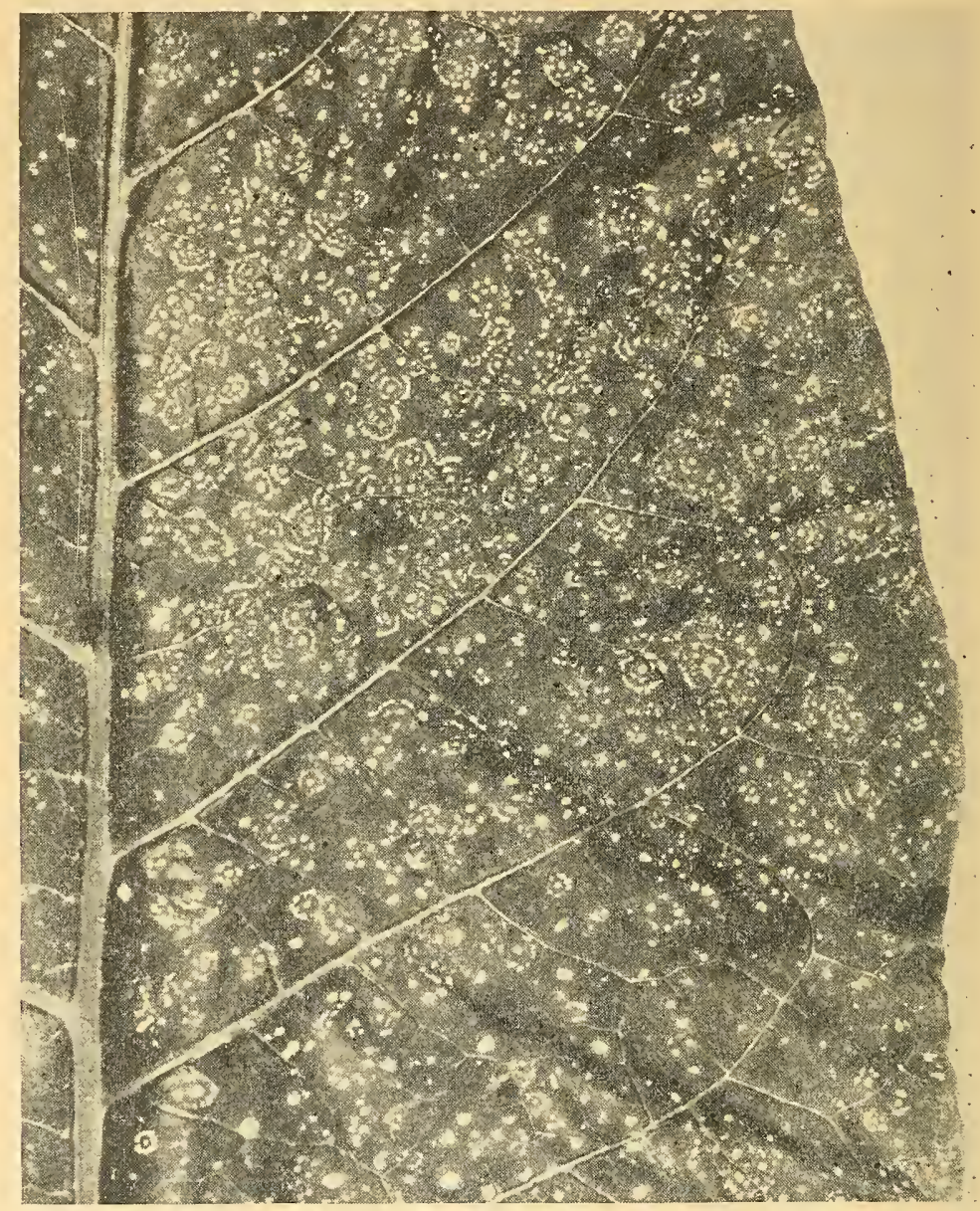

Figure 26. Non-parasitic leafspot. The John Williams Broadleaf type.

Their presence is not considered a fault by tobacco handlers. On the contrary, buyers like to see this development because it is a sign that the plant is the true John Williams type and that it is ripe tobacco.

The other kind of Broadleaf spot has sometimes been called the "star and crescent spot" because it frequently has a small central portion partly surrounded, beyond an intervening band of green tissue, by a circular, 
white narrow band of dead tissue. This marking suggests the Turkish star and crescent. Sometimes the circle is complete; sometimes there are two or more concentric circles or parts of circles. There are numerous modifications but the whole appearance is quite different from other types of spots. They occur only on Broadleaf, or on hybrids which have been derived by crossing with Broadleaf.

On Cuban Shade tobacco there occur at times numerous small, round, deep brown spots of less than a quarter of an inch in diameter. Somewhat similar but larger spots appear also on Havana Seed tobacco. It has never been definitely proved that a parasite causes these spots, although various fungi may be found on them as they become older.

The writer has frequently noticed that all these kinds of non-parasitic spots are prone to break out suddenly a few days after hard rains. On the whole, they do not cause very serious injury to the tobacco crop and no method of preventing them is known.

References: R 1898:254. B 367:126.

\section{BROWN SPOT}

Brown spot is a disease of somewhat minor importance here but occasionally causes considerable loss to the lower leaves of Broadleaf and Havana Seed just previous to harvesting. The name "brown spot" is not very distinctive since various types of dead brown spots occur on tobacco leaves. Such are the "red rust" accompanying mosaic and some of the nonparasitic spots mentioned above. We restrict the name here to that type of brown spot which is caused by the parasatic tungus described below.

Symptoms. The spots appear mostly on "ripe" leaves at the bottom of the plant, usually when they are losing their deep green color and taking on a yellowish cast. The spots start between the veins, are roughly circular in outline, up to an inch or more in diameter, and at first a deep, chestnut brown that may fade to an ashen gray as they grow older. A characteristic of this type of spot is the occurrence of concentric rings of darker color although all do not have these. In dry weather the margin of the spot shows a sharp dividing line between the brown dead area and the green living tissue. In more humid weather, however, there is an indefinite halo of yellow gradually fading out as it advances into the green. Whole leaves, or large sections of them, may turn brown and die within a few days giving the bottom leaves the appearance usually termed "firing". In contact with the damp ground the tissue passes quickly into a wet rot.

Cause. Brown Spot is the result of invasion of the leaf tissues by a parasitic fungus, Alternaria tenuis (Figure 2, F, G). This is the same fungus which causes "freckle-rot", one of the types of pole rot described above. It is only weakly parasitic and attacks the leaves when they are past their prime in vitality.

Influence of Environmental Conditions. A high temperature and humidity are essential for the development of brown spot.

Control. No practical control methods have been developed.

References: B 367:128-135. B 391:111. B 410:412. 


\section{DEAD-BLOSSOM LEAFSPOT}

Dead-blosson leafspot is primarily a disease of Shade tobacco-although occasionally seen on other kinds-because blossoms in great numbers are allowed to develop on Shade, while the tops and suckers are removed from the sun-grown types. When the flowers are mature, the corollas, or pink-colored parts, drop, and many of them, especially in wet weather, adhere to the gummy leaves and decay. As shown in Figure 27 , the dead spot spreads in all directions from the decaying blossom as a center. The higher liumidity under the tent also favors the development of the spots on this type of tobacco.

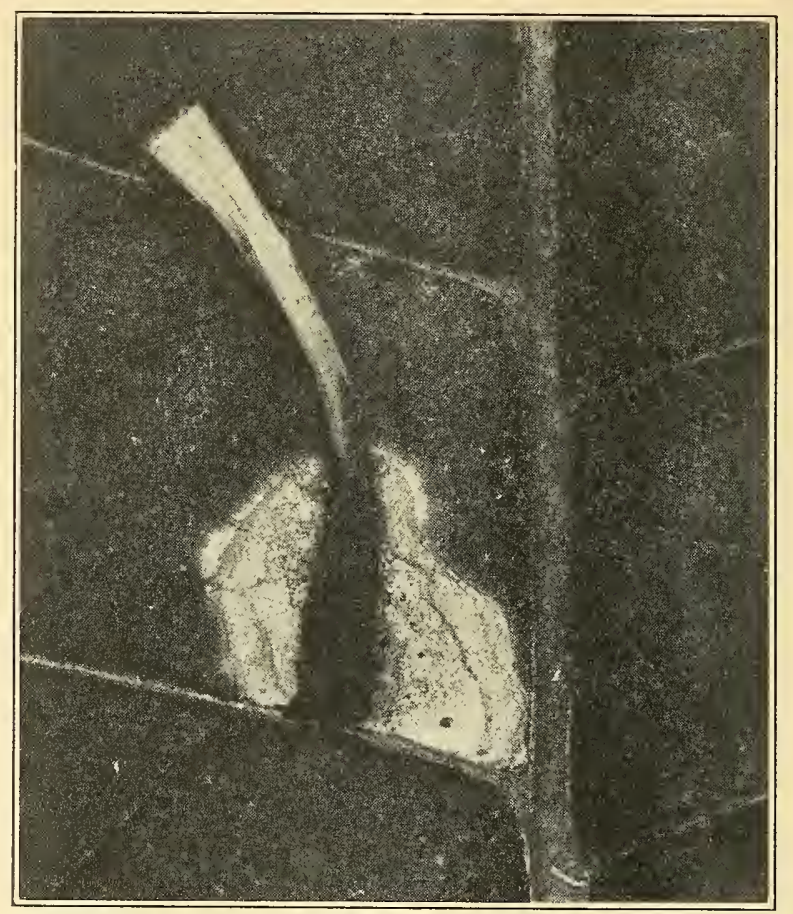

Figure 27. Dead-blossom leafspot. Note the adherent, partly decayed blossom and dead leaf area about it.

Symptoms. Spots are irregular and wavy - not angular - in outline, up to an inch or more in diameter, with a quite definite margin. In color they vary from light tan to reddish brown, while some are faded to ashen gray. Spots are usually bordered more or less by an indefinite, narrow, light yellow halo that fuses outward gradually into the normal green of the leaf. The dead tissue is brittle and breaks out easily. The dead blossom remains tightly adherent to the center of the dead spot and usually becomes more or less blackened by masses of Alternaria spores. There may be one to a half-dozen spots on a leaf, thus rendering it worthless for wrapper or binder. 
In the curing shed, where the leaf is in close contact with others on the same lath, the rot frequently spreads from one to the next until a dozen may be rotted. In the shed, under these conditions, the trouble has all the symptoms of pole rot.

Cause. Several species of fungi which are at best only weakly parasitic are always associated with these spots. The most common species are Alternaria tenuis (Figure 2, F, G) and Botrytis cinerea (Figure 2, H). Bacteria are also frequently found in the older spots. Of the various species of organisms found in the rotting flower, not one seems to be able to infect the healthy green leaf. It is possible, however, that in moist, warm weather, beneath a wet rotting corolla, the conditions might be such as to permit infection and a limited spread of Alternaria or other fungi in the tissues. Or perhaps the virulence of the fungus is "stepped up" by previous growth on the tobacco blossom to such a degree that it becomes truly parasitic on the green leaf. Possibly the combined influence of all the rot-producing organisms, in direct contact with a somewhat etiolated part of the leaf, might produce infection where any single one of them would fail. The presence of the dead blossom on the leaf is absolutely essential to the parasitism of whatever organism or organisms produce this type of spot. In the absence of blossoms, the spots do not occur.

The spread of the rot in the curing shed from one leaf to adjacent leaves is readily understood in view of the known capacity of Alternaria or Botrytis to infect curing leaves under these conditions. This is no different from the usual pole rot except that the presence of the rotten corolla and adjacent dead tissue provides a very favorable nursery to serve as a starting point for spreading to the adjacent leaves under the moist conditions of a packed shed.

Influence of Environmental Factors. Rainy weather at the time the blossoms are falling is favorable to incidence of this type of spot. Little trouble is experienced during dry seasons.

Control. No practical method of preventing the spots in the field under the usual cultural practices for Shade tobacco has been found. In the shed, the same methods must be used as for the control of pole rot. The surfaces of the leaves must be dried as soon as possible by proper firing and ventilation.

Reference: B 386:595-598.

\section{LEAF BLOTCH OR SCAB}

LEAF BLOTCH is a very rare disease in Connecticut. It was first reported here in 1922 and again in 1938 when, throughout the month of August, the writer observed it on the mature bottom leaves of both Broadleaf and Havana Seed tobacco in many fields. For the most part, it was confined to the low-lying and poorly drained parts of the fields and the lower three or four mature leaves of the plant, frequently after the over-mature leaves had started to fade.

Symptoms. In this disease the blotches or spots are scattered irregularly over the upper surface of the leaves. They are roughly circular in 
outline, of indefinite margins, one-eighth to one-quarter of an inch in diameter, mostly separate but sometimes, when numerous on a leaf, coalescing to form irregular blotches. The color of the spots is olivaceous to olivaceousbrown on the green leaves and a more distinct chestnut brown on the yellow background. As may be seen in Figure 28, the centers of the older spots are often lighter in color.

Blotch differs from all the other typical leafspots of tobacco in that the spot is visible only on the upper surface of the leaf. Only in very advanced stages does the underlying leaf tissue die so that spots may be seen from

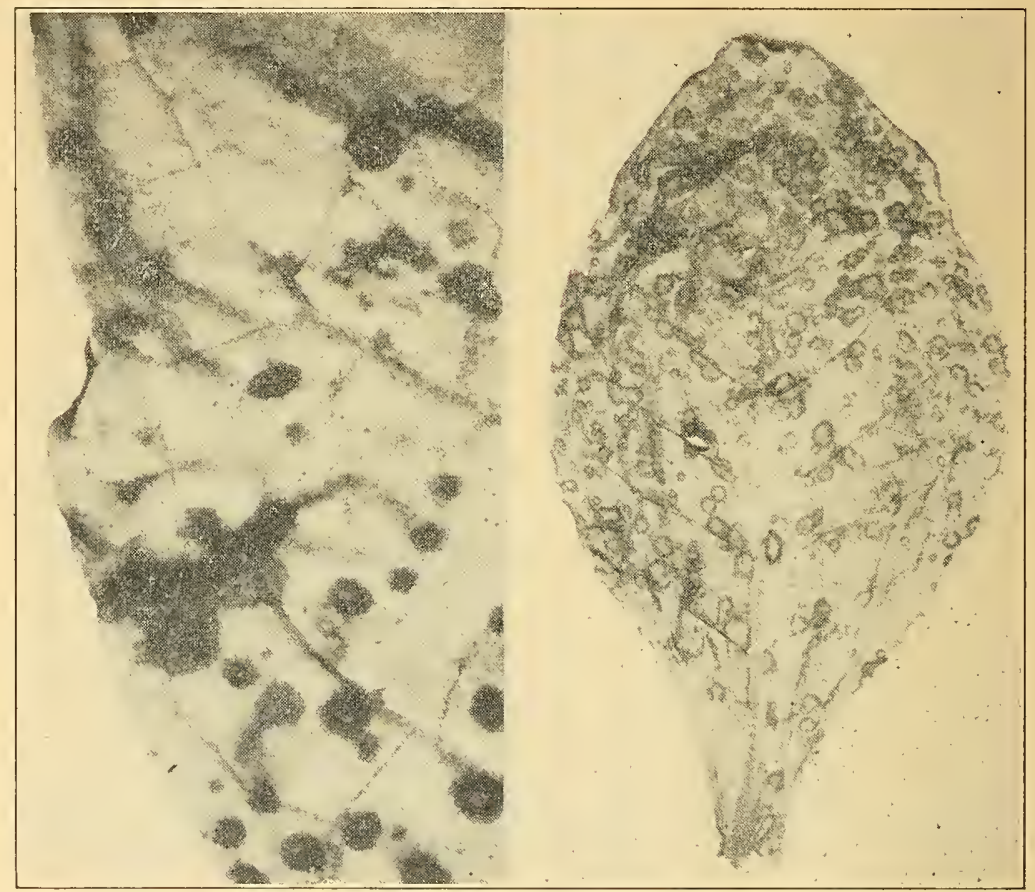

Figure 28, Leaf blotch. Natural size at left and one-quarter natural size at right.

below. On account of this distinction. the names "blotch" or "scab" seem more appropriate than "leafspot". The appearance of the disease immediately recalls that of various scab diseases, such as those of fruit trees.

The actual damage caused by the disease is not great since only the smaller bottom leaves, mostly "sand leaves", are affected, and in curing, the blotches become less distinct on a brown background. Moreover, it probably never occurs except during exceptionally wet years, such as the 1938 season, or in very wet parts of the field.

In other states, but not here, blotch is reported as a seedbed trouble where it may exhibit a variety of symptoms ranging from a slight browning or girdling of the stem to damping-off and wet rot in severe cases. 
Cause. The disease is produced by a parasitic fungus, Fusarium affine, which first attacks the upper epidermis of the leaf and later penetrates into the deeper cells (Figure 2, I).

Influence of Envirommental Factors. Dependent on excessive moisture, this disease occurs only during very wet years and on leaves near the ground in the damper parts of the field.

Control. No method of control is known. The amount of damage is usually too little to warrant the trouble of attempting control.

Reference: B 422:10-42.

\section{MALNUTRITION DISORDERS}

There are nine food elements which the tobacco plant absorbs from the soil: Nitrogen, potash, phosphorus, magnesium, calcium, iron, sulfur, manganese and boron. If there is an inadequate supply of any one of these, the plant becomes abnormal (diseased). The disease symptoms produced by a shortage of any one of these differ from those of the others, with the possible exception of sulfur. Symptoms resulting from deficiency of iron, sulfur and boron never appear in the field because a sufficient quantity of these elements is always present in the soils of Connecticut. Abnormal condilions may also be brought about by absorption of an excess amount of some of the food elements. Moreover there are elements which are not nutrients but which may be taken into the plant from the soil under certain conditions in sufficient quantity to produce abnormal symptoms.

All these disturbances are called malnutrition diseases. Two of them, potash deficiency and ammonia injury, have already been described as seedbed troubles. Some other common ones are described below. Possibly brown rootrot and frenching should also be included in this group.

\section{Magnesia Hunger or Sand Drown}

Magnesia hunger is seen perhaps most frequently because, until recent years, no effort was made to include a supply of this element in the fertilizer mixture and some sandy soils do not contain an amount that becomes available fast enough for the needs of the plant. The trouble is most often seen during wet years because magnesia is easily leached from the soil.

The characteristic symptom is chlorosis, or blanching of the leaves, beginning with the tips and margins of those on the lower part of the stalk and progressing inward and upward. The chlorosis is principally between the veins. It may continue until the leaf is almost white except for the network of veins which remain green (Figure 29). The leaves are somewhat thicker than normal and remain flat and stiff without puckering or rolling down at the margins. Dead spots are not ordinarily produced and the leaves do not die abnormally early. Cured leaves show uneven colors and burn with a black ash.

The remedy lies in keeping a sufficient supply of magnesia in the soil. 


\section{Calcium Deficiency}

Calcium oxide makes up 4.5 to 8 percent of the dry weight of the tobacco plant and performs very necessary functions in metabolism. Most of our soils contain a large supply of calcium naturally and more is added in lime or land plaster as well as in bone phosphates and some of the other fertilizer materials. Consequently it is only very rarely that acute shortage of calcium occurs to a degree resulting in calcium starvation symptoms in the plant. Calcium leaches very easily from the soil, however, and, in the extremely wet year of 1938, starvation symptoms occurred in many fields.

The symptoms appear in the unfolding bud or youngest leaves of the plant. The terminal leaves are distorted, dwarfed or fail to develop at all. The tips of the youngest leaves turn brown or black. The partly developed, deformed leaves have ragged and incised margins. The appearance of the bud is shown in Figure 30 .

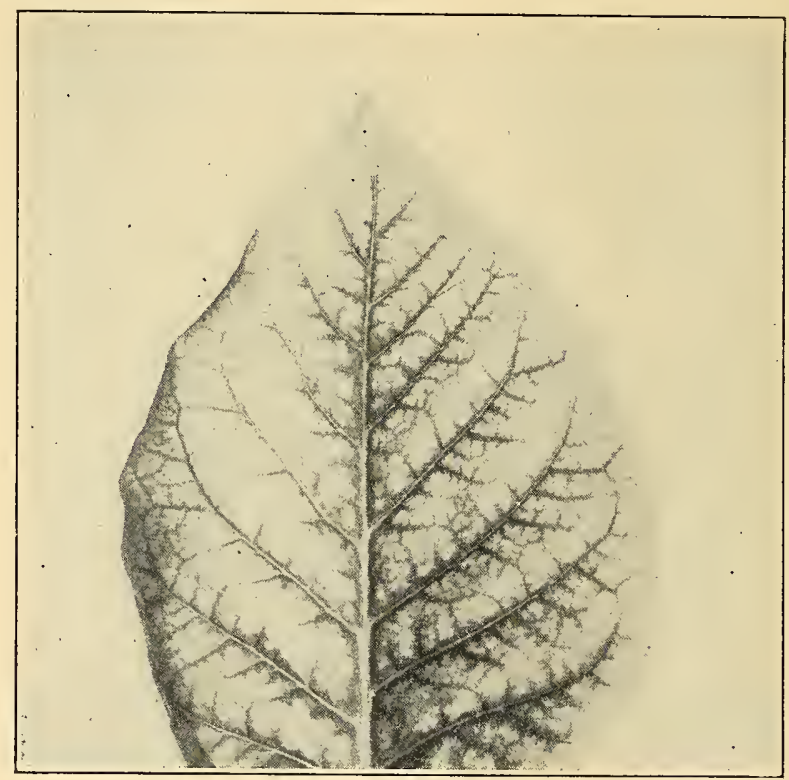

Figure 29. Magnesium hunger or "sand drown". Green network of veins against the white web of the leaf.

The obvious remedy is to apply to the soil enough lime or land plaster to keep up the supply. At least 500 pounds to the acre of lime or land plaster should be added if starvation symptoms are found in a field. As a basis for the treatment, however, the soil should first be tested for degree of acidity and quantity of calcium.

\section{Nitrogen Starvation}

Nitrogen starvation causes the entire plant to turn pale and in severe cases to remain smaller and produce narrower leaves than normally. This trouble is well known by tobacco growers and is remedied by nitrate applications in the bed, or by side dressing in the field. 


\section{Phosphorus Deficiency}

Phosphorus deficiency is evidenced by slow, "pinched" or stunted growtl, and narrow, dark leaves. The narrowing is particularly evident at the heel of the leaves, giving them a somewhat spatulate shape. They do not become pale or yellow but, when viewed at an oblique angle, have a bronze cast. On old tobacco fields this trouble is rarely seen but sometimes may be found in new fields during the first year or two of tobacco culture.

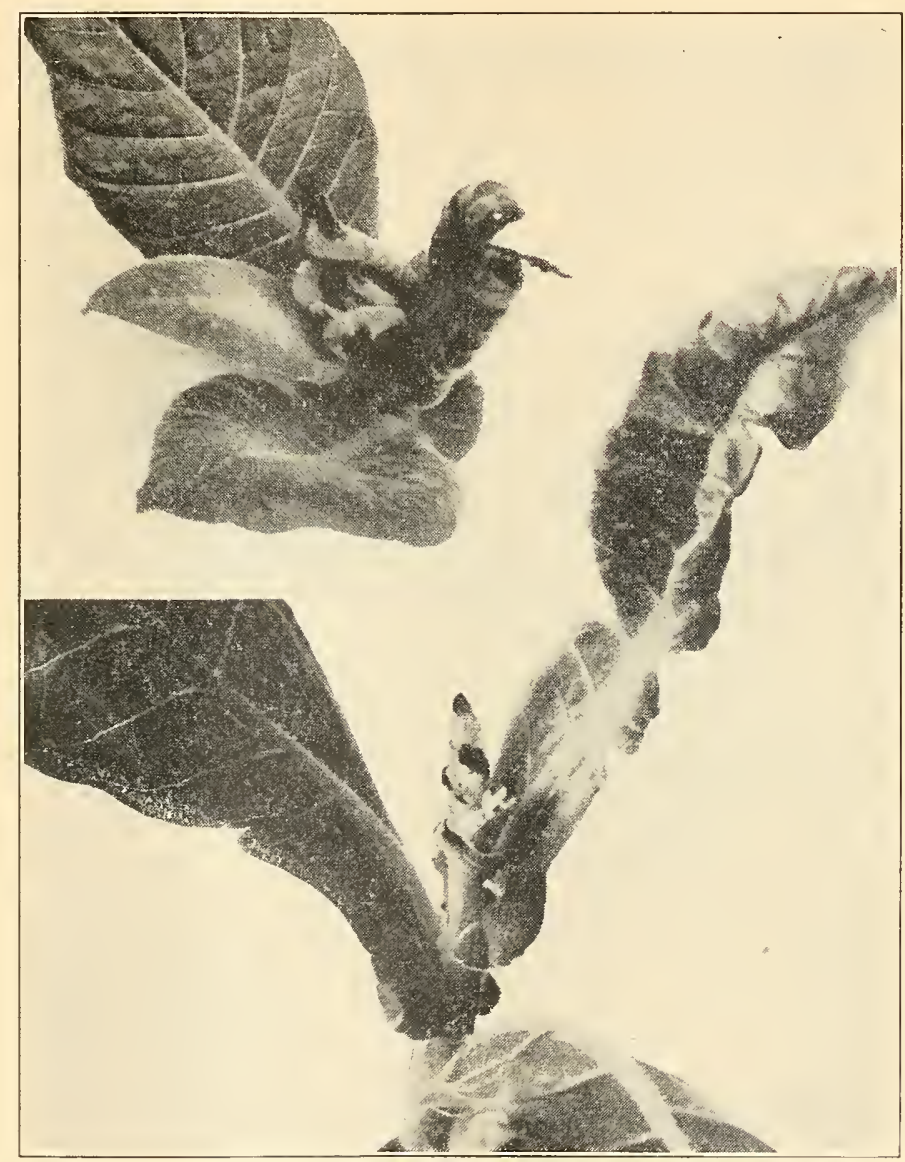

Figure 30. Calcium deficiency symptoms on field-grown plants.

\section{Manganese Poisoning}

All tobacco leaves normally contain a small amount of manganese - usually less than one-quarter of 1 percent of $\mathrm{Mn}_{3} \mathrm{O}_{4}$. The more acid the soil, the higher the percentage of manganese in solution in the soil water and consequently in the plant. At a somewhat increased concentration it becomes toxic to the plant and produces symptoms of poisoning. 
Affected leaves grow pale and may be distorted. The yellow color develops between the minute ramifications of the veins. In later stages the leaf is dotted with small, irregular, brown dead spots. The plants remain stunted throughout the affected part of the field. Cured leaves are yellow, nonelastic and of inferior quality.

The remedy is to apply lime to correct the extreme acidity of the soil. The disease has been observed only on fields testing below $4.5 \mathrm{pH}$. Sufficient lime should be applied to bring this reaction up to $5.0 \mathrm{pH}$ or somewhat above.

References: B 299:178-180. B 410:393-406. B 422:30.

\section{DECAYS AND DISORDERS DURING CURING}

A FTER harvest the leaves must be dried out slowly. During the entire process, lasting from two to six weeks, they must not dry too rapidly, because they are worthless if they "hay down" quickly in a green state. The humidity and temperature must be kept high enough so that the leaves remain soft for a long time. In such condition they undergo those internal chemical changes at a proper speed to insure the desired color, elasticity, grain, texture and other characters which good cured cigar leaf must have.

\section{POLE ROT}

During the curing process, while the cells of the leaf are slowly dying although still soft and containing considerable moisture, they do not have the resistance of normal living cells and are favorable subjects for attack by decay organisms. The higher the humidity of the surrounding air, the greater the danger of damage from rot-producing organisms. Since the cells can no longer be considered normal living cells, attacking organisms should be called saprophytes rather than parasites. The injury produced by growth of these organisms in the leaves has received a variety of names in different parts of the country, such as pole-sweat, pole rot, shed burn, "sweat", house burn and stem rot. The disease in all its various manifestations is nothing more than a "rot" of vegetable matter as this word is used and understood by English speaking people. This term is, therefore, used here to avoid hazy misconceptions on the part of the reader which the other names frequently connote. The term "pole rot", then, designates all forms of rot that affect the curing tobacco while hanging on the poles, and distinguishes it from other rots that may occur in the bundle, the case, or in the field.

Symptoms. Pole rot as a rule does not occur during the first stages of curing, that is, while the leaves are still green. Only occasionally and under very moist conditions, when the leaves have retained their color for a long time in the shed, has the writer ever seen pole rot on a green leaf. In general, the symptoms may be looked for on leaves which are in the yellow stage and just turning brown. The rot may appear on any of them at that critical time, if continued moist weather prevails. When the leaves wilt, the middle and lower ones droop down, forming an overlapping sheath around the top of 
the stalk. Lack of air circulation and the greater quantity of water transpired from the green stalk and the crowded leaves create a very moist atmosphere for the inner leaves and such conditions favor the development of pole rot. It is here, rather than on the outside leaves, that the trouble is found first. Even where charcoal firing is resorted to, it is difficult to dry out the leaves in such places and an insufficient firing is apt to make conditions more favorable to rot because the temperature is raised but the surfaces are not dried. The primed leaves of Shade tobacco are better distributed and there are no green stalks to furnish a continuous supply of moisture. Therefore pole rot is not so common in Shade tobacco as in the stalkcut type. As a rule also, Shade tobacco is more carefully fired during the cure.

There is considerable and often confusing variation in the symptoms exhibited, depending on the part of the leaf attacked, severity of infection, time of infection and location of the leaf with respect to the other leaves.

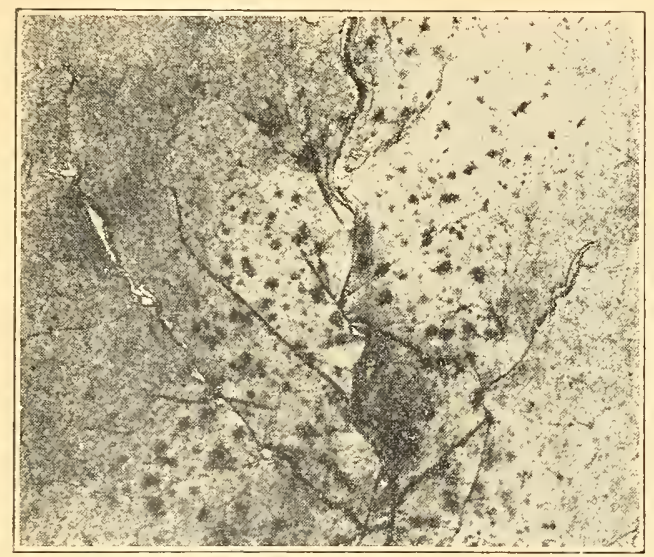

Figure 31. Freckle rot on cured leaf.

For convenience in discussion we may distinguish three types of pole rot: (1) Freckle rot, (2) web rot and (3) vein rot. One, two or all of these may be present on the same leaf and they may intergrade into each other.

Freckle rot has usually been considered the initial stage of the diseases but this is not universally true since the other symptoms may appear first. Small dark specks, from pinhead size up to a quarter of an inch in diameter, appear on the blacle of the leaf. They resemble in size, shape, distribution, and often in color, the freckles on a red-headed urchin's face. On light leaves they are deep, reddish brown, while on dark, heavy leaves they are almost black. When the leaf is held up to a strong light, the spots appear translucent. There is no fungous growth on the surface. Freckle rot is shown in Figure 31.

In web rot, large areas of the leaf blade are rotted and discolored and there is no indication of small local spots. The affected parts are usually several inches in diameter or may include the whole side of the leaf. In 
severe cases in the shed, the tissue is so disintegrated that the leaf tears apart between the hands when one tries to open it; that is, it no longer has any tenacity. The color, although varied, is always darker than that of the unaffected part of the leaf (Figure 32). Such areas, after curing, do not become soft and pliable when the rest of the tobacco comes "into case", but remain stiff and brittle and are easily broken in sorting and packing. There is no elasticity and affected leaves are worthless for cigar wrappers and binders. Sometimes there seems to be a connection between the web-

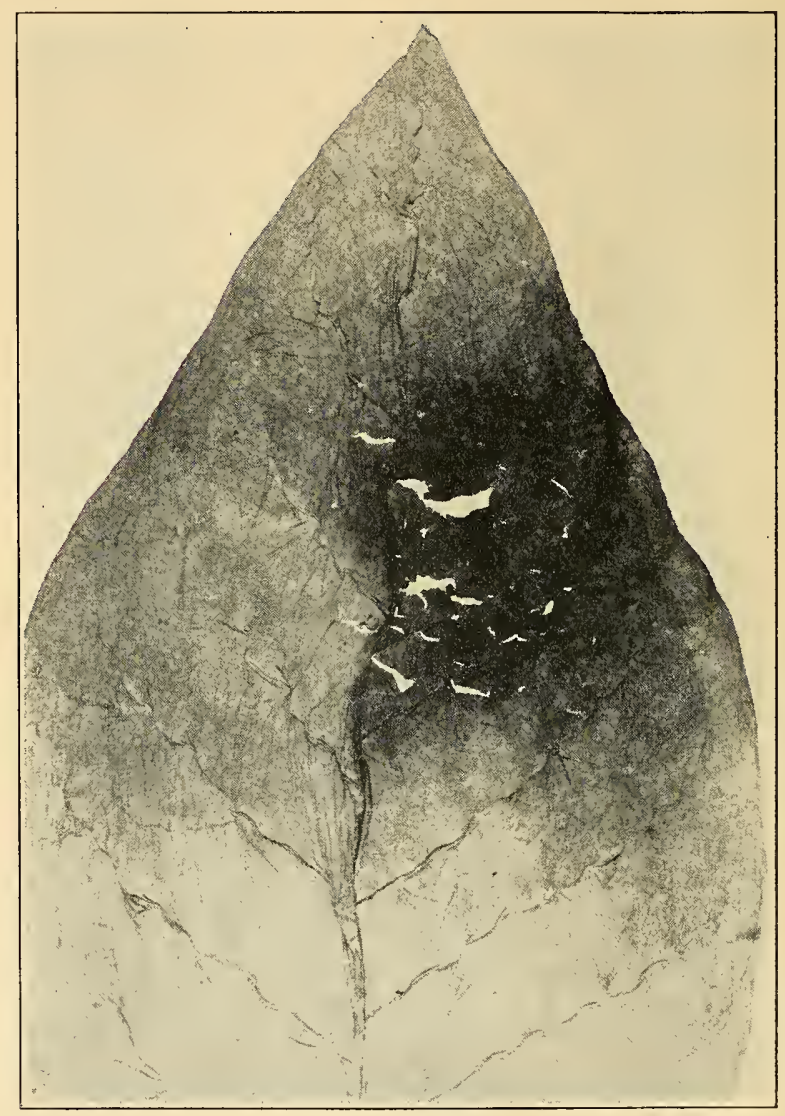

Figure 32. Web-rot type of pole rot causing large, indefinite, darkened patches of rotted blade.

rot,type and the freckle-rot type when a large lesion of web rot is bordered bylfreckles which gradually become less noticeable and disappear in the healthy tissue. One gets the impression that the web-rot type of lesion is produced by the enlargement and coalescence of the freckle spots. This theory, however, does not explain the many cases in which there are no freckles at all in connection with many pole-rotted leaves. It is apparently possible to have web rot without an initial stage of freckle rot. 
Vein rot, including stem rot, is the name applied when the rot involves principally the mid-vein or the large lateral veins. These, especially the midribs, retain their moisture long after the leaf web has dried and therefore furnish very favorable substrata for growth of rot-producing organisms. They turn brown, become soft, and then are covered with a growth of white,

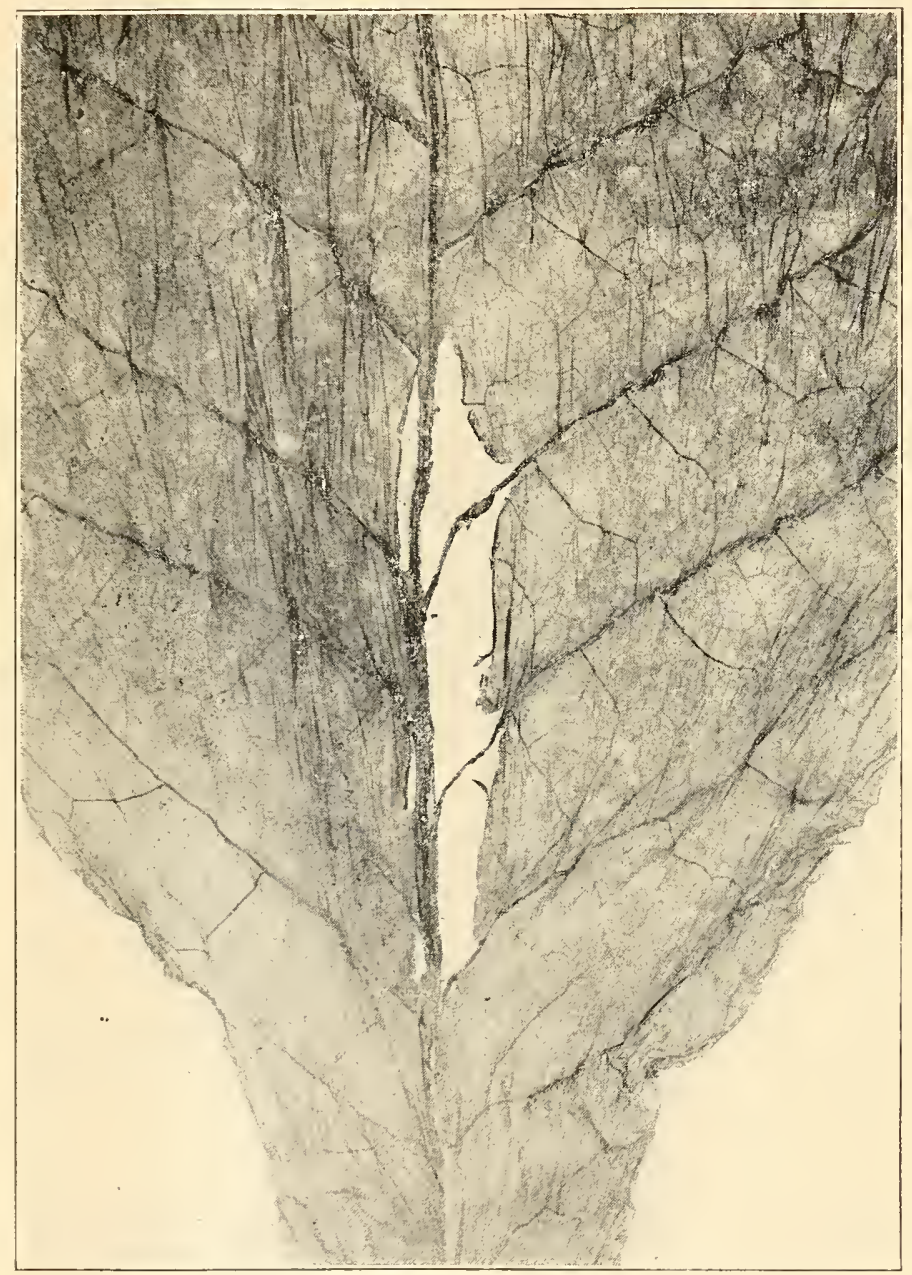

Figure 33. Vein-rot type of pole rot on cured tobacco leaf.

gray or variously colored molds. The juncture between midrib and stalk is an especially susceptible spot. At this point frequently the rot progresses so far that the leaf is severed from the stalk by the slightest pull, or sometimes falls to the ground by its own weight. The rot also usually passes out somewhat into the adjacent web. When the leaf is stretched between the 
hands, the blade pulls away from the large midrib and the latter, being all rotted except the stringy fibers, frays out as the leaf is stretched (Figure 33). The same may be true for the large lateral veins. Leaves thus affected are graded as "brokes" in the sorting, even though the blade may be perfectly sound.

Cause of pole rot. From the beginning of tobacco culture it was recognized that moisture bears an important relation to prevalence of pole rot, because the rot is always worse during wet curing seasons. Moisture, however, is not the direct cause, but is of importance only because it provides conditions in the shed which favor the growth of decay organisms that are the direct agents. Although it is now agreed by all investigators that organisms produce pole rot, there is considerable difference of opinion as to which of the various fungi and bacteria found in rotted tobacco are the primary agents in decay. There is the possibility that the organisms that cause the trouble in one tobacco section are not the same as those that operate in another; or that the organisms that produce one type of rot are not the same as those that produce another.

In Connecticut, the writer has always found the freckle rot type associated with the fungus Alternaria tenuis (Figure 2, F, G) and he believes that this is the only organism producing this symptom. As a weak parasite, associated also with brown spot and dead-blossom leaf spot, it is able to infect the half-dead cells of the leaves and soon discolors the restricted parts invaded. The rapidly spreading web-rot type is more commonly associated with a species of Botrytis (Figure 2, H.). This fungus works more rapidly than Alternaria and entirely decomposes the tissues of large areas of the leaves in a few days. However, Alternaria and other species of fungi also occur in the web-rot lesions and it is not known exactly what part each one may play in causing the damage.

Alternaria and Botrytis are also the two fungi most commonly associated with vein-rot and are probably most often responsible for it, but a considerable number of other fungi may frequently be found in the rotted veins and may play some part. Under damp conditions, bacteria also aid in the decay but are probably never the primary pathogens.

Influence of Environmental Conditions. Humidity in the air immediately surrounding the curing leaves in the shed is the all important determining factor in the incidence of pole rot. If the surfaces of the leaves are kept dry, no infection by spores of the fungi mentioned above can occur. Tons of water must be evaporated from the curing leaves of a shed. In a dry air - low humidity - this evaporation proceeds normally. As fast as the water comes out of the leaves it is taken up by the air and passes outdoors through the ventilators or other openings in the sheds by means of air currents. If, however, the air is already nearly or quite saturated with moisture, the water escaping from the leaves cannot be absorbed into the atmosphere. It remains on the surface of the leaves, keeping them damp, or in the form of drops, a condition that is ideal for germination of, and infection by, spores of the rot-producing fungi.

Temperature is of secondary importance, but heat accompanied by high relative humidity increases pole rot more than a low temperature, $65^{\circ}$ F. or below, with the same relative humidity. If, however, the temperature 
is raised and the relative humidity lowered thereby, as in firing, the progress of the rot will be checked. Wind or air currents are important in producing a continuous change of air around the leaves, thus removing it before it becomes saturated.

Prevention. The spores of the rot-producing fungi are almost omnipresent in the soil and shed and on the leaves when the tobacco is brought in from the field. Thus there is no practical way of excluding them or of spraying or fumigating the tobacco. Obviously the only practical method of preventing the trouble is to establish and maintain air conditions in the shed which are unfavorable to infection and development of the rot fungi. This means a dry air so that the surfaces of the leaves never become damp, or do not remain long in that condition.

Proper manipulation of ventilation and raising the temperature of the sheds by use of charcoal fires are the two important operations in prevention of pole rot. The purpose of opening the ventilators on the sides and in the ends of the sheds is to allow free circulation of air, the dry outside air entering the shed to displace the more moist air inside. During a calm night there are no air currents and usually the humidity outside is very high. Thus, as a general rule, it is well to close the ventilators at night and open them during the day.

In a dry or an average curing season, proper manipulation of the ventilators will suffice to prevent pole rot. But during some seasons there are long continued periods of rainy, cloudy or foggy weather when the humidity even during the day is just as high outside the shed as inside. Obviously no amount of ventilation under these conditions can dry the inside air. The practical procedure then is to use charcoal fires to raise the temperature, set up air currents and thus reduce the relative humidity and dry the leaf surfaces. Detailed directions for "firing" are presented in the Appendix.

Two good farm practices which may aid considerably in preventing pole rot loss should be mentioned: (1) Tobacco should be as ripe as possible before harvesting. Fully mature leaves cure much more quickly and are thus exposed to the danger of pole rot during a shorter period. Experiment and experience have shown that ripe tobacco is less apt to spoil than tobacco harvested too green. (2) Tobacco should not be hung too close in the shed. There should always be adequate space between the leaves to allow the air to pass freely up to the roof.

References: R 1891:168-176, 184. R 1893:84. R 1899:265-269. B 386:600-607 B 391:112-117. B 410:410.

\section{WHITE VEINS}

Sometimes the large lateral veins cure out white or very light in color which gives the leaf the appearance of a prominent white skeleton of ribs against the darker background of the web. Such conspicuous veins make the leaf wholly unfit for wrappers and objectionable for binders. There are two kinds of white veins. The first is caused by insects (thrips) which puncture and kill the cells along the veins. This kind can be distinguished by the irregular margins of the whitened lines, the injury pushing out in some places more than others into the adjacent web. In the second 
type, the blanched effect is confined to the vein cells and therefore gives a very regular effect. This type seems to be associated with, and is usually found after, a curing season that is too dry. The white appearance seems to be due to a layer of air just under the epidermis of the vein. This develops during curing when different rates of shrinkage pull the underlying cells from the epidermal layer. If the curing is very gradual, such a cleavage is not so apt to develop. Hence it is recommended that if the curing season is too dry the ventilators should be opened during the night and closed during the day.

\section{BUNDLE ROT}

Sometimes, after the leaves have been stripped from the stalks and packed into bundles enclosed in heavy paper, and while these are still in the shed, they are damaged by rots or molds. This may be a further development of pole rot. More often, however, it is an early stage of blackrot such as occurs later in the case. This type forms pockets of rot where disintegration runs rapidly from leaf to leaf so that a small pocket may ruin a large number of leaves. It is described in more detail under blackrot.

The conditions under which the tobacco is stripped and packed in the bundle have a great influence on incidence of this trouble. If the stripping is done too soon, while some of the midveins are still "sappy," these veins first decay and then the fungi quickly pass into the adjacent leaves. Early stripping also involves the risk of having the tobacco in the bundles during warm weather which is favorable to the development of molds and rots. It is better to have the tobacco still hanging on the poles during such warm periods. Putting it in bundles when it is in too high "order" is another source of danger. Finally, the bundles should not be packed too tightly. Heavy bundles are always the first to spoil.

Occasionally the tobacco develops a green or yellowish mold in the bundle due to growth of fungi of the genus Penicellium. This type of mold is more common in poor tobacco, especially that which is nitrogen-starved.

If the faulty practices mentioned above are avoided, bundle trouble should be redaced to a minimum.

\section{DECAY AND MOLD OF FERMENTING OR STORED TOBACCO}

A FTER curing, tobacco is fermented either by stacking it in large piles, called "bulks", of 3000 to 5000 pounds each, or by pressing it tightly in wooden boxes, "cases", 200 to 300 pounds in a case. Shade tobacco is fermented in bulks while Havana Seed and Broadleaf are usually fermented in cases. The tobacco must contain sufficient moisture so that it can be handled without damage, 20 to 30 percent. Also this amount of moisture is necessary to induce fermentation which is accompanied by a rise in temperature. In bulk fermentation, as soon as the temperature rises to 116-120 degrees F., the bulk is taken down, the hands shaken out and repiled in another bulk. This process is repeated as often as the temperature rises to the above mentioned degree, four to ten times at intervals of four to 
fifteen days. Finally, the tobacco becomes too dry to induce further rises in temperature and then it is sorted and stored. In case fermentation, the temperature rise is not so rapid nor so extensive and it is not shaken out or disturbed until the process is complete.

During the fermentation, while the moisture content is still high, the tobacco may be spoiled or damaged by black-rot or by must. Since these are two quite distinct disorders, they will be considered separately.

\section{BLACK-ROT IN THE CASE}

THIs disease, often called "canker" by the packers, is particularly a trouble of Havana Seed and Broadleaf tobacco while it is fermenting in cases. It seldom occurs in the bulks of Shade tobacco, probably because of the frequent turning and aeration of the bulks. Sometimes it occurs in the bundles as previously mentioned. It is one of the more serious diseases and the damage to the crop as a whole during some years has been estimated as high as a million dollars.

Symptoms. As indicated by the name, this rot causes the leaves to turn black or at least a very dark color, which contrasts sharply with the natural brown color. It occurs most often at the tips or upper halves of the leaves where they overlap. Another distinctive feature is that the rot occurs in "pockets" and is only rarely found distributed equally through the case. Such pockets may be no larger than the tip of the finger, or several inches across, involving all of the leaves below and above which touch this area. It is not a wet rot and the affected parts retain their natural shape until they are disturbed. But when such a hand is shaken out, the whole pocket breaks up into a powder, showing that the dry rot has completely destroyed the cohesion of the affected leaves. The line of demarcation between the diseased and sound parts of the hands is rather distinct and the unaffected part of the case does not lose its value. Experienced packers recognize a distinctive odor in a case affected with black-rot even before it is opened.

Cause. Black-rot is caused by the attack of a very common saprophytic fungus, Sterigmatocystis nigra (Figure 2, L). This fungus grows on decaying organic material of almost any kind. Here it produces myriads of tiny spores that are readily blown about in the air. They are carried from the fields on the tobacco leaves. The air in the packing shops is full of them; therefore it is not practical to attempt to eliminate them.

Effect of Environmental Factors. Outside of the abundance of the infecting spores, there are three factors which are of decisive importance in determining whether or not a case of tobacco will have black-rot. These are moisture, temperature and oxygen. Increase in moisture content of the leaves favors the development of the rot. Sometimes a part of two different crops is packed in the same case and one spoils while the other remains sound. In such instances we have found that the crop with the higher moisture content is the one which spoils. Havana Seed tobacco should not be packed when it has a moisture content of over 26 percent, according to tests we have made. This does not necessarily mean that all cases packed with a higher moisture will spoil. Often a very moist, overdamp case comes through the sweat perfectly. Such results may be explained on the basis 
of oxygen supply, however. In packing binder tobacco, it is easy to have a higher moisture condition in certain small areas in the case than in the rest. This might easily account for the development of restricted rot pockets.

The fact that black-rot occurs only during fermentation when the tobacco is heated up suggests that a high temperature is most favorable to its incidence. Although the fungus will grow at a wide range of temperatures, about 68 to 111 degrees F., it grows most vigorously at about 100 degrees. It is not practical to avoid the rise in temperature which accompanies fermentation. One cannot ferment tobacco at a low temperature, nor would it be advisable to try to hold the temperature above 111 degrees F., which would be safe. The length of time during which it remains at a favorable temperature is important. One reason why bulk fermentations keep the tobacco free from rot is that they allow the tobacco no opportunity to stay very long at high temperatures.

Oxygen is necessary for the growth of the fungus. Even in the center of tightly packed cases there is some oxygen. It has been suggested that one reason the pockets stop spreading is that the fungus has exhausted the supply of air in these local areas. Also the fact that in cases which are packed overdamp probably the leaves are so tight together that the air is reduced to a minimum, may prevent the growth of the fungus through lack of oxygen and thus such cases do not spoil.

Control. No harmless method of treating the leaves to free them from the fungus has been found. Therefore control must depend on modification of the environmental factors mentioned above so as to make them as unfavorable as possible for development of the fungus. The factor that can be manipulated to the best advantage is the moisture content. Not only should it be kept as low as it is possible to handle tobacco without breakage, but the moisture should also be evenly distributed. Bundles that are overdamp should be shaken out and aerated. All tobacco should be kept in the shop until all the hands feel equally damp before it is finally packed in the case.

Some packers have resorted to bulk fermentation for binder tobacco in the same way that Shade tobacco is fermented, especially when the binder crop is too moist. Others bulk first and then pack in cases only after one or two turns in the bulk. Both methods have been entirely successful in eliminating rot.

The use of a re-drying machine will eliminate the difficulty but this is an expensive apparatus which is not available to a large percentage of the packers.

Reference: R 1904:328.

\section{MUST OR WHITE MOLD}

Sometimes, after the tobacco has been packed for some time in the case, the leaves become blotched with a white or light gray fuzz or mold. This may occur in large patches on the leaves or may entirely cover them. It is accompanied by a musty, disagreeable odor which gives the popular 
name to this trouble. This is not a true rot since the tissues of the leaf are not weakened. The damage arises from the unsightly appearance and the disagreeable odor.

Cause. The visible mold consists of mycelium and spores of fungi but not always of the same species. Species of the genera Oospora and Actinomyces are most often found.

Effect of Environmental Factors. Black-rot and must are almost never found in the same case. Hence it appears that the conditions which favor the former are not the same as those favoring the latter. Must is most apt to occur in cases that have been kept at a low temperature and in which active fermentation has been delayed. The moisture content seems to have no influence here. Air is probably favorable since loosely packed cases often develop must.

Control. No satisfactory control has been found. Conditions favoring must, as mentioned above, should be avoided. Packers often resort to brushing off the moldy growth, spraying the tobacco with a water solution of 4 percent acetic acid or vinegar and repacking. This has not been entirely successful in eliminating the odor, however.

Reference: R 1904:328.

\section{APPENDIX}

\section{STERILIZING' THE SOIL IN THE SEEDBEDS}

THE purpose of sterilizing the seedbed soil is to destroy the fungi and bacteria that cause mildew, wildfire, blackfire, bed rot and black rootrot, the virus of calico and also certain insects. Of the two methods which are practiced, steam sterilization and chemical sterilization, the former is most commonly used in Connecticut.

\section{Steam Sterilizing the Soil}

Steaming the soil not only kills germs which may have been carried to the beds, but it also kills weed seeds. Many growers consider this latter benefit alone worth the cost of the operation. It also makes the plant nutrients in the soil more available and produces a more vigorous growth. It should be mentioned in this connection, however, that steaming under certain conditions may be injurious.

Soil may be sterilized either in late autumn or in spring. The advantage of fall sterilization is that it distributes the labor better by avoiding the spring rush, and also eliminates the danger of ammonia injury. Spring sterilization may delay considerably the time of seeding, especially during late springs. The disadvantage of fall sterilization is that the soil may become reinfested with weed seeds, insect pests and fungi to some extent during the winter. On this account, the operation should be delayed until as late in the season as possible.

Injury to the germinating seeds sometimes results when the bed is seeded immediately after steaming. For this reason it is best to wait a few days before the sowing-a lapse of 10 days is better if it does not delay the time of seeding too seriously. 
Of the various ways for steaming soils, the only one used in Connecticut is the "inverted pan" method. A galvanized iron pan, reinforced with angle irons, about 10 inches deep, 12 to 16 feet long and just wide enough to

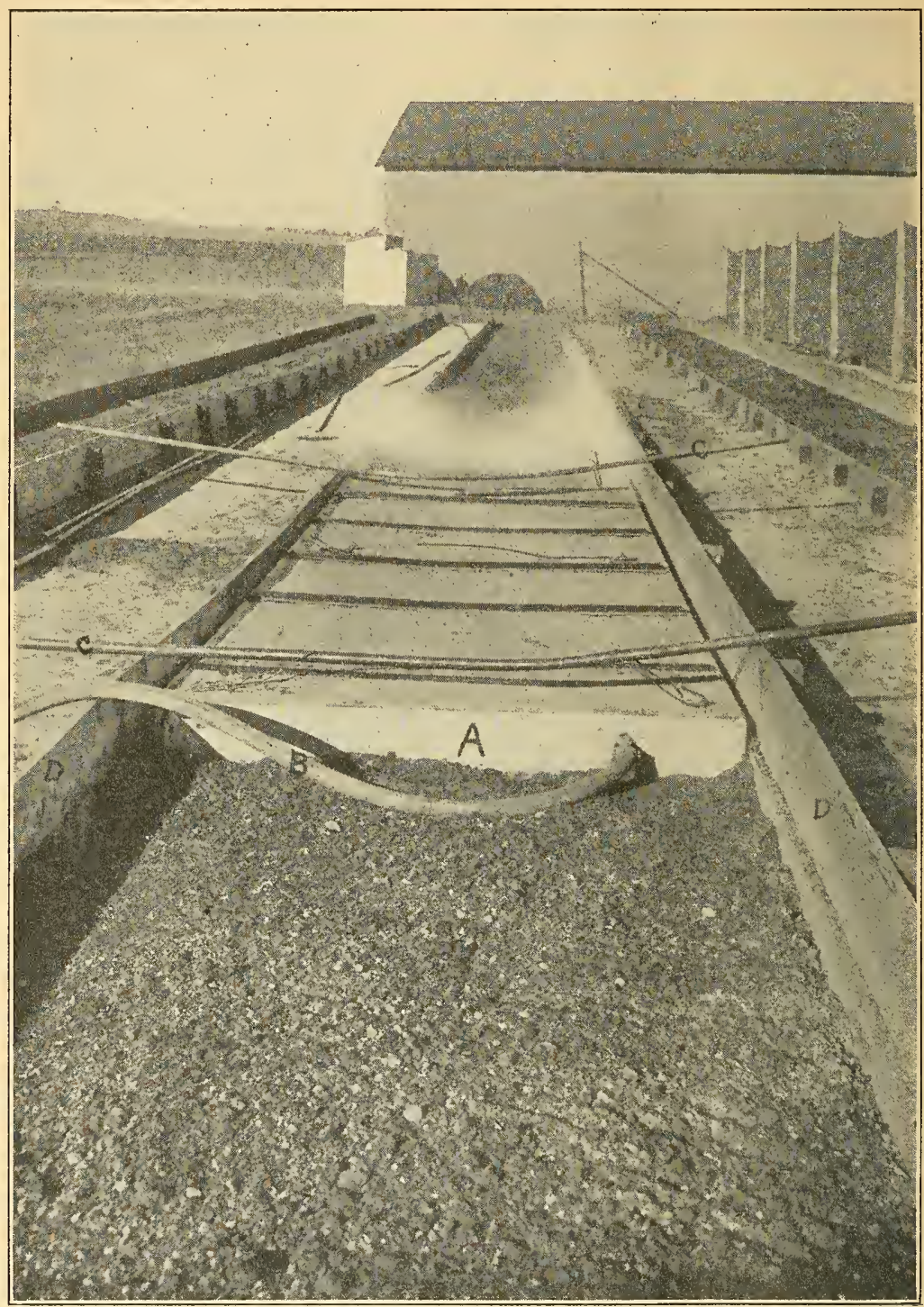

Figure 34. Steam pan in position. (A) Pan; (B) steam supply line; (C) cross bar for lifting pan; (D) sides of seedbeds. Steam beyond pan is rising from soil from which the pan has just been removed.

fit inside the bed, is inverted over the soil and the sharp edges pressed a few inches into the loose earth (Figure 34). Steam under high pressure from a steam boiler is forced through a pipe into the end of the pan and penetrates 
into and sterilizes the soil. The method is too well known to require further description except for the following precautions:

The soil should be well worked up and loose before steaming. Any manure or humus to be added should be applied in advance. Commercial fertilizers may be added before or afterward. A moderately dry soil is more easily sterilized than one that is water-logged, because steam penetrates mud very slowly. Twenty to thirty minutes with a pressure of 75 to 125 pounds is usually sufficient. If, after removing the pan, the soil is so hot that you cannot hold your hand in it at a depth of 5 to 6 inches, the steaming is sufficient. Otherwise the length of steaming time should be prolonged. Another method of finding how long to steam is to bury a small potato a few inches under the soil. If it is mealy and soft clear through when the pan is remor ed, the length of steaming is sufficient. The soil should not be worked deeply after steaming because there is danger of turning up some of the unsterilized earth.

\section{Chemical Sterilization with Formaldehyde or Acetic Acid}

The soil may also be sterilized effectively with formaldehyde solution instead of steam, although this process does not kill all of the hard weed seeds. The solution should be made at the rate of one part to 50 of water and the soil soaked at the rate of one-half gallon to one square foot of soil if it is pretty damp. If the soil is dry, a more dilute solution of one to 100 , and used at the rate of one gallon to 1 square foot, is advisable. Seed should not be sowed for ten days to two weeks after drenching, or until the odor of formaldehyde has disappeared. Stirring up the soil a few times may hasten escape of the fumes.

More recently it has been found that a 1 percent solution of acetic acid is just as effective as formaldehyde and costs less. The solution is made by mixing 8 pounds of acetic acid ( 56 percent) in 50 gallons of water and applying at the rate of one-half gallon to one square foot of soil. Otherwise the procedure is the same as with formaldehyde.

\section{PREPARATION OF BORDEAUX MIXTURE FOR SPRAYING SEEDBEDS}

1. Slake 25 pounds of quick lime (granulated lime is perhaps best) in a barrel with just enough water to keep it boiling. Too much water at first will "drown" the lime, i.e., it will not heat. Stir the mixture continually until it is slaked. Afterward add water to fill the barrel up to 25 gallons. If hydrated lime is used, the quantity should be increased to about 35 pounds.

2. Put 25 pounds of copper sulfate (blue-stone, blue vitriol) in a burlap bag (fertilizer or onion bag). Hang the bag in 25 gallons of water in a wooden barrel over night to dissolve the copper sulfate, or stir the compound about in the water until all of it is in solution.

The above are the stock solutions and may be kept all season. Keep them covered and stir well before using.

To make a barrel (50 gallons) of Bordeaux Mixture:

1. Pour four gallons of lime stock solution through cheesecloth stretched over the top of the mixing barrel. (The cloth may be held in 
place by a hoop slipped over the top). Much of the lime will be left on the cloth. Wash as much of it through as you can with 25 to 30 gallons of water.

2. Pour four gallons of the copper stock solution through the same cheesecloth and add enough water to fill the barrel.

The solution is now ready for use. Stir each time before using. Don't mix together more than you need at one time. It will not keep until the next application.

\section{CURING WITH THE AID OF CHARCOAL FIRES}

DURING the time that the tobacco hangs in the shed, the color of the leaves changes from green to brown and there is a loss in weight of about 80 percent, mostly in water. However, the drying - evaporation of water from the leaves-does not constitute curing; in fact it is merely incidental to the process. The essential part of the curing is a series of chemical changes in some of the compounds which make up the leaf, internal changes which transform raw, bitter, bad-smelling leaves into mild, fragrant tobacco. For these processes to occur to the best advantage it is necessary that the cells remain alive for a considerable period and a certain amount of moisture be present. If the leaf is dried too rapidly ("hayed down"), the cells die, the leaf remains green, and curing does not take place.

On the other hand, if the curing is prolonged for too long a time, the leaf becomes darker in color and also is exposed for a longer period to the danger of pole rot and other curing troubles. There is then an optimum rate of cure, at which the above mentioned chemical changes take place to the best advantage and the fullest extent, and at which curing troubles are least dangerous.

Temperature and humidity of the air are the most important factors in determining the rate and character of the cure. Up to a certain point, we may say that the higher the temperature, the more rapid and the better the cure. According to experiments at the Windsor Station, the optimum temperature lies between 85 and 95 degrees $\mathrm{F}$. But temperature alone cannot be considered without reference to humidity of the air, which is of at least equal importance. A high temperature, with low humidity maintained for any considerable period of time, causes too rapid loss of water from the leaf with consequent "haying-down", i.e., the leaves become dry while still green. A low temperature with high humidity, or even a higher temperature with too high humidity, causes slow cure, dark colors and danger of curing disorders. In Connecticut, working with Shade tobacco, it has been found that best colors and quality are produced by keeping the humidity percentage about 10 points below the temperature; for example, with a temperature of 90 degrees, the humidity should be 80 percent.

Under actual shed conditions where no effort is made to control temperature and humidity artificially, there are naturally wide fluctuations in both of these factors. In clear weather the temperature falls at night and the humidity rises, while the reverse is true during the day. Atmospheric changes in the shed follow those of the outside air but do not swing in quite as broad a range. The temperature at the top of the shed is usually higher and the humidity lower, which accounts for the fact that during dry seasons 
the tobacco in the peak "hays down", while in bad pole sweat years the best tobacco is from this section. During prolonged rains, conditions are static and the humidity may remain at 95 to 100 percent for a sufficiently long period to cause serious pole rot or other disorders.

The original method of curing was to hang the tobacco in the shed and trust all to the weather until time to take it down. This gave a successful cure during some seasons but was disastrous during others, especially when the weather was not so favorable. The weather outside cannot be changed but certain practices may be employed to modify the humidity and temperature inside the shed so that they may more nearly approach the desired optima.

Correct construction and manipulation of the sheds are of immense benefit here. The sheds should be tight but provided with ventilators which may be closed or opened as desired, as previously mentioned. During the curing of tobacco from one acre, about five tons of water must pass out of the shed into the air. The larger part of this goes out during the first 10 days. With sufficient ventilation and air movement this can be accomplished easily in favorable weather. During rainy weather, however, the air is saturated with moisture and is less effective in evaporating moisture. Drops are likely to come to the surface and remain on the leaves. If this happens during the critical stages for pole sweat infection, some method of evaporating the water must be used. In good weather at this stage, it is well to keep the ventilators open in day time. On the other hand sometimes, especially in the later stages of the cure, the loss of water may be too rapid and it is better to open the ventilators during the night and close them during the day in order to keep up the humidity.

Nearly all growers of Shade tobacco, and some growers of outdoor iobacco, use charcoal fires to raise temperature and lower humidity. Thus they are able to approximate conditions that are optimum for wilting, for acceleration of chemical changes involved in curing and for prevention of pole rot.

The fires are made in holes about 6 to 8 inches deep by 12 inches in diameter dug in the soil of the shed floor. From two to six fires to each bent of 16-foot square are used. Growers differ in their opinions as to the best number of fires. If a larger number is used, the heat is better distributed. In this case more labor is required in tending the fires and each fire must necessarily be smaller to avoid raising the shed temperature too high. Wet-and-dry-bulb thermometers are hung in the middle of the bents so that the operator may keep the proper temperature and humidity. It is important that no tobacco be hung directly over the fires in the first tier. A good method of hanging the first tier is to leave out the second run from each side through the whole length of the shed. This allows room for the fires and free walking space for the operator. The fires may be started by pouring a little kerosene or denatured alcohol over the first charcoal before igniting. In starting the fires it is a good practice to leave the ventilators open until the smoke which fills the sheds at first has cleared out. Then the ventilators should be closed. More charcoal is added as the temperature dictates.

In firing to wilt, the fires are started immediately, or within a day or two after the shed is filled with tobacco, and continued for 18 to 72 hours, 
or until the leaves are well wilted. The experienced operator regulates his firing by watching the condition of the leaves. If the tips become stiff while they are still green or yellow, firing has continued long enough and he lets the fires die out. After three or four days the leaves have become damp again and shade growers frequently fire a second time but for a shorter period.

Later firings are not necessary except to prevent pole sweat. If the weather stays damp for two or more days in the critical stage of curing, and especially if there are drops of water standing on the leaves, the fires must be started again and continued until the surfaces of the leaves feel dry. One
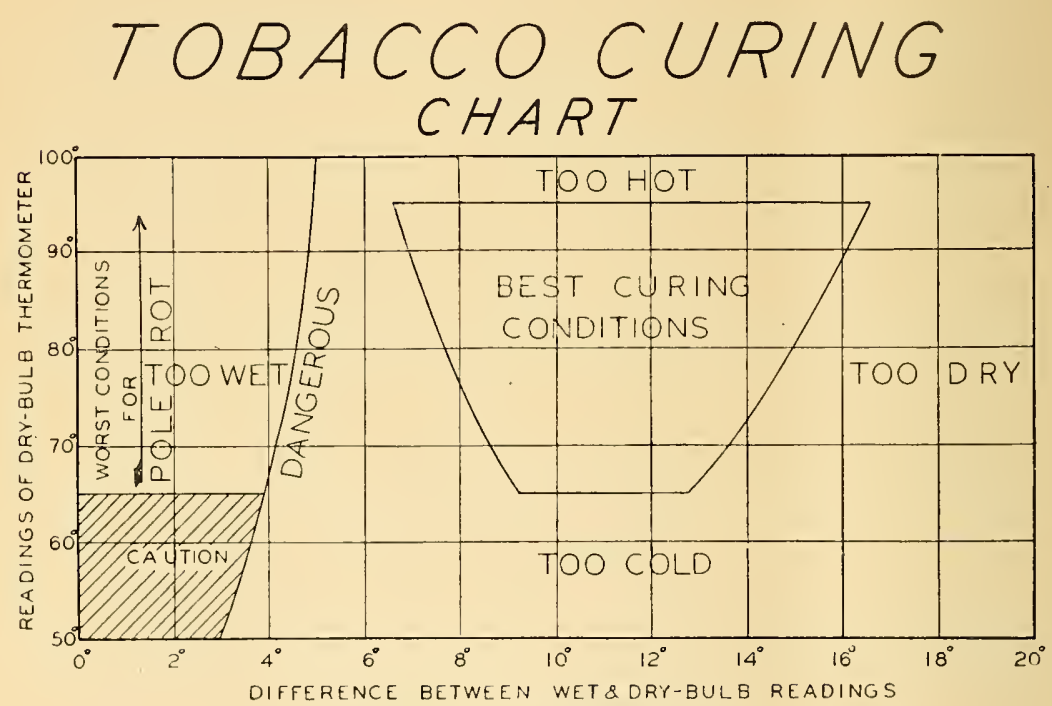

Figure 35. Tobacco curing chart.

should not wait, however, until the symptoms of pole rot, as described previously, are found, because it is then too late to prevent infection. If this has already occurred, however, it is best to fire at high temperature and low humidity until the leaves are entirely cured. Moderate firing at this time will only make conditions more favorable for development of the trouble.

Sometimes it is advisable to fire after the web of the leaf is cured but the midrib is still uncured. This is to prevent stem rot or vein rot.

Metal spreaders are frequently used over the fires to disperse the heat and to keep the leaves directly above the fires from scorching.

The quantity of charcoal consumed varies naturally with the character of the season. If the grower has at hand 50 bushels to each acre, it should be sufficient. 
The most common fuel is lump charcoal, while processed charcoal and coke are used to a limited extent. Lump charcoal is available in large amounts, is not difficult to manage, and can be used in small pits in the shed. Processed charcoal, such as Ford Briquets and Eastman Charkets, may be used similarly, but shallow metal basins in place of pits in the soil are coming into more general use and save fuel and labor. Lump charcoal is too bulky for basins. Coke requires the use of salamanders or burners, and must be started with charcoal. The fuel cost is low but more skill is required in management. Coke which has a high content of sulfur compounds may produce yellow veins in the leaves.

It is generally agreed that alternate periods of drying and moistening are better than a continuous dry condition. This gives opportunity for the pigments to diffuse, thus making the colors more uniform. Also chemical changes can continue to operate only when the leaves are damp.

The chart shown in Figure 35 may be used by the operator in connection with the wet-and-dry-bulb thermometers hung in the first tier of the shed.

References: R 1891:176-184, 187-197. R 1898:297-301. B 36:4755-760. 


$5388-15$ 


University of

Connecticut

Libraries 


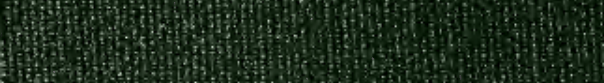

Whom

that

(2)

(3)

Hit

क.

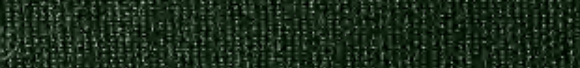

Fin

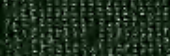

Wi:

样

Hon

特

Hon

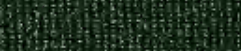

ond

Hons

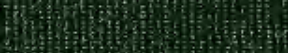

(1)

(3)

4

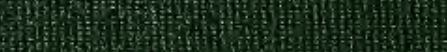

(1)

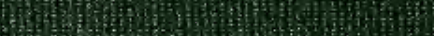

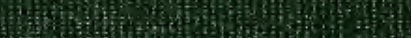

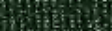

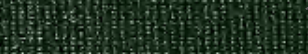

What

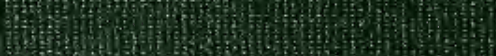

W

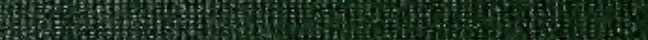

Whom

How

H.

(5)

(H)

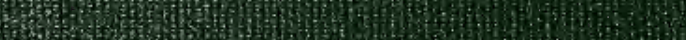

H.

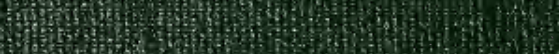

W

mom

5 n

(3)

H.

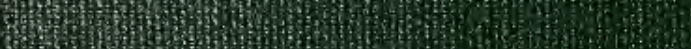

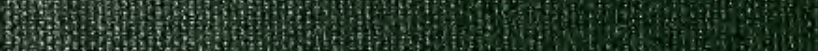

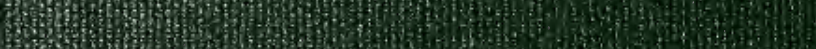

2010)

6.

17

H. Wh 400 H. 